The copyright of this thesis vests in the author. No quotation from it or information derived from it is to be published without full acknowledgement of the source. The thesis is to be used for private study or noncommercial research purposes only.

Published by the University of Cape Town (UCT) in terms of the non-exclusive license granted to UCT by the author. 


\title{
APPLICATION OF THE SEQUENTIAL T-TEST ALGORITHM \\ FOR ANALYSING REGIME SHIFTS TO THE SOUTHERN \\ BENGUELA ECOSYSTEM
}

\author{
ZOOLOGY DEPARTMENT \\ FACULTY OF SCIENCE \\ UNIVERSITY OF CAPE TOWN \\ Submitted in partial fulfilment of the requirements for the \\ degree of Master of Science by coursework and dissertation \\ in \\ APPLIED MARINE SCIENCE
}

by

James A. E. Howard

Co-supervisors: Dr Coleen Moloney

Marine Biology Research Centre,

Zoology Department, University of Cape Town

: Dr Astrid Jarre

Research Associate, Marine Research (MA-RE) Institute and Zoology

Department, University of Cape Town

: Allan Clark

Statistics Department, University of

Cape Town

CAPE TOWN

March 2007 


\section{Declaration}

I declare that this thesis is my own, unaided work and has not been submitted in this form or any other form to another university. Where use has been made of the research of others, it has been duly acknowledged in the text. Analytical work discussed in this thesis was carried out under the supervision of Dr Coleen Moloney of the Marine Biology Research Centre, Zoology Department, Dr Astrid Jarre of the Marine Research (MA-RE) Institute and Allan Clark of the Statistics Department, University of Cape Town.

\section{Signed by candidate}

James Alexander Edward Howard

Zoology Department, University of Cape Town

March 2007 


\section{Table of Contents}

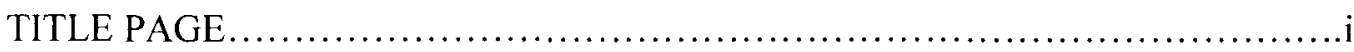

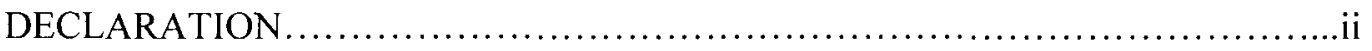

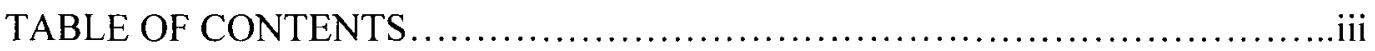

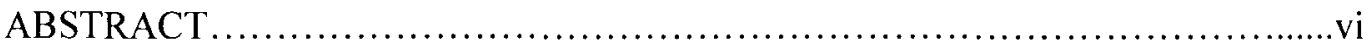

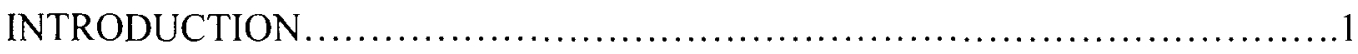

MATERIALS AND METHODS .............................................. 10

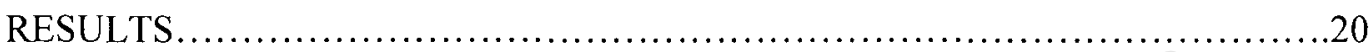

Environmental forcing variables....................................20

Anthropogenic forcing variables.....................................23

Observed state variables compared to Benguela Niños.....................25

Modelled state variables compared to Benguela Niños....................28

Observed state variables compared to SST anomalies at $30^{\circ} \mathrm{S}$ and $32^{\circ} \mathrm{S} \ldots \ldots .31$

Observed state variables compared to upwelling anomalies at $30^{\circ} \mathrm{S}$ and

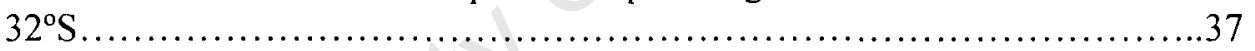

Modelled state variables compared to upwelling anomalies at $30^{\circ} \mathrm{S}$ and

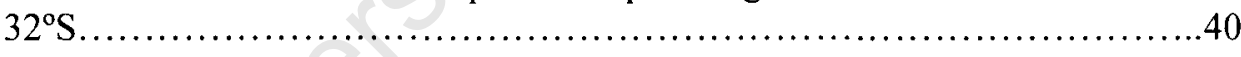

Observed state variables compared to sardine landings..................40

Modelled state variables compared to sardine landings and sardine mean length...................................................... 45

Observed state variables compared to horse mackerel purse seine landings and anchovy mean length landed........................................45

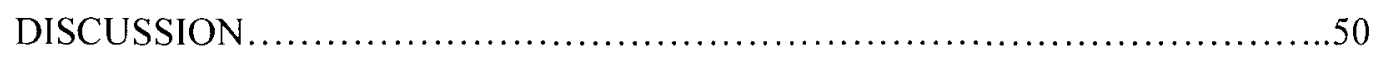

Methods discussion.................................................... 50

Application to the southern Benguela ecosystem........................52

Eastward shift of sardine stocks.......................................61 
Regime shifts in other marine ecosystems.

CONCLUSIONS

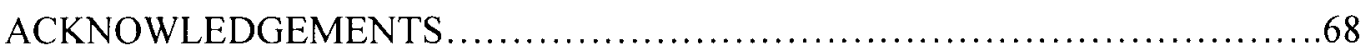

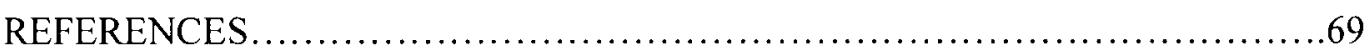

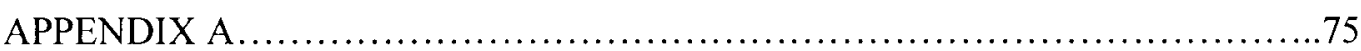

Observed state variables compared to Benguela Niños.....................75

Observed state variables compared to SST anomalies at $30^{\circ} \mathrm{S}$ and $32^{\circ} \mathrm{S} \ldots \ldots .77$

Observed state variables compared to upwelling anomalies at $30^{\circ} \mathrm{S}$ and $32^{\circ} \mathrm{S}$.

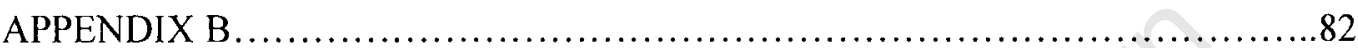

Modelled state variables compared to Benguela Niños......................82

Modelled state variables compared to SST anomalies at $30^{\circ} \mathrm{S}$ and $32^{\circ} \mathrm{S} \ldots \ldots .84$

Modelled state variables compared to upwelling anomalies at $30^{\circ} \mathrm{S}$ and $32^{\circ} \mathrm{S}$

Observed state variables compared to sardine landings .90

Modelled state variables compared to sardine landings...................92

Observed state variables compared to anchovy landings..................94

Modelled state variables compared to anchovy landings...................98

Observed state variables compared to horse mackerel purse seine landings.

Modelled state variables compared to horse mackerel purse seine landings.

Observed state variables compared to fisheries of large horse mackerel. 101

Modelled state variables compared to fisheries of large horse mackerel....

Observed state variables compared to demersal landings 103 
Modelled state variables compared to demersal landings..................104

APPENDIX D ........................................................ 106

Observed state variables compared to sardine mean length landed...........106

Modelled state variables compared to sardine mean length landed...........108

Observed state variables compared to sardine L95 catch..................108

Modelled state variables compared to sardine L95 catch...................110

Observed state variables compared to anchovy mean length landed.........110

Modelled state variables compared to anchovy mean length landed.........110

Observed state variables compared to anchovy L95 catch..................112

Modelled state variables compared to anchovy L95 catch..................112 


\section{Abstract}

Long-term ecosystem changes, such as regime shifts, have occurred in several marine ecosystems worldwide. Multivariate statistical methods have been used to detect such changes, but they have to date not been applied to the southern Benguela ecosystem. A weakness of many of the methods is that they require long time series data and do not provide robust results at the end of time series. A new method known as the sequential t-test algorithm for analysing regime shifts (STARS) is applied to a set of biological state variables and environmental and anthropogenic forcing variables in the southern Benguela. Since 1950, two major long-term ecosystem changes have occurred, involving observation and modelled based state variables as well as environmental and anthropogenic forcing variables. The first occurred in the 1960s, caused predominantly by heavy fishing pressure but with some environmental forcing influence and the second occurred in the early 2000 s, caused mainly by environmental forcing changes. The shift in the 1960 s comprises a decrease in upwelling intensity, an increase in copepod abundance, a decrease in sardine biomass and sardine landings and an increase in sardine gonad mass. The shift in the 2000s includes a decrease in upwelling and an increase in SSTs along the west coast. Shifts in biological variables at this time include a decrease in copepod abundance, exceptional increases in anchovy recruitment and reductions in anchovy mean weight in the catch and L95. Increases in sardine biomass, reductions in sardine condition factor and a change in sardine egg distribution are detected during this shift. A shift in Cape gannet (Morus capensis) diet from predominantly sardine to anchovy occurs on the west coast, whereas the opposite is true for the south east coast. The STARS method was able to detect shifts in relatively short time series and identify when these shifts occurred without a priori hypotheses. Shifts were accurately detected at the end of time series, 
however some further development of the method is needed to enhance its performance in view of auto-correlated time series. The detected long-term changes in the southern Benguela are compared to those in other marine ecosystems. 


\section{Introduction}

The Benguela is a highly productive, coastal upwelling system that is situated on the southwestern coast of southern Africa. It is a typical eastern boundary current system, which relies on Coriolis forces and strong equatorward winds to drive the process of upwelling, which in turn drives a productive food web and marine ecosystem (Armstrong and Thomas 1989). The Benguela is commonly split into two areas: the northern and southern Benguela. The Luderitz upwelling cell $\left(26-27.5^{\circ} \mathrm{S}\right)$ is the barrier between the two systems, in terms of fish movement and ocean dynamics (Shannon 1985). The northern Benguela comprises the oceanic area out to the shelf edge along the coast of Namibia $\left(15^{\circ} \mathrm{S}-26^{\circ} \mathrm{S}\right)$ and the southern Benguela comprises the area along the west and south west coast of South Africa $\left(26^{\circ} \mathrm{S}-35^{\circ} \mathrm{S}\right)$, extending to the edge of the continental shelf.

A characteristic of such an upwelling system is its variability in both oceanographic and biological components. This is observed especially in the pelagic component, which is comprised of a few fish species, which dominate the ecosystem and form the basis of one of the most important commercial fisheries in South Africa (Cury et al. 2000). Pelagic species are thought to exert wasp-waist control in such ecosystems (Bakun 1996). Being low to middle trophic level species, pelagic fish simultaneously apply bottom up forcing on their predators and top down control on their prey species. The two dominant pelagic fish species of the Benguela upwelling system are sardine (Sardinops sagax) and anchovy (Engraulis encrasicolus), which have displayed inverse population dynamics over several decades, i.e. an increase in anchovy abundance and productivity is linked with a corresponding decrease in abundance and productivity of sardine (Lluch-Belda et al. 1992). These fluctuations, which operate in 
synchrony, occur over decadal time scales and are associated with all major eastern boundary current systems (Schwartzlose et al. 1999). From known historic pelagic stock fluctuations, it would appear that regimes in eastern boundary current systems persist for 10-40 years (de Young et al. 2004). The dominance of one species in the northern and southern Benguela lasts for 10-30 years (Shannon 2001); this is similar to the Peruvian system where dominance tends to last $15-30$ years (Alheit and Niquen 2004). Recent modelling simulations have shown that changes in the environmental forcing on the Benguela system, which affected zooplankton over three-year and tenyear periods, could result in ecosystem changes over 10 and 20 years respectively (Shannon et al. 2003).

The changes in pelagic stock abundance and their fluctuations in the northern and southern Benguela systems have been found to be out of phase with those shifts within the various Pacific and North Atlantic systems, whereas the shifts in different systems within the Pacific are in phase with one another (Schwartzlose et al. 1999). Eastern boundary current systems' regime shifts often appear to be relatively abrupt, such as in the Humboldt current system where rapid decreases in anchovy biomass and consequent increases of sardine were observed over alternating ten year periods, with the most famous being that of the collapse of the anchovy stock in 1972 (Alheit and Niquen 2004). Abrupt changes between regimes are also characteristic of shifts in the southern Benguela. However, de Young et al. (2004) describe the decrease in sardine and the purported increase in anchovy in the southern Benguela during the late 1960 s and 1970s as a far more gradual change which induced further gradual changes and effects on the entire ecosystem. 
The two areas of the Benguela have experienced different regime timings and species dominance. Possible regime shifts would occur along $1600 \mathrm{~km}$ of coastline in the northern Benguela and $2000 \mathrm{~km}$ of coastline in the southern Benguela, affecting areas of approximately 180,000 and $220,000 \mathrm{~km}^{2}$ respectively (Cury and Shannon 2004, Shannon and Jarre-Teichman 1999). Historic catch and fishing effort data have been used to determine stock abundance and thus the periods of dominance of sardine and anchovy. In the southern Benguela, anchovy was believed to be abundant in the 1920 s, yet stocks declined in the 1930s and remained low until the 1940s when these stocks made a recovery (Crawford and Jahncke 1999). Sardine stocks increased in the late 1950 s but declined drastically in the 1960 s. To sustain the pelagic fishery at this time, anchovy was targeted, by reducing the size of net mesh from $32 \mathrm{~mm}$ to $13 \mathrm{~mm}$ in the 1960s. This led to high catches of anchovy in the 1970s. During the 1980s and early 1990s anchovy fluctuated at low levels. Since the mid 1990s anchovy stocks have been increasing and reached peak levels in the early 2000s. Sardine remained at low levels in the 1980s, increased in abundance throughout the 1990s and reached a peak in spawner biomass in the early 2000 s and have declined since then until present. Anchovy also has declined in abundance since 2001/02 (Coetzee et al. 2006). Management of a resource that varies on a decadal scale and that has high interannual variation in recruitment remains a major difficulty (Barange et al. 1999).

In contrast, the species composition of the northern Benguela ecosystem has changed considerably. The sardine stock declined in the 1960s and subsequently in the 1970s the anchovy stock collapsed after an increase in fishing effort for anchovy was implemented in an attempt to allow sardine to recover (Butterworth 1983). Instead both stocks collapsed, and have been replaced by a suite of pelagic and mesopelagic species such as horse mackerel, bearded gobys and jellyfish species, which now 
dominate the system. The anchovy and sardine shifts in dominance appear to affect both the northern and southern Benguela, causing changes to many aspects of the ecosystem, often rapidly and abruptly; these are sometimes known as regime fluctuations or regime shifts (Lluch-Belda et al. 1992, Shannon et al. 2004).

A regime shift is defined in a number of ways, but is here assumed to be an abrupt change from one, relatively stable ecosystem state to another. These states are notoriously difficult to define as there are only a few measurements of ecosystem state and the signal to noise ratio of these measurements is likely to be small (de Young et al. 2004). Ecosystem states can be described in relation to species composition, different levels of productivity or a combination of these factors. Defining ecosystem states in the marine environment is a complex problem, and much of our understanding and knowledge of such states has come from work on terrestrial and freshwater systems (Scheffer et al. 2001). Such closed and/or more accessible systems have provided empirical evidence of the ecological theory, as regime shifts between stable states have been detected in ecosystems as diverse as deserts and lakes (Scheffer et al. 2001). Thus it appears increasingly likely that such shifts occur within oceanic ecosystems. Recent studies have described such shifts as having occurred e.g. in the North Sea in the 1980s (Beaugrand 2004), the North Pacific in the late 1970s (Hare and Mantua 2000) and the Bering Sea in 1977, 1989 and 1998 (Rodionov and Overland 2005).

There are several agreed upon criteria that define such a regime shift in the ocean. The duration of the shift is relatively abrupt in comparison to the length of the actual regimes, and changes are recorded across a wide range of trophic levels and species. There are also disturbances to the energy and oceanographic processes within each 
system (de Young et al. 2004). The regime shift in the late 1970s in the North Pacific was characterised by basin scale environmental changes (e.g. wind stresses, pressure indices, Ekman transport and upper ocean temperatures), the predominant factor being a shift in the Pacific Decadal Oscillation (PDO) (Hare and Mantua 2000). The period was characterised by rapid shifts in phytoplankton and zooplankton production and changes in zooplankton species assemblages in the California current system. Shifts from very low to very high salmon productivity were observed in Alaska, with the reverse being true for salmon productivity off the coasts of California, Oregon and Washington. In addition, a shift occurred from productive benthic prawn and crab populations to productive gadoid populations in the Bering Sea and Alaska (Hare and Mantua 2000). Both physical and biological observations indicate there was significant physical forcing which caused the regime shift; the shift in the PDO at that time was possibly linked to El Niño Southern Oscillation (ENSO) events, through ocean-climate coupled systems. In upwelling systems the major factors that could drive a regime shift are assumed to be changes in physical forcing or fishing pressure (Larkin 1996). Forcing from ENSO events are hypothesised to trigger regime shifts in the Humboldt current system (Alheit and Niquen 2004). However the mechanisms that drive such climatic and ecosystem changes remain poorly understood (de Young et al. 2004).

There is empirical evidence of regime shifts occurring in the North Pacific and the North Atlantic, but do they also occur in the Benguela? It has only become possible in recent years to detect such regime shifts, as many oceanic biotic and abiotic data series have now been collected for over 50 years. By applying several, different, multivariate, statistical methods to these multi-decadal data time series, it is possible to determine the timing and extent of regime shifts in various marine ecosystems. 
Mantua (2004) used five different methods to show the occurrence of the regime shift in the Northern Pacific in the late 1970s. Each method has assumptions and negative aspects in terms of accurate detection; by using several methods the confidence that a shift definitely occurred becomes far more certain (Mantua 2004). Multi-decadal time series of biological and oceanographic data from surveys and fisheries sources have been collected for the marine ecosystem of the southern Benguela, yet these methods have not been applied to these datasets to test their efficacy in detecting regime shifts in the southern Benguela. Previous studies have been carried out to identify the existence of regime shifts in the last $40-50$ years in the Benguela system. These studies have questioned whether regime shifts have occurred or whether observed changes have been simply species alternations. Attempts to uncover the underlying causal mechanisms resulting in these shifts have been undertaken based on observations of changes in the ecosystem data (Cury and Shannon 2004, Crawford et al. unpublished manuscript), through modelling stock dynamics and applying various forcings to the system (Shannon et al. 2004), and by modelling trophic flows of the southern Benguela to determine causes for the fluctuations in pelagic populations over different regime periods (Shannon et al. 2003). Cury and Shannon (2004) suggest that a regime shift occurred in the northern Benguela in the early 1970s, due to both environmental forcing as well as extreme fishing pressure, but they concluded that the long-term changes observed in pelagic species in the southern Benguela had not affected the ecosystem over many trophic levels, and so termed these changes species dominance shifts.

An important question in terms of fisheries management and sustainability is whether regime shifts are reversible. The limited length in biological datasets to date makes this a challenging question to answer. Shannon et al. (2004) and Moloney et al. (2004) 
have shown that the fluctuations and shifts detected in the southern Benguela have been reversible, e.g. the resurgence of large sardine stocks recently after their collapse in the 1960s. However the collapse of sardine and anchovy stocks in the northern Benguela and their replacement by a suite of other pelagic fish species and jellyfish suggest that reversibility of the shift that seems to have occurred in this area is unlikely to occur as model simulations have shown a dramatically altered structure of the food web (Roux and Shannon 2004). In addition to this, a reversal in the environmental regimes in this system and its effect on the ocean triad of enrichment, retention and concentration may also suggest the irreversibility of this shift (Daskalov et al. 2003). The combined effect of heavy fishing and environmental perturbations has dramatically altered the northern Benguela ecosystem, resulting in several fish stocks remaining at extremely low levels (Boyer and Hampton 2001). Collie et al. (2004) hypothesise that discontinuous shifts, which occur in terrestrial ecosystems and appear to be not immediately reversible, seem to have occurred in certain marine ecosystems, e.g. the haddock of Georges Banks. Such a discontinuous shift occurs when a certain threshold is exceeded in the forcing variable, causing the trajectory of the response to be different from when external forcing increases, to when it decreases. Previously to the study by Collie et al (2004) it was not known, whether discontinuous shifts occurred in marine ecosystems, as it was acknowledged that from certain types of data it was not possible to discern if discontinuous shifts had occurred. Reasons for this included the use of time series data in which a controlling variable was not identified and often these time series were catch data that were not standardised by fishing effort (Collie et al. 2004). However there is growing evidence now that thresholds do exist in marine ecosystem response to human intervention as well as environmental perturbations (Steffen et al. 2004), which would provide a possibility that a discontinuous shift may have occurred in the northern Benguela. 
Boyer et al. (2001) have hypothesised mechanisms that may be holding the northern Benguela ecosystem in such a reduced biomass state. It has been theorised that areas under heavy fishing, i.e. areas exposed to top down induced shifts, may be sensitised to further environmental forcing, due to reduced resilience (Collie et al. 2004), therefore producing a stronger, more enhanced effect (Cury and Shannon 2004). Despite this, the time series data available for the northern Benguela is temporally very short and so a reversal of the situation in this area may still be possible. However it appears that changes in fishery practice could cause further negative impacts due to previously unidentified, complex, indirect interactions within the system (Roux and Shannon 2004). It may be in a constant altered diversity state, which has not been observed to date and may only reverse from this state over a long time period.

The dynamical processes and mechanisms that cause shifts in marine ecosystems are still not understood, or even identified at inter-decadal time scales (de Young et al. 2004). However, as anthropogenic forcing and/or environmental forcing can cause changes in biological components of an ecosystem, links between shifts in environmental forcing variables and biological state variables and between shifts in anthropogenic forcing variables and biological state variables should be explored. For the Benguela system, environmental data such as sea surface temperatures and upwelling indices can be used to detect shifts to determine if, like the PDO in the Pacific and the ENSO events in the Humboldt system, environmental changes are linked to biological changes in the southern Benguela.

This study focuses on the southern Benguela system and aims to detect possible regime shifts in both environmental and biological time series data with the use of a new statistical method, devised by Rodionov (2004), and known as the "sequential t- 
test algorithm for analysing regime shifts" or "STARS". STARS has been developed for, and applied successfully, to Northern Pacific time series. The objective of this study is to determine whether this newly developed method can detect regime shifts in time series from the southern Benguela, which include biological, fisheries and oceanographic data. Because it is likely that any shifts detected within biological variables will be caused by a combination of environmental and anthropogenic forcing, the study also aims to use STARS to detect shifts within these datasets as well. 


\section{Material and methods}

\section{Data sources}

All analyses were carried out on two data sets, the first one represented biological and catch time series, which were obtained from Marine and Coastal Management; most of these are described in Crawford et al. (unpublished manuscript). The second data set comprised oceanographic time series from the South African west and south coasts that were extracted from Reynolds and Smith V2 dataset (a blend of satellite, ship and buoy data), and were processed and made available by Dr. Claude Roy (IRD, France).

The data were split into three categories: anthropogenic forcing variables, which comprised mainly catch series and did not include effort series, environmental forcing variables and state variables. State variables were further split into model derived and observation based variables (Table 1). The full data set described the pelagic ecosystem of the southern Benguela and consisted of 44 biological state variables, 16 anthropogenic forcing variables and five environmental forcing variables. Each of the five environmental forcing variables was compared in turn to model derived (seven) and survey based (37) state variables. Anthropogenic forcing variables (16) were compared to all biological state variables. 
Table 1. Categorisation of biological, anthropogenic and environmental variables of the southern Benguela dataset.

\begin{tabular}{|c|c|c|c|c|}
\hline Variable Name & Units & Data period & Categorisation & Source \\
\hline SST anomalies@30 $30^{\circ}, 16^{\circ} \mathrm{E}$ & ${ }^{\circ} \mathrm{C}$ & $1910-2006$ & $\begin{array}{l}\text { Environmental } \\
\text { forcing }\end{array}$ & Roy (IRD) \\
\hline SST anomalies@32 $3,18^{\circ} \mathrm{E}$ & ${ }^{\circ} \mathrm{C}$ & $1910-2006$ & $\begin{array}{l}\text { Environmental } \\
\text { forcing }\end{array}$ & Roy (IRD) \\
\hline $\begin{array}{l}\text { Upwelling anomalies index } @ \\
\qquad 30^{\circ} \mathrm{S}, 16^{\circ} \mathrm{E}\end{array}$ & & 1910-2006 & $\begin{array}{l}\text { Environmental } \\
\text { forcing }\end{array}$ & Roy (IRD) \\
\hline $\begin{array}{l}\text { Upwelling anomalies index } @ \\
\qquad 32^{\circ} \mathrm{S}, 18^{\circ} \mathrm{E}\end{array}$ & & $1910-2006$ & $\begin{array}{l}\text { Environmental } \\
\text { forcing }\end{array}$ & Roy (IRD) \\
\hline Benguela Niños & & $\begin{array}{c}1934,1963,1974 \\
1984,1995\end{array}$ & $\begin{array}{l}\text { Environmental } \\
\text { forcing }\end{array}$ & $\begin{array}{c}\text { Shannon et al. 1986; } \\
\text { Gammelsrod et al } \\
1998\end{array}$ \\
\hline Anchovy landings & Thousand tons & $1950-2005$ & $\begin{array}{l}\text { Anthropogenic } \\
\text { forcing }\end{array}$ & $\mathrm{MCM}$ \\
\hline Sardine landings & Thousand tons & $1950-2005$ & $\begin{array}{l}\text { Anthropogenic } \\
\text { forcing }\end{array}$ & $\mathrm{MCM}$ \\
\hline Round herring landings & Thousand tons & $1950-2005$ & $\begin{array}{l}\text { Anthropogenic } \\
\text { forcing }\end{array}$ & $\mathrm{MCM}$ \\
\hline $\begin{array}{l}\text { Horse mackerel purse seine } \\
\text { landings }\end{array}$ & Thousand tons & $1950-2005$ & $\begin{array}{l}\text { Anthropogenic } \\
\text { forcing }\end{array}$ & MCM \\
\hline $\begin{array}{c}\text { Fisheries of large Horse } \\
\text { mackerel catch }\end{array}$ & Tons & $1950-2003$ & $\begin{array}{l}\text { Anthropogenic } \\
\text { forcing }\end{array}$ & MCM \\
\hline Snoek total catch & Tons & $1950-2001$ & $\begin{array}{l}\text { Anthropogenic } \\
\text { forcing }\end{array}$ & $\mathrm{MCM}$ \\
\hline Revised total catch & Tons & $1950-2003$ & $\begin{array}{l}\text { Anthropogenic } \\
\text { forcing }\end{array}$ & MCM \\
\hline Landings of predatory fish & Tons & $1950-2003$ & $\begin{array}{l}\text { Anthropogenic } \\
\text { forcing }\end{array}$ & $\mathrm{MCM}$ \\
\hline Demersal landings & Tons & $1950-2003$ & $\begin{array}{l}\text { Anthropogenic } \\
\text { forcing }\end{array}$ & $\mathrm{MCM}$ \\
\hline Pelagic landings & Tons & $1950-2003$ & $\begin{array}{l}\text { Anthropogenic } \\
\text { forcing }\end{array}$ & MCM \\
\hline Demersal/ total landings & $\%$ & $1950-2003$ & $\begin{array}{l}\text { Anthropogenic } \\
\text { forcing }\end{array}$ & $\mathrm{MCM}$ \\
\hline Revised Trophic level of catch & - & $1950-2003$ & $\begin{array}{l}\text { Anthropogenic } \\
\text { forcing }\end{array}$ & MCM \\
\hline $\begin{array}{l}\text { Mean length of anchovy } \\
\text { landed }\end{array}$ & $\mathrm{cm}$ & $1987-2004$ & $\begin{array}{l}\text { Anthropogenic } \\
\text { forcing }\end{array}$ & MCM \\
\hline Anchovy L95 catch & $\mathrm{n}$ & $1987-2004$ & $\begin{array}{l}\text { Anthropogenic } \\
\text { forcing }\end{array}$ & MCM \\
\hline Mean length of sardine landed & $\mathrm{cm}$ & $1987-2004$ & $\begin{array}{l}\text { Anthropogenic } \\
\text { forcing }\end{array}$ & $\mathrm{MCM}$ \\
\hline Sardine L95 catch & $\mathrm{cm}$ & $1987-2004$ & $\begin{array}{l}\text { Anthropogenic } \\
\text { forcing }\end{array}$ & MCM \\
\hline Anchovy larvae per tow & Billions & $1950-1966$ & Observed State & $\mathrm{MCM}$ \\
\hline Sardine larvae per tow & Billions & $1950-1966$ & Observed State & MCM \\
\hline $\begin{array}{c}\text { Anchovy \% eggs WEST of } \\
\text { Cape Agulhas }\end{array}$ & $\%$ & $1984-2004$ & Observed State & $\mathrm{MCM}$ \\
\hline $\begin{array}{c}\text { Sardine \% eggs WEST of } \\
\text { Cape Agulhas }\end{array}$ & $\%$ & $1984-2004$ & Observed State & MCM \\
\hline $\begin{array}{c}\text { Anchovy \% eggs EAST of } \\
\text { Cape Agulhas }\end{array}$ & $\%$ & $1984-2004$ & Observed State & MCM \\
\hline $\begin{array}{c}\text { Sardine } \% \text { eggs EAST of Cape } \\
\text { Agulhas }\end{array}$ & $\%$ & $1984-2004$ & Observed State & $\mathrm{MCM}$ \\
\hline Cyclopoid copepods & Numbers. $\mathrm{m}^{-2}$ & $\begin{array}{c}1951-1967 \& 1988 \\
-2005\end{array}$ & Observed State & MCM \\
\hline Small calanoid copepods & Numbers. $\mathrm{m}^{-2}$ & $\begin{array}{c}1951-1967 \& 1988 \\
-2005\end{array}$ & Observed State & MCM \\
\hline Medium calanoid copepods & Numbers. $m^{-2}$ & $\begin{array}{c}1951-1967 \& 1988 \\
-2005\end{array}$ & Observed State & $\mathrm{MCM}$ \\
\hline Large calanoid copepods & Numbers. $m^{-2}$ & $\begin{array}{c}1951-1967 \& 1988 \\
-2005\end{array}$ & Observed State & $\mathrm{MCM}$ \\
\hline Total copepods & Numbers. $m^{-2}$ & $\begin{array}{c}1951-1967 \& 1988 \\
-2005\end{array}$ & Observed State & $\mathrm{MCM}$ \\
\hline
\end{tabular}


Table 1 (continued). Categorisation of biological, anthropogenic and environmental variables of the southern Benguela data set

\begin{tabular}{|c|c|c|c|c|}
\hline $\begin{array}{l}\text { Counts of seal pups south of } \\
\text { Orange River, Dec every year }\end{array}$ & Numbers & $\begin{array}{c}1971,1976,1979 \\
1982,1985,1988 \\
1992,1994-1997 \\
2001,2003\end{array}$ & Observed State & $\mathrm{MCM}$ \\
\hline $\begin{array}{c}\text { Anchovy recruit biomass } \\
\text { surveyed }\end{array}$ & Thousand tons & $1985-2005$ & Observed State & $\mathrm{MCM}$ \\
\hline $\begin{array}{l}\text { Anchovy recruit numbers } \\
\text { surveyed }\end{array}$ & Billions & $1985-2005$ & Observed State & $\mathrm{MCM}$ \\
\hline $\begin{array}{c}\text { Anchovy recruit weight } \\
\text { surveyed }\end{array}$ & $\mathrm{g}$ & $1985-2003$ & Observed State & $\mathrm{MCM}$ \\
\hline $\begin{array}{c}\text { Sardine recruit biomass } \\
\text { surveyed }\end{array}$ & Thousand tons & $\begin{array}{c}1985-1987 \& 1991 \\
-2005\end{array}$ & Observed State & $\mathrm{MCM}$ \\
\hline $\begin{array}{c}\text { Sardine recruit numbers } \\
\text { surveyed }\end{array}$ & Billions & $\begin{array}{c}1985-1987 \& 1991 \\
-2005\end{array}$ & Observed State & $\mathrm{MCM}$ \\
\hline $\begin{array}{l}\text { Sardine recruit weight } \\
\text { surveyed }\end{array}$ & g & $\begin{array}{c}1985-1987 \& 1991 \\
-2003\end{array}$ & Observed State & $\mathrm{MCM}$ \\
\hline $\begin{array}{l}\text { Anchovy Nov spawner survey } \\
\text { mean length }\end{array}$ & $\mathrm{cm}$ & $1984-2004$ & Observed State & $\mathrm{MCM}$ \\
\hline Anchovy Nov mean weight & $\mathrm{g}$ & $1984-2004$ & Observed State & $\mathrm{MCM}$ \\
\hline Anchovy Nov L95 & $\mathrm{cm}$ & $1984-2004$ & Observed State & $\mathrm{MCM}$ \\
\hline $\begin{array}{c}\text { Sardine Nov spawner survey } \\
\text { mean length }\end{array}$ & $\mathrm{cm}$ & $1984-2004$ & Observed State & $\mathrm{MCM}$ \\
\hline Sardine Nov mean weight & $\mathrm{g}$ & $1984-2004$ & Observed State & $\mathrm{MCM}$ \\
\hline Sardine Nov L95 & $\mathrm{cm}$ & $\begin{array}{l}1984-2004 \\
1958-1963\end{array}$ & Observed State & $\mathrm{MCM}$ \\
\hline $\begin{array}{l}\text { Freq of occurrence of anchovy } \\
\text { in snoek diet }\end{array}$ & $\%$ & $\begin{array}{c}1965-68,1970- \\
1974,1979,1985 \\
1994-1997 \\
1958-1963\end{array}$ & Observed State & $\mathrm{MCM}$ \\
\hline $\begin{array}{l}\text { Freq of occurrence of sardine } \\
\text { in snoek diet }\end{array}$ & $\%$ & $\begin{array}{c}1965-68,1970- \\
1974,1979,1985 \\
1994-1997\end{array}$ & Observed State & $\mathrm{MCM}$ \\
\hline $\begin{array}{l}\% \text { Anchovy in diet of Cape } \\
\text { Gannet Lamberts Bay }\end{array}$ & $\%$ & $1978-2005$ & Observed State & $\mathrm{MCM}$ \\
\hline $\begin{array}{l}\% \text { Anchovy in diet of Cape } \\
\text { Gannet Malgas Island }\end{array}$ & $\%$ & $1978-2005$ & Observed State & $\mathrm{MCM}$ \\
\hline $\begin{array}{c}\% \text { Anchovy in diet of Cape } \\
\text { Gannet Algoa Bay }\end{array}$ & $\%$ & $1979-2005$ & Observed State & $\mathrm{MCM}$ \\
\hline $\begin{array}{l}\% \text { Anchovy in diet of Cape } \\
\text { Gannet West Coast }\end{array}$ & $\%$ & $1978-2005$ & Observed State & $\mathrm{MCM}$ \\
\hline $\begin{array}{l}\% \text { Sardine in diet of Cape } \\
\text { Gannet Lamberts Bay }\end{array}$ & $\%$ & $1978-2005$ & Observed State & $\mathrm{MCM}$ \\
\hline $\begin{array}{l}\text { \% Sardine in diet of Cape } \\
\text { Gannet Malgas Island }\end{array}$ & $\%$ & $1978-2005$ & Observed State & $\mathrm{MCM}$ \\
\hline $\begin{array}{c}\% \text { Sardine in diet of Cape } \\
\text { Gannet Algoa Bay }\end{array}$ & $\%$ & $1979-2005$ & Observed State & $\mathrm{MCM}$ \\
\hline $\begin{array}{l}\% \text { Sardine in diet of Cape } \\
\text { Gannet West Coast }\end{array}$ & $\%$ & $1978-2005$ & Observed State & $\mathrm{MCM}$ \\
\hline $\begin{array}{l}\text { Sardine mean condition factor } \\
\text { (Jan-May) }\end{array}$ & $\begin{array}{l}\text { Least squares } \\
\text { (LS) means CF }\end{array}$ & $\begin{array}{c}1953-1954 \& 1956 \\
-2004\end{array}$ & Observed State & $\mathrm{MCM}$ \\
\hline $\begin{array}{l}\text { Sardine mean condition factor } \\
\text { (Jun-Aug) }\end{array}$ & $\begin{array}{l}\text { Least squares } \\
\text { means } \mathrm{CF}\end{array}$ & $\begin{array}{c}1953-1954,1956- \\
72,1975-78,1980 \\
-2005\end{array}$ & Observed State & $\mathrm{MCM}$ \\
\hline $\begin{array}{l}\text { Net Sardine standardised } \\
\text { gonad mass (SGMn) }\end{array}$ & $\begin{array}{l}\text { LS means of } \\
\log (S G M n)\end{array}$ & $\begin{array}{c}1953-1954 \& 1956 \\
-2004\end{array}$ & Observed State & $\mathrm{MCM}$ \\
\hline Sardine stock size (VPA) & Million tons & $1950-1982$ & Modelled State & $\overline{\mathrm{MCM}}$ \\
\hline Anchovy stock size (VPA) & Million tons & $1964-1982$ & Modelled State & MCM \\
\hline Anchovy spawner biomass & Thousand tons & $1984-2005$ & Modelled State & MCM \\
\hline Sardine spawner biomass & Thousand tons & $1984-2005$ & Modelled State & $\mathrm{MCM}$ \\
\hline $\begin{array}{l}\text { Redeye spawner biomass } \\
\text { (uncapped) }\end{array}$ & Thousand tons & $1987-2004$ & Modelled State & $\mathrm{MCM}$ \\
\hline $\begin{array}{c}\text { Anchovy model recruits } \\
\text { numbers }\end{array}$ & Billions & $1985-2003$ & Modelled State & $\mathrm{MCM}$ \\
\hline $\begin{array}{c}\text { Sardine model recruits } \\
\text { numbers }\end{array}$ & Billions & $1985-2003$ & Modelled State & $\mathrm{MCM}$ \\
\hline
\end{tabular}




\section{Data analysis}

Attention was focused primarily on observation based state variables, as these would be the least biased, and on post 1983 data as these data are more reliable than earlier data because of the concerted research effort within the larger framework of the Benguela Ecology Programme that started in the early 1980s (Moloney et al. 2004) and the start of the hydroacoustic surveys to estimate sardine and anchovy biomass and recruit data.

The data set was analysed using STARS, which was developed specifically for detecting regime shifts within time series data by Rodionov (2004). This method differs from typical empirical statistical methods to detect regime shifts, such as those used by Mantua (2004), because it employs a sequential analysis, i.e. the number of observations is not fixed and thus observations can be added to the time series as they become available. This is assumed to prevent the deterioration of the test statistic towards the end of the time series, which is common in other statistical methods applied to time series data (Rodionov and Overland 2005), and makes it possible to detect a shift near the end of time series. There is also no need to have extremely long, complete time series for variables that are to be tested. Instead, each observation is tested in sequence as it becomes available; a new test is performed for each observation added to the previous observations. STARS analysis tests the null hypothesis $\left(\mathrm{H}_{0}\right)$ each time: a regime shift does not exist. There are three outcomes to the test: reject $\mathrm{H}_{0}$, cannot reject $\mathrm{H}_{0}$ or keep testing. This method also does not require an a priori shift date to be hypothesised, and thus data from any time period can be analysed and possible shifts detected. 
The algorithm described by Rodionov (2004) comprises seven steps, following which the test continues in a loop until all the data for a certain variable are processed. Each new observation is tested to see if it differs significantly from the mean of the current regime under the statistical criteria of a Student's t-test. If the current value is found to be greater or less than the critical level of the current regime mean, then the current time (year) is marked as a possible change point and subsequent observations are tested in the same manner to confirm this change point as a new regime or merely an outlier. The testing consists of calculating the so-called regime shift index (RSI) that represents a cumulative sum of normalized anomalies relative to the critical level: $R S I=\frac{1}{l_{\overline{s i}}} \sum_{i=t_{\text {cur }}}^{m}\left(x_{i}-\bar{x}_{c r i t}\right) \quad m=t_{c u r}, t_{c u r}+1, \ldots, t_{c u r}+l-1$.

(taken from Rodionov 2004).

where $t_{\text {cur }}$ denotes the current time of the testing period

$l$ denotes the cut off length (years) of the regimes to be tested

$x_{i}$ denotes the value of the variable being tested

$\bar{x}_{\text {crit }}$ denotes the critical mean value of $x$

$m$ denotes the number of years since the start of a new regime

$\bar{S}_{1}$ denotes the average standard deviation for all one year intervals in the time series

If at any time during the testing period from $t_{c u r}$ to $t_{c u r}+l-1$ the index becomes negative, or positive, the null hypothesis about the existence of a shift in the mean at time $t_{c u r}$ is rejected, and the value $x_{c u r}$ is included in the "current" regime. Otherwise, the time $t_{c u r}$ is declared a change point, $c$, and a new regime is indicated (Rodionov 2004). 


\section{Straight vs. prewhitened analyses}

A problem with most methods used to detect shifts in time series (including this method) is that they are unable to determine whether the regimes detected are realisations of a Gaussian, red noise process with stationary statistics or are in fact 'real' regimes with different statistics (Overland et al. 2006). A red noise signal within the time series is characterised by long intervals of data points above or below the overall mean, thus these time intervals could be misconstrued as regimes with different statistics. The STARS method does assume that there is no autocorrelation within the time series to be analysed, i.e. that each data point is independent of each other. However time series data often show serial correlation. Therefore prior to running analyses using the Rodionov STARS method this autocorrelation had to be removed using a process known as "prewhitening".

The IP4 (Inverse Proportionality with 4 corrections) method is one of the prewhitening methods available within the STARS programme, and was used to remove the red noise component of the time series. This prewhitening method was chosen as it was found to outperform other methods such as the MPK (Mariott- Pope and Kendall) method (Marriot and Pope 1954, Kendall 1954) at small subsample sizes in terms of the magnitude of the bias and variability of the estimates (Rodionov 2006). This process involves sub-sampling and bias correction of the least squares estimate of the serial correlation. It results in a reduction in the magnitude of the regime shifts (Rodionov 2006). 


\section{Sensitivity to model settings}

STARS analysis was performed on all variables and each variable was analysed straight and prewhitened, to explore how they compared, but prewhitened runs were taken as the most robust results. In both straight and prewhitened analyses, three parameters must be set prior to running the analysis: these are the cut off length $(l$ in equation 1), the significance level and the Huber parameter. These parameters are described in greater detail below and all were assigned a number of different values to determine the robustness of the results.

\section{Cut off length (I)}

The STARS method allows shifts of different time scales and magnitudes to be detected. By setting the cut off length $(l$, number of years) within the time series, the time scale of regimes to be detected is also set; if the cut off length is reduced, the time scale of regimes to be detected will also be reduced and vice versa. If regimes last longer than the cut off length, they will be detected. If they are shorter than the cut off length then their chances of being detected are reduced. The cut off length also influences the magnitude of shifts detected by influencing the statistically significant difference between neighbouring regimes (Rodionov 2004).

The sensitivity of the results of the STARS method was explored for different cut off lengths to determine whether shifts in the same year or in different years for the same variable were detected and whether the total number of shifts changed. A cut off length of ten years was used first, as regime shifts are known to be associated with decadal scale oceanic variability. Five year cut off lengths were used next to see whether the same signals were identified on a shorter time scale. Finally, to further strengthen the confidence in the model outputs, cut off lengths of seven and 13 years were tested for all the variables, anthropogenic, environmental and biological. As 
seven and 13 are prime numbers, they were assumed to be unbiased, as they will not be affected by regular variability in the time series, which might be the case by using five and ten year cut off lengths. For each cut off length, both $5 \%$ and $10 \%$ significance levels were used against all variables to identify differences in the shift detection results.

\section{Significance level $(\alpha)$}

The significance level, as well as the cut off length, influences the statistical significance of each regime detected and thus the magnitude of each shift. The significance level set prior to running analyses is the maximum significance level at which a new regime is detected from shifts in the mean. The lower the significance level, the larger the required magnitude of the shift is in order to be detected. Usually the calculated significance level for detected shifts is less than $\alpha$.

\section{Huber parameter $(H)$}

The Huber weight parameter controls the weight assigned to outliers and therefore controls the magnitude of the average values of each regime.

It is calculated by the formula:

$$
\text { weight }=\min (1, \text { parameter } /(\mid \text { anomaly } \mid))
$$

where anomaly is the deviation from the expected mean value of the new regime, normalised by the standard deviation averaged for all consecutive sections of the cutoff length in the series. If the normalised anomalies are less than or equal to the value of the Huber parameter then their weights are set to one. Otherwise, the weights are inversely proportional to the distance from the expected mean value of the new regime (Rodionov 2004). For example, if $\mathrm{H}=6$ then all data points that are equal to or less than six standard deviations from the mean are not considered outliers. The 
Huber parameter was tested at $\mathrm{H}=1, \mathrm{H}=3$ and $\mathrm{H}=6$ whilst keeping cut off length at $l=10$ years and the significance level at $\alpha=0.1$.

\section{'Robust', 'Possible' and 'Prewhitened' shifts}

From these sensitivity tests of the model settings, a robust shift was defined as a shift in a specific variable that occurred in the same year with $70 \%$ or more of the model settings and during both straight and prewhitened analyses. Those shifts that occurred with $70 \%$ or more of parameter inputs, but only during straight analyses were termed 'possible' shifts. Those shifts that occurred with $70 \%$ or more of parameter inputs, but only during prewhitened analyses were termed 'prewhitened' shifts. The biological state variables with 'robust', 'possible' and 'prewhitened' shifts were compared to similar shifts in oceanographic/environmental forcing variables and anthropogenic forcing variables. Not all shifts detected within the analyses were scrutinised; where several shifts were detected over the time series of a certain state variable, only those that were classified as 'robust', 'possible' or 'prewhitened' shifts were analysed further. Those shifts that did not occur with $70 \%$ or more of parameter inputs were not included when comparing the biology of the system to the oceanography.

\section{Definition of maximum acceptable lag times}

Maximum lag times between a change or shift in a possible driver in the marine system and a subsequent response from a biological state variable were defined on the basis of biological considerations, and are shown in Table 2. Changes in zooplankton abundance occur sub-annually and therefore a maximum lag time of one year was assigned. Anchovy spawn at an age of one year and sardine spawn at an age of two to three years, therefore a maximum lag time between shifts in environmental forcings and responses in small pelagic fish was given as two generations. In contrast small pelagic fish eggs would respond to changes in oceanography in the same year. Two 
years is given as a maximum lag time for an effect to be noticed in the diet of Cape Gannets, as this relates to the lag time in which changes would be apparent in the small pelagic fish species that comprise their diet. These lag times were used to interpret the results of STARS analysis, providing a threshold value which was used to compare forcing variables to response variables. Any lag times greater than these maxima are disregarded, whereas those that fall within the lag time range are considered.

Table 2. Maximum lag times between a shift in an ecosystem forcing variable and the response in the biological state variables. Generation times relate to the specific biological variable.

\begin{tabular}{ccc}
\hline Forcing & State variable & Maximum Lag time \\
$\begin{array}{c}\text { Oceanography } \\
\text { (Benguela Niños, SST \& Upw) }\end{array}$ & Zooplankton & 1 year \\
Oceanography & Small pelagic fish eggs & The same year/season \\
Oceanography & $\begin{array}{c}\text { Cape Gannet (Mons capensis) diet } \\
\text { of Anchovy/ Sardine } \\
\text { Recruits of small pelagic fish }\end{array}$ & 2 years \\
Oceanography & $\begin{array}{c}\text { Sardine condition factor \& gonad } \\
\text { mass }\end{array}$ & 2 generations \\
Oceanography & Anchovy recruits & 2 generations \\
Anchovy landings & Sardine recruits \\
Sardine landings & Small pelagic fish & 2 generations \\
Demersal landings & Small pelagic fish & 2 generations \\
Horse mackerel purse seine & Recruits of small pelagic fish & 2 generations
\end{tabular}




\section{Results}

Results of the STARS analysis of the environmental forcing variables are presented first, followed by the results from analysing the anthropogenic forcing variables. Finally the results of the STARS analysis of the biological state variables are presented and compared to Benguela Niño events and the previously determined shifts in the environmental and anthropogenic forcing variables. The results, in which the links between forcing and state variables were difficult to discern or where maximum lag times were greater than those in Table 2 are described and shown in the Appendices.

\section{Environmental forcing variables}

\section{Benguela Niños}

Benguela Niños are warm water intrusions from equatorial waters north of the Angola-Benguela front, which is situated between $14^{\circ} \mathrm{S}$ and $16^{\circ} \mathrm{S}$, into the cooler waters of the Benguela system to the south. It is believed that ENSO events in the Pacific are similar, yet more intense events than Benguela Niños, (Shannon et al. 1986). When these warmer waters north of the Angola-Benguela front move further south than usual, the merging of the two bodies of water increases sea temperatures and disrupts the typical upwelling cycle and ecosystem (Shannon et al. 1988). Many adverse effects on species ranging from plankton to fish, have been noted at the time of previous Benguela Niño events (Boyer et al. 2001). Since 1950, Benguela Niños have occurred in 1963, 1974, 1984 and 1995 (Shannon et al. 1986, Gammelsrød et al. 1998), (Table 1). 


\section{SST anomalies at $30^{\circ} \mathrm{S}$ and $32^{\circ} \mathrm{S}$}

Results of the STARS analysis showed that SST anomalies at $30^{\circ} \mathrm{S}$ and $32^{\circ} \mathrm{S}$ only increased significantly over the period 1950-2006. Positive possible shifts in SSTs at $30^{\circ} \mathrm{S}$ were detected in 1956,1971 and 1985 (Figure 1a) and positive prewhitened shifts were detected in 1991 and 2004/05 at $30^{\circ}$ S (Figure 1b). In 1956 and 2000/01 positive robust shifts were detected at $32^{\circ} \mathrm{S}$ as well as a negative prewhitened shift in 1950 (Figure 1b) and a positive possible shift in 1991 (Figure 1a).

\section{Upwelling anomalies at $30^{\circ} \mathrm{S}$ and $32^{\circ} \mathrm{S}$}

Four possible shifts were identified from the STARS analysis in upwelling anomalies at $30^{\circ} \mathrm{S}$, a positive shift in 1951, a negative shift in 1991, a further positive shift in 1998 and a negative shift in 2004/05 (Figure 1a). In 1956 a positive prewhitened shift was detected and in 2004/05 a positive prewhitened shift was detected at $30^{\circ} \mathrm{S}$ (Figure 1b). Negative possible shifts occurred in 1964 and $2000 / 01$ at $32^{\circ} \mathrm{S}$ (Figure 1a), whereas in 1971/72 a positive robust shift in upwelling was detected and a negative prewhitened shift was identified in $2004 / 05$ at $32^{\circ} \mathrm{S}$ (Figure $1 \mathrm{~b}$ ).

A property of the prewhitening procedure is that it reduces the magnitude of shifts detected (Rodionov, 2006), therefore the smaller magnitude prewhitened shifts of environmental variables are shown alone in Figure $1 \mathrm{~b}$ for clarity, whereas the larger magnitude possible shifts of all environmental variables are shown in Figure la. Those shifts that occur in both Figure $1 \mathrm{a}$ and $\mathrm{b}$ are the robust shifts. This difference in the magnitude of shifts detected by the different methods of the STARS analysis was viewed as less important than the detection of the exact timing of a shift. Therefore, although the magnitudes of the shifts in environmental forcings are shown in Figures $1 \mathrm{a}$ and $\mathrm{b}$, when comparing these to the biological state variables, only the timing and 


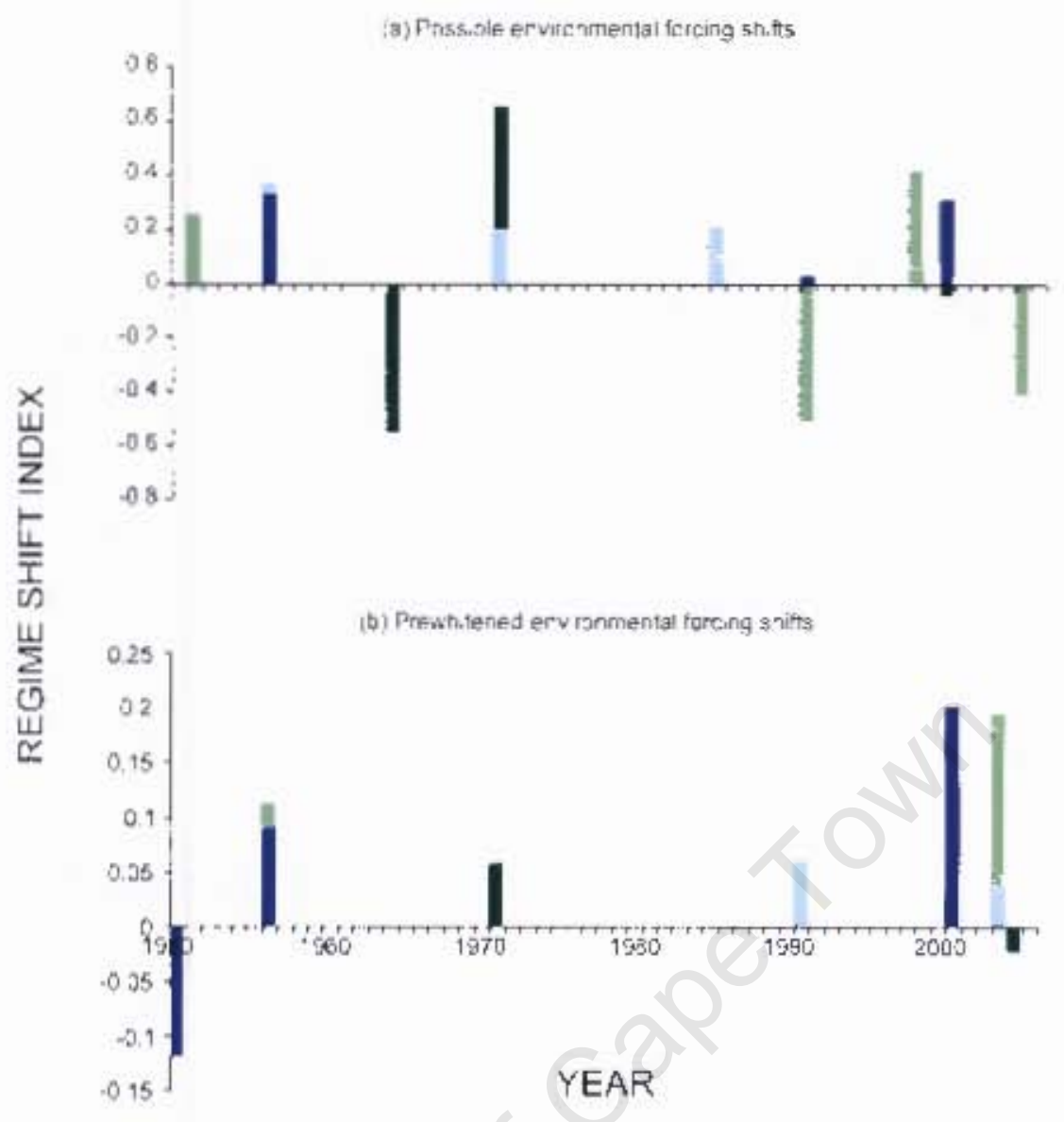

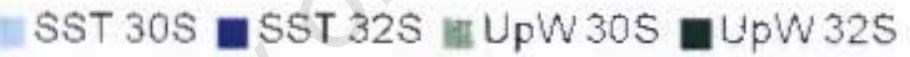

Figure I: Results of the STARS analysis showing the maznitude and ciming of shitts in RSI (colourd bars) for invironnental forcing variahles as (a) possitle shifts and (b) prewhitened shifts since 1950. 
direction of the forcing shift is shown by arrows. It is likely that the system would respond differently to the same magnitude of environmental change depending on the state of the system at the time (Schwartzlose et al. 1999).

\section{Anthropogenic forcing variables}

Prewhitened shifts were only detected in 13 of the 15 anthropogenic forcing variables and from these 13 , nine variables which related most to the biological variables with robust shifts were analysed further.

Anchovy, sardine and demersal landings.

Positive possible shifts in anchovy landings were detected in 1963/64, 1978/79 and 1999/00 (Figure 2a). No robust shifts were detected in anchovy landings. A positive possible shift in sardine landings occurred in 1957/58 (Figure 2a) and a negative and a positive prewhitened shift were identified in 1963/64 and 2000/01 respectively (Figure 2b). A positive possible shift in demersal landings in $1958 / 59$ was detected (Figure 2a) and two robust shifts, in 1963-65 (positive) and 1972-74 (negative) were also identified (Figure $2 \mathrm{a}$ and $\mathrm{b}$ ).

Fisheries for large horse mackerel and horse mackerel purse seine landings In 1969/70 and 1992/93, a positive and a negative possible shift in fisheries catches of large horse mackerel were identified respectively (Figure 2a), however no robust or prewhitened shifts were detected. A negative possible shift in $1957 / 58$ was shown to occur (Figure 2a) and negative prewhitened shifts were detected in 1955/56 and 1962/63 in horse mackerel purse seine landings (Figure 2b). 


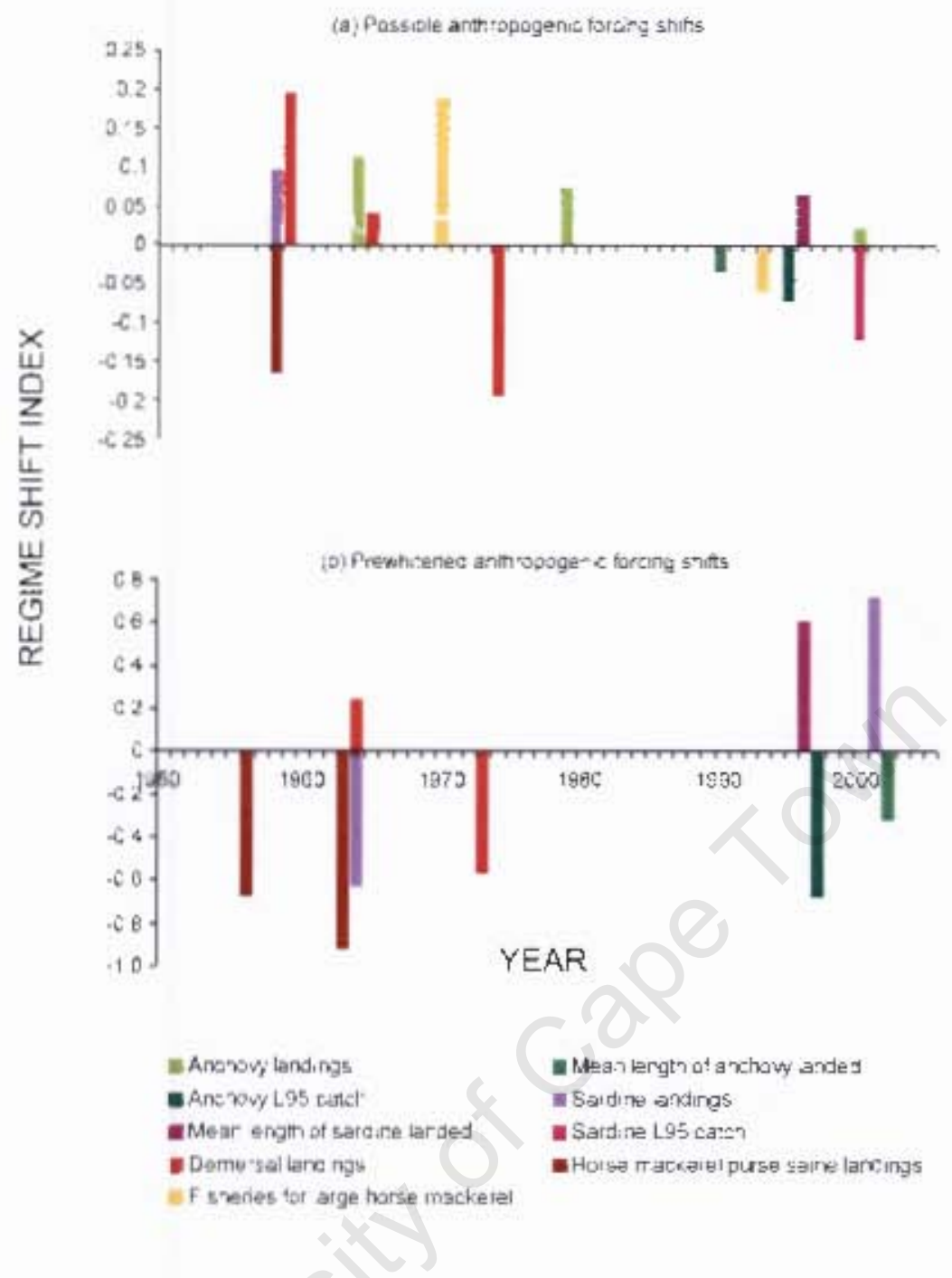

Figure 2: Resulis of tbe STARS cualysis showing the mugntiude and timing of shifts in RSI (coloured bars) for ur:thropogenic forcing variables us (a) possible shiflis und (b) presslitened shilis since 1950. 
Anchovy and sardine mean length and L95 in the catch

In 1989/90 a negative possible shift was detected in anchovy mean length (Figure 2a), whereas a negative prewhitened shift in anchovy mean length was detected in 2000/01 (Figure 2b). A negative possible shift was identified in anchovy L95 in 1994/95 (Figure 2a) and a negative prewhitened shift was detected in 1996/97 (Figure 2b). A positive robust shift in sardine mean length was detected in 1995/96 (Figure 2b). Sardine L95 showed a negative possible shift in 1999/00 (Figure 2a) but no prewhitened shift was detected.

\section{Observation state variables compared to Benguela Niños} Copepod abundance (1951-1967)

A positive robust shift in four out of the five copepod groups in the data set was detected in 1964/65 (Figure 3a-d). This shift occurred one to two years after the 1963 Benguela Niño event, (Table 1) and one year after the collapse of the sardine fishery in 1963-64.

\section{Sardine mean condition factor and standardised gonad mass}

A positive possible shift in sardine standardised gonad mass occurred two to three years after the 1963 Benguela Niño event (Figure 4a), but similar shifts did not occur after the other Benguela Niño events. In contrast, two to three years after the 1984 event a negative robust shift in standardised gonad mass occurred (Figure 4a). Negative possible shifts in sardine mean condition factor between January and May (high condition season) were detected two to three years after the 1984 event (Figure 4b) and within one year of the 1995 event. Sardine mean condition factor between June and August (low condition season) showed a positive robust shift three to four 

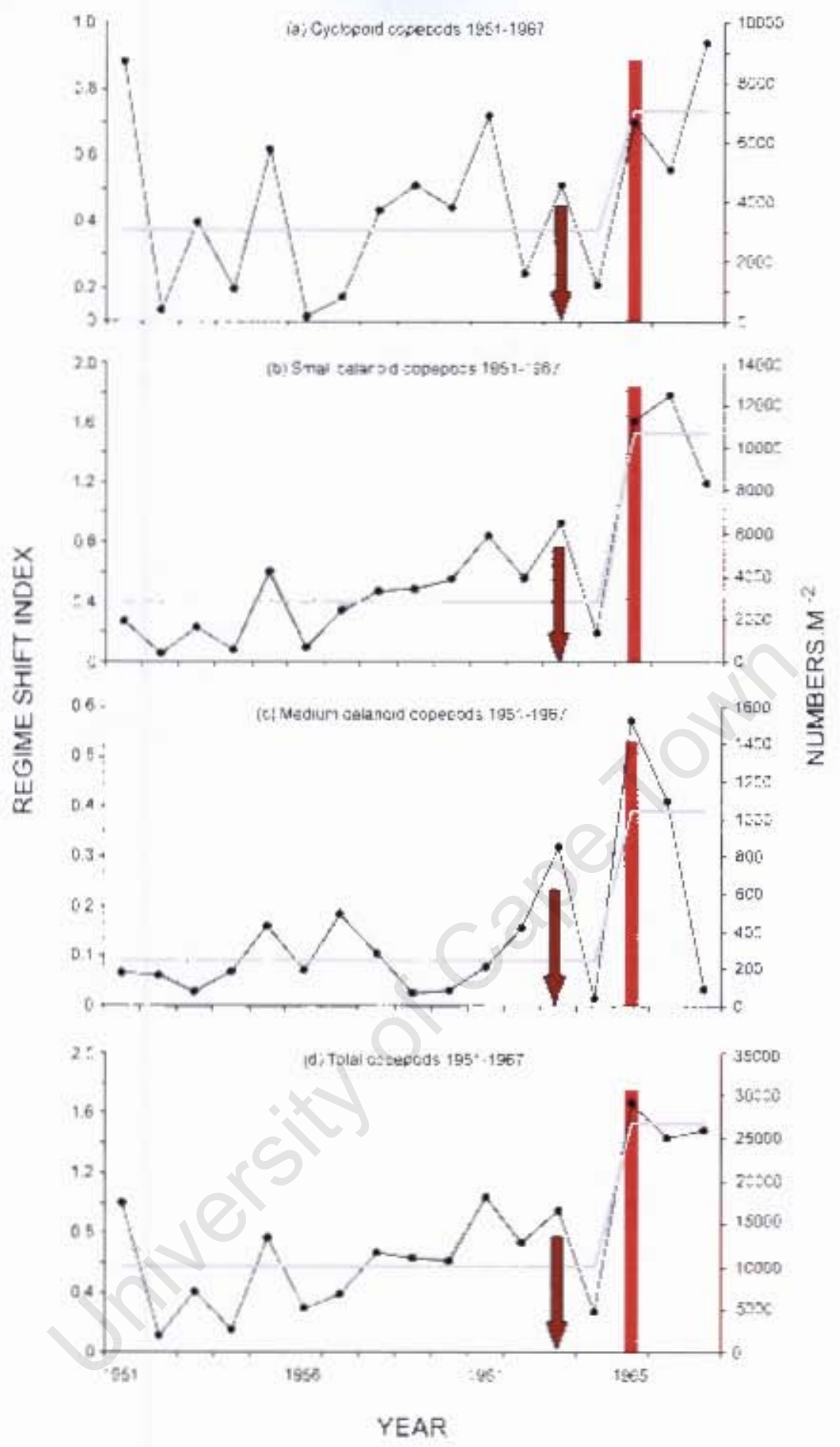

- - Time seres Time series as step unction Robus: shif:

Figure 3: Results of STARS analysis showing the magnitude of shitts in RSI (coloured bars), the werull time scrics (black linc) and the weighted mean of observation state variables (grey line) for (a) cyclopoid copipods, (b) small calanoid copkeds, (c) medium calanoid copepods and (d) total

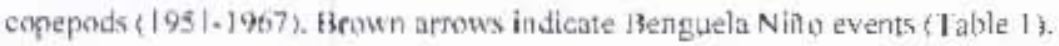




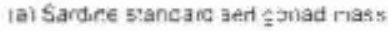
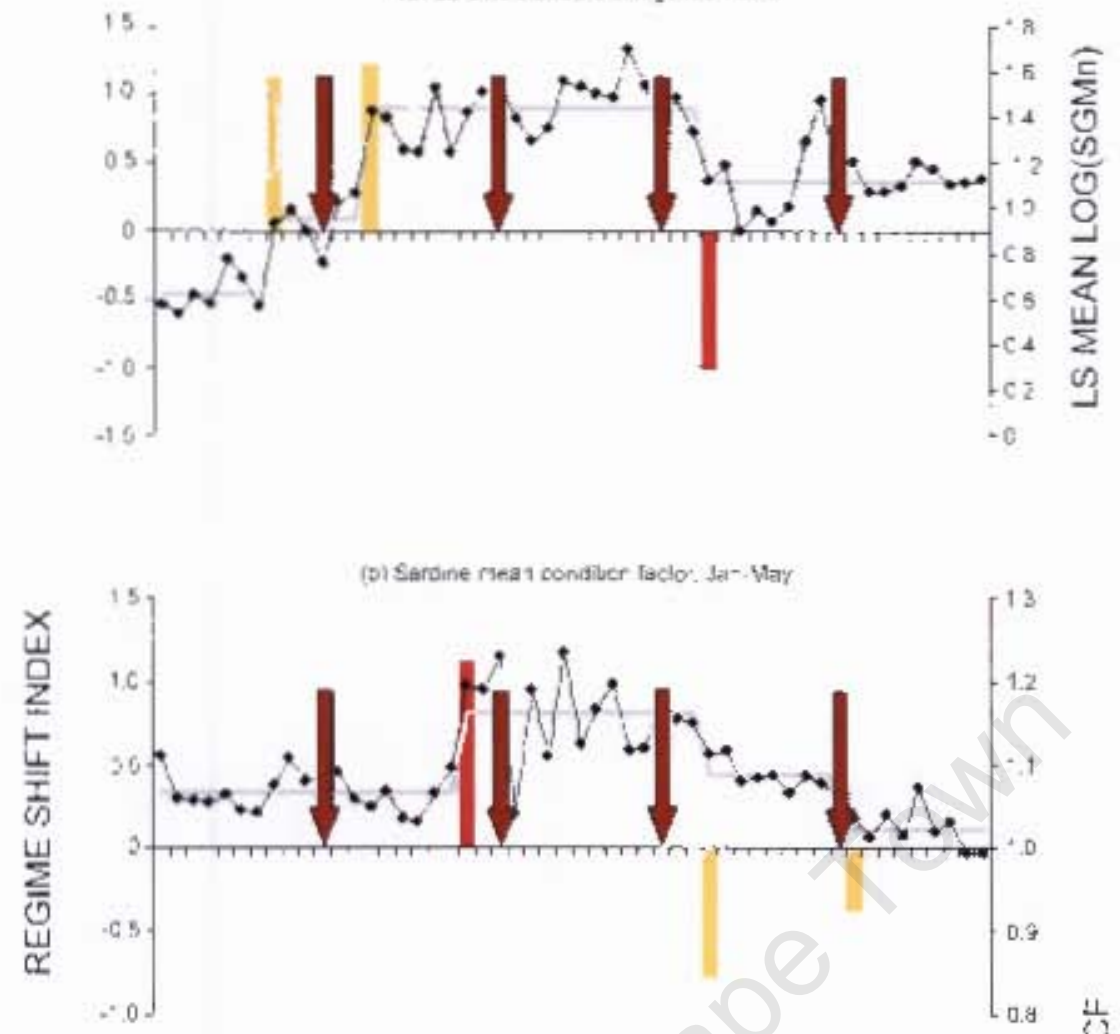

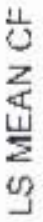

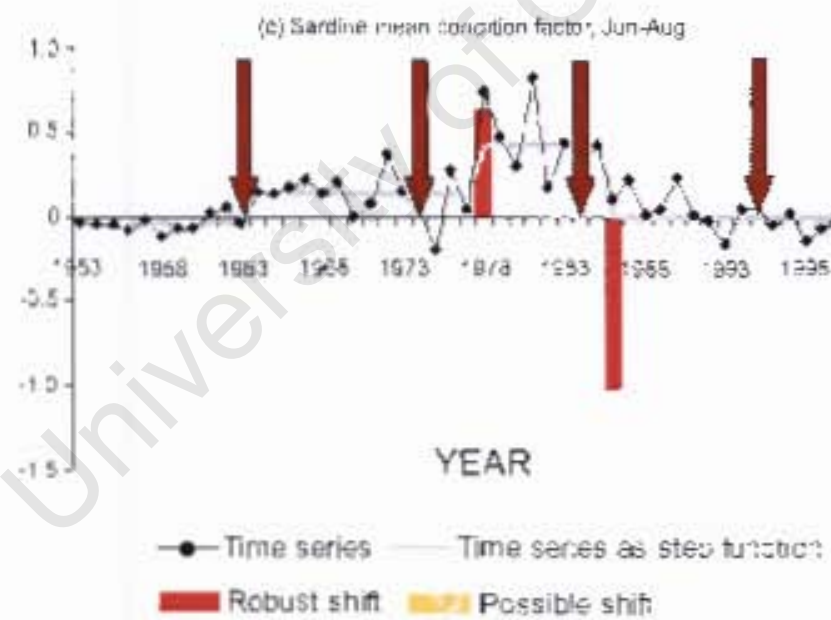

Figure 4: Results of STARS unulysis stowing the magnicude of shifts in RSI (coloured burs), the wcrall time scries (black lins) and the weighted meun of obscrvation stabe variables (grey line) for (a) sardine standardised gond mass, (b) sardine mean condition factor. Jan-May and (c) sardine muan condition factor, Jun-Aug. Jsrown arrows indieste [3engutta Nino events. Buth robust and possible shifts identified by the STARS analysis are shown. 
years after the 1974 Benguela Niño (Figure 4c) and, similarly to Jan-May series, there was a negative but robust shift one to two years after the 1984 event (Figure 4c).

\section{$\%$ Anchovy in diet of Cape gannets}

In Algoa Bay (south east coast), one negative possible shift of the anchovy component in gannet diet was detected in $2002 / 03$, which was unlikely to be linked to the Benguela Niño event in 1995 (Figure 5a). In Lambert's Bay there was a positive robust shift and on the west coast a positive prewhitened shift in 2004/05 (Figure 5b and c). These two shifts also could not be linked to Benguela Niño events. However, there were negative possible shifts in 1983/84 at Lamberts Bay and on the west coast, which were in the same year as a Benguela Niño event. From 1983, the percentage of anchovy in Cape gannet diet fluctuated greatly. At Lambert's Bay it varied from $9-$ $62 \%$ and at Algoa Bay from $0.6-40 \%$. The fluctuations from high to low at Lambert's Bay and on the west coast have a period of approximately five to ten years, whereas fluctuations from high to low at Algoa Bay occur every ten years. No shifts were detected in the percentage of anchovy in Cape gannet diet at Malgas Island (results not shown).

\section{Modelled state variables compared to Benguela Niños}

\section{Sardine and redeye spawner biomass and sardine model recruit numbers}

Sardine spawner biomass from model outputs showed a positive possible shift in 1996/97, one to two years after a Benguela Niño event (Figure 6a). There was a positive robust shift in redeye modelled biomass and sardine model recruit numbers in 1997/98. The Benguela Niño in 1995 could be an explanatory factor in these shifts 
\{a: Wi Anço:y in dier of Cace zan e: a: Ajgca Bay
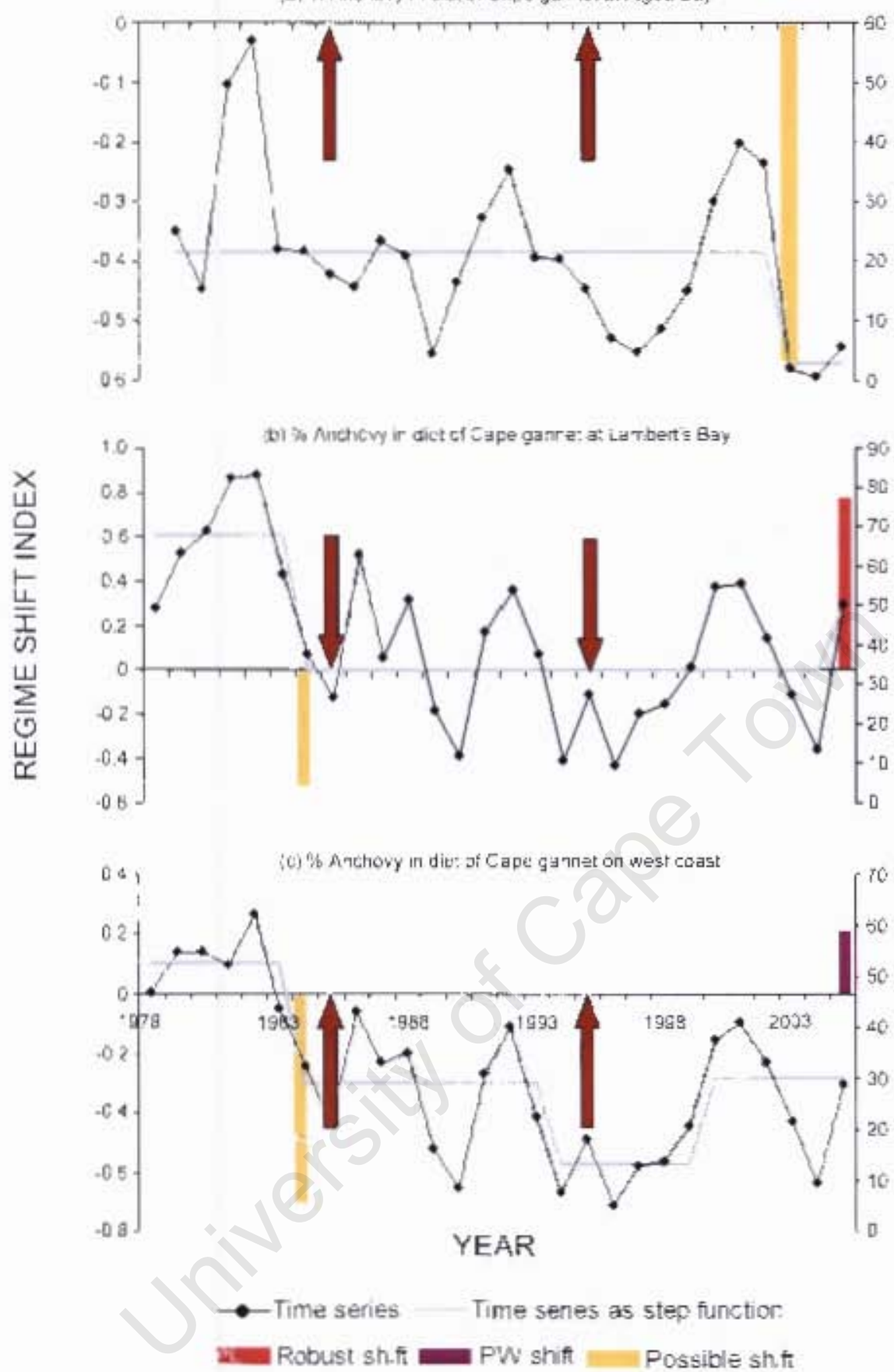

Figure 5: Results of STARS analysis showing the magnitude of shifts in RSI (coloured bars), the overall time series (black line) and the weighted niean of observation sluk vuriables (grcy line) for the $\%$ anchovy in gannet diet, which is given for (a) Algoa Bay, (b) Lurnber1's Buy and (c) the west coust. Isrown arrows indicate isenguela Nino events. Rutsusi, prowhiteued (PW) and possible shifts identified by the STARS analysis are showir. 


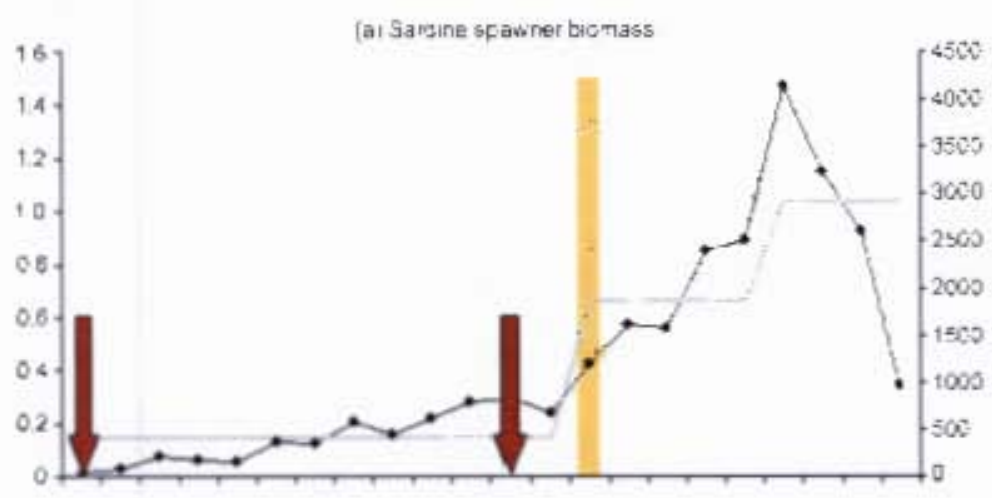

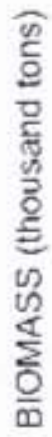
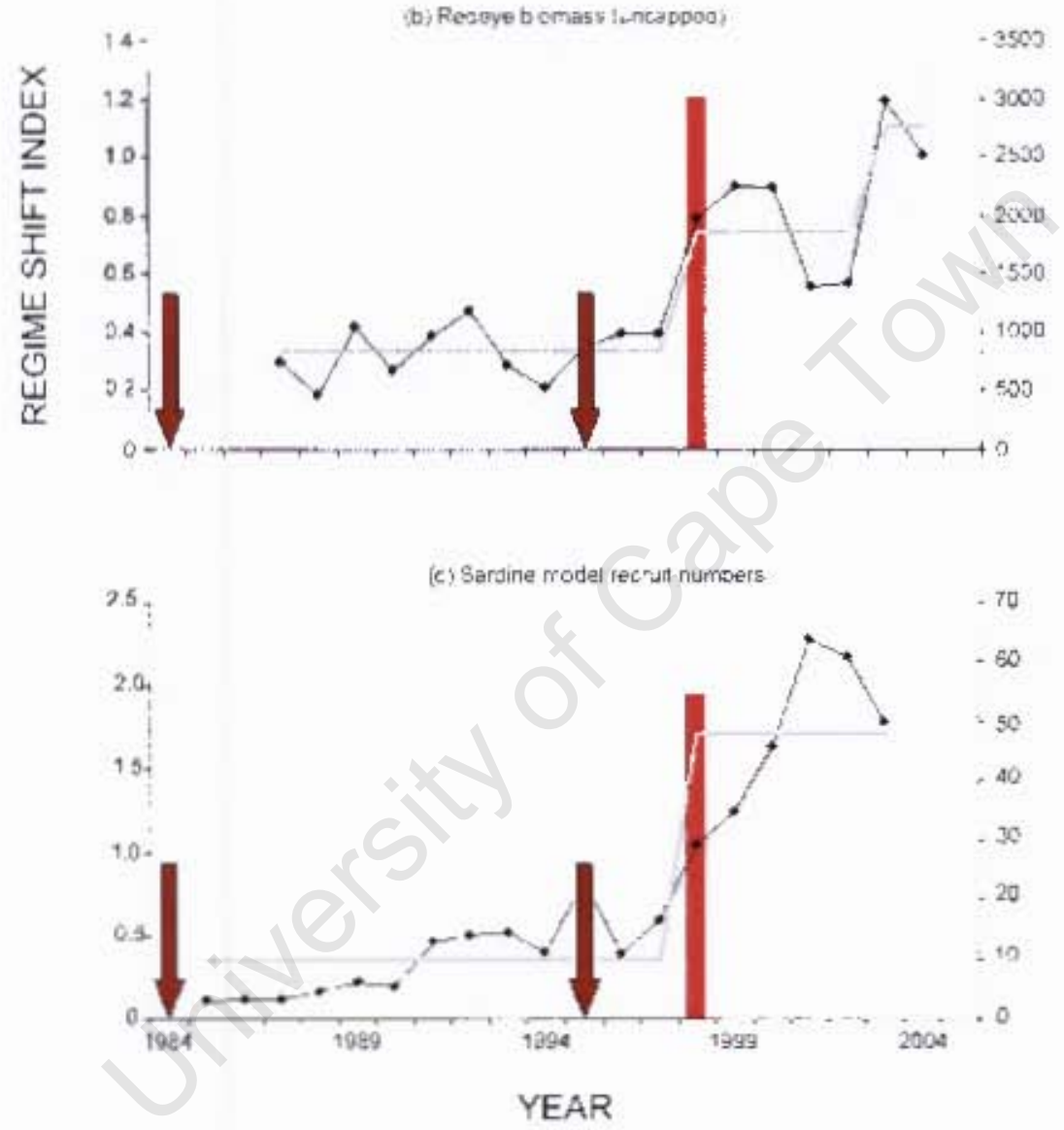

告

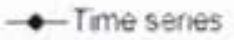

Tme series as step function:

Robust shit moss.b.e srit?

Figure 6: Results of STARS analysis showing the magnitude of shifts in RSI fcoloured bars). the overall time series (black line) and the weighted mean of observation state wariables terey line) for (a) sardine spawner bionass, (h) redeye biomass and (c) sardine model recruit numbers. Brown arrows indicate Henguela Nino events. Hoth robust and possibie shitts juentilied by the STARS anulysis are shown. 
as, it falls within the maximum acceptable lag time between oceanographic changes and a response in sardine recruit numbers (Table 2, Figure $6 \mathrm{~b}$ and $\mathrm{c}$ ).

\section{Observation state variables compared to SST anomalies at $30^{\circ} \mathrm{S}$ and $32^{\circ} \mathrm{S}$}

\section{Copepod abundance (1988-2005)}

A negative possible shift reducing the abundance of cyclopoid and total copepods by half occurred in $2000 / 01$ the same year as the positive robust shift in SST at $32^{\circ} \mathrm{S}$ (Figures 7a and c). A positive prewhitened shift in SST at $30^{\circ} \mathrm{S}$ was detected in $2004 / 05$, the same year in which small calanoid copepods undergo a negative robust shift, reducing abundance by half (Figure $7 b$ ) and total copepods undergo a negative prewhitened shift reducing abundance by a third (Figure $7 \mathrm{c}$ ). There were no robust shifts detected in medium or large calanoid copepods for this more recent period of zooplankton data (results not shown).

$\%$ Sardine eggs west and east of Cape Agulhas

In $2000 / 01$ the positive robust shift in SST anomalies at $32^{\circ} \mathrm{S}$ is linked to a negative robust shift in the percentage of sardine eggs found west of Cape Agulhas (Figure 8a) and a corresponding positive robust shift in the percentage east of Cape Agulhas (Figure 8b).

\section{Anchovy recruit numbers and biomass surveyed}

A positive possible shift in anchovy recruitment occurred in 1999/2000 (Figures 8c and d). From 1985, anchovy recruits had been at mean biomass levels of approximately 384 million tons until the extraordinarily successful recruitment year in 2000 , which occurred one year prior to the robust shift detected in SST at $32^{\circ} \mathrm{S}$. 


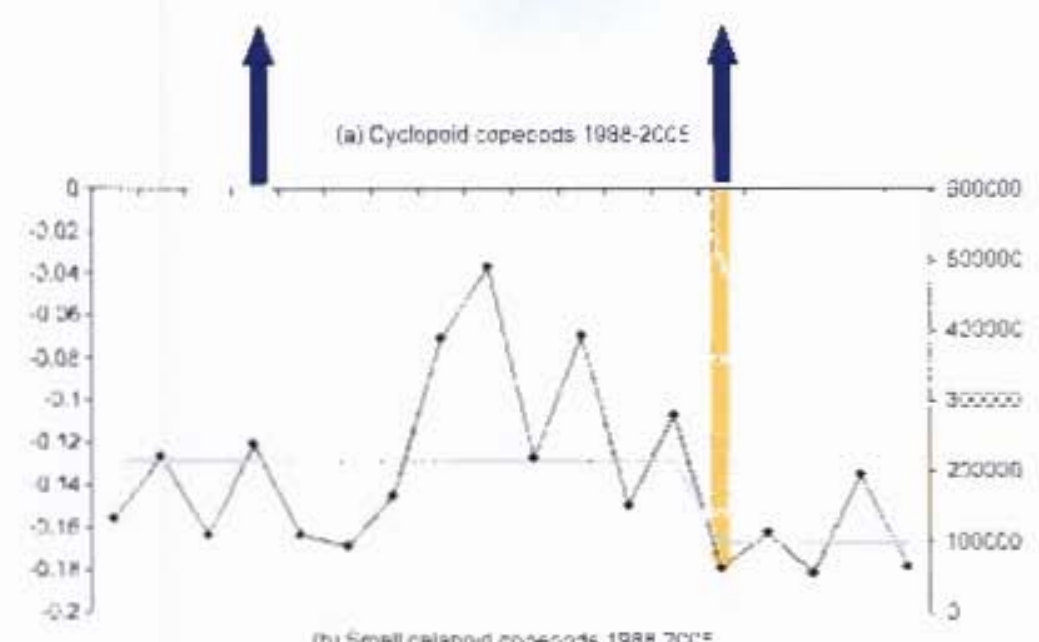

(D) Simall Caianaid cosepats 19aE 2CCE

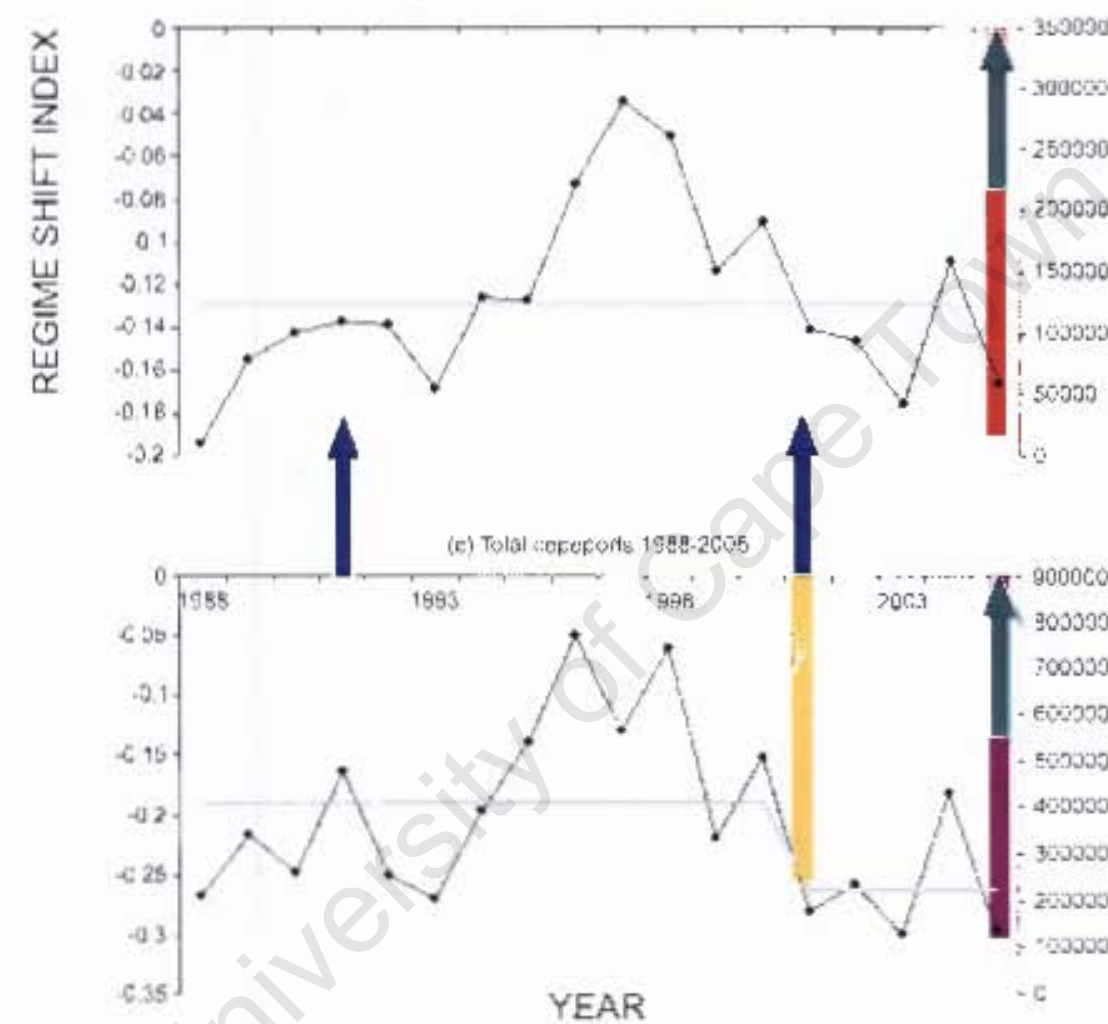

Figure 7: Results of STARS analysis showing the magnitude of shifts in RSI (coloured bars), the overall time scrics (black line) and the weighted mean of observation state variables (grey line) for (at cyclopoid copepods 1988-2005, (b) small calanoid copepods 1988-2005 and (w) total copepouds 19882005. Dark blue arrows indicare robus and possible shifts in SS1 at $32^{\circ} \mathrm{S}$ and light blue arrows indicate prowhitened shifts in SST at $30^{\circ}$ S. Arrows pointing us indizate positive shifts in SST anomalics. Robust. prewhitened and possible shifts identified by the SI ARS analy sis are shown, 


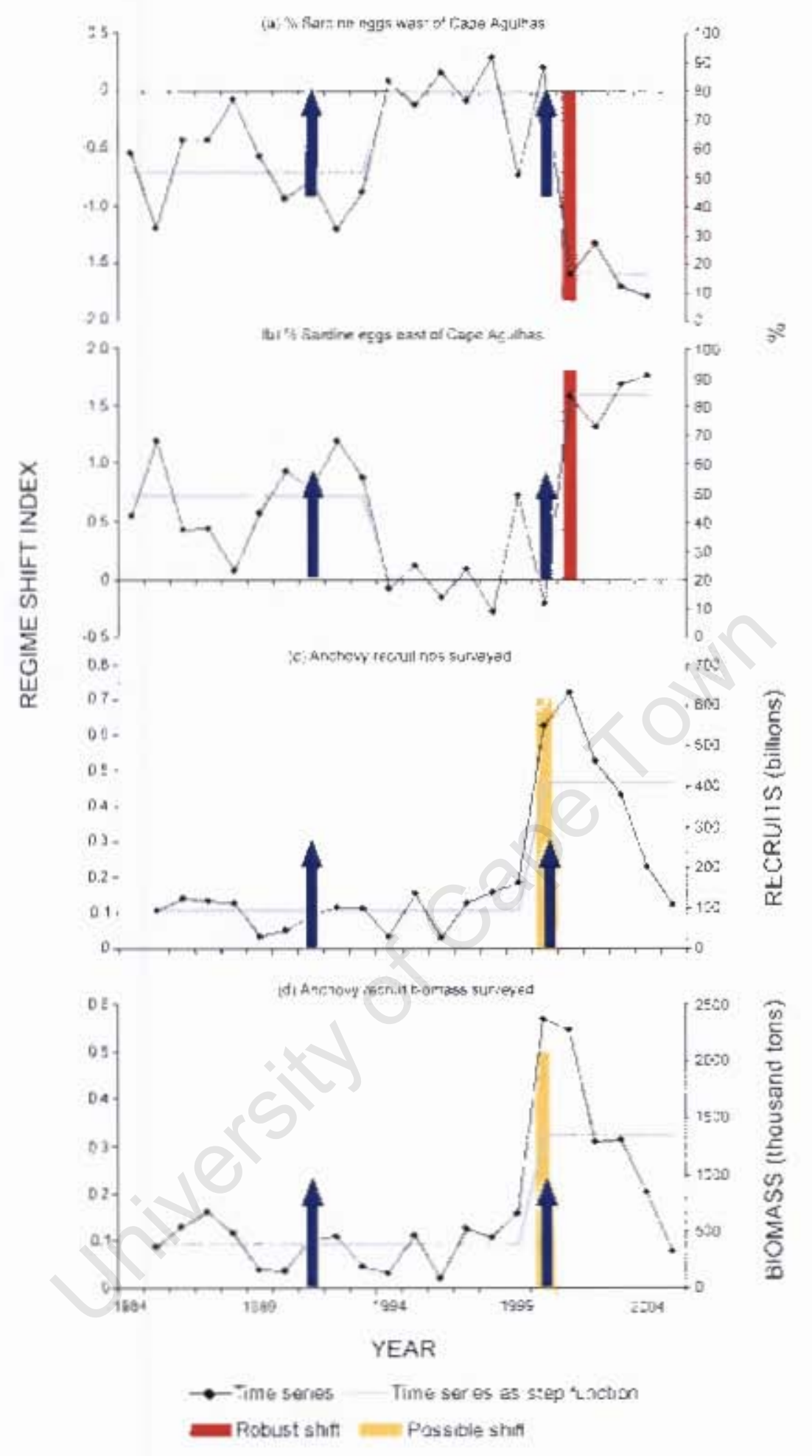

Figure 8: Results of STARS analysis showing the magnitude of shifts in RS! (coloured bars), the overall time suries (black line) and the weighted incan of otxicsation state sarables (grey line). The \% sardinte eggs is given for (a) west and (b) cast of Cape Agulhas. Anchovy recruitument fron surveys is given in ferms of (c) numbers and (d) biomess. Dark blue arrows indicate polust and possible shifis jn SST ut $32^{\circ} \mathrm{S}$. Up urrows indicate positive shifts in $\$ \mathrm{ST}$ anomalies. 


\section{$\%$ Anchovy and sardine in diet of Cape gannets}

The possible shift in anchovy in the diet of Cape gannets in Algoa Bay (Figure 2a) cannot easily be explained by shifts detected in SSTs at $30^{\circ} \mathrm{S}$ or $32^{\circ} \mathrm{S}$, as Algoa Bay is approximately 800 kilometres east of where these measurements were taken. At Lambert's Bay (situated at $32^{\circ} \mathrm{S}$ ), a positive robust shift in $\%$ of anchovy in gannet diet was detected in 2004/05 (Figure 9a), three to four years after a positive robust shift in SST at $32^{\circ} \mathrm{S}$. The time lag is greater than that identified a priori as being acceptable (Table 2). On the west coast there was a positive prewhitened shift detected in \% of anchovy in gannet diet in 2004/05 (Figure 9b), the same year as a positive prewhitened shift in SST at $30^{\circ} \mathrm{S}$. No robust or prewhitened shifts in SST occurred prior to the negative possible shift in $\%$ of anchovy in gannet diet in $1983 / 84$.

No robust shifts were detected in the percentage of sardine in the diet of Cape gannets on the west coast. On the west coast (Figure 9c) and at Malgas Island (Figure 9d) a negative possible shift occurred in 1999/2000, and there was a shift in SST anomalies at $32^{\circ} \mathrm{S}$ in 2000 . A negative prewhitened shift in $\%$ sardine in gannet diet was detected in 2003/04 on the west coast (Figure 9c), but a similar timed shift was not detected at Malgas Island (Figure 9d). The west coast shift could be related, after a lag time of two to three years, to the robust shift in SST at $32^{\circ} \mathrm{S}$ in $2000 / 01$ or to the shift in $\mathrm{SST}$ at $30^{\circ} \mathrm{S}$ in 2004 (Figure $9 \mathrm{c}$ ). There were no shifts identified in the percentage of sardine in gannet diet at Lambert's Bay. At Algoa Bay, one positive robust shift was detected in 2002/03, but the gannet diet data from Algoa Bay could not be compared directly to oceanographic data, which was collected off the west coast and not the south east coast. 


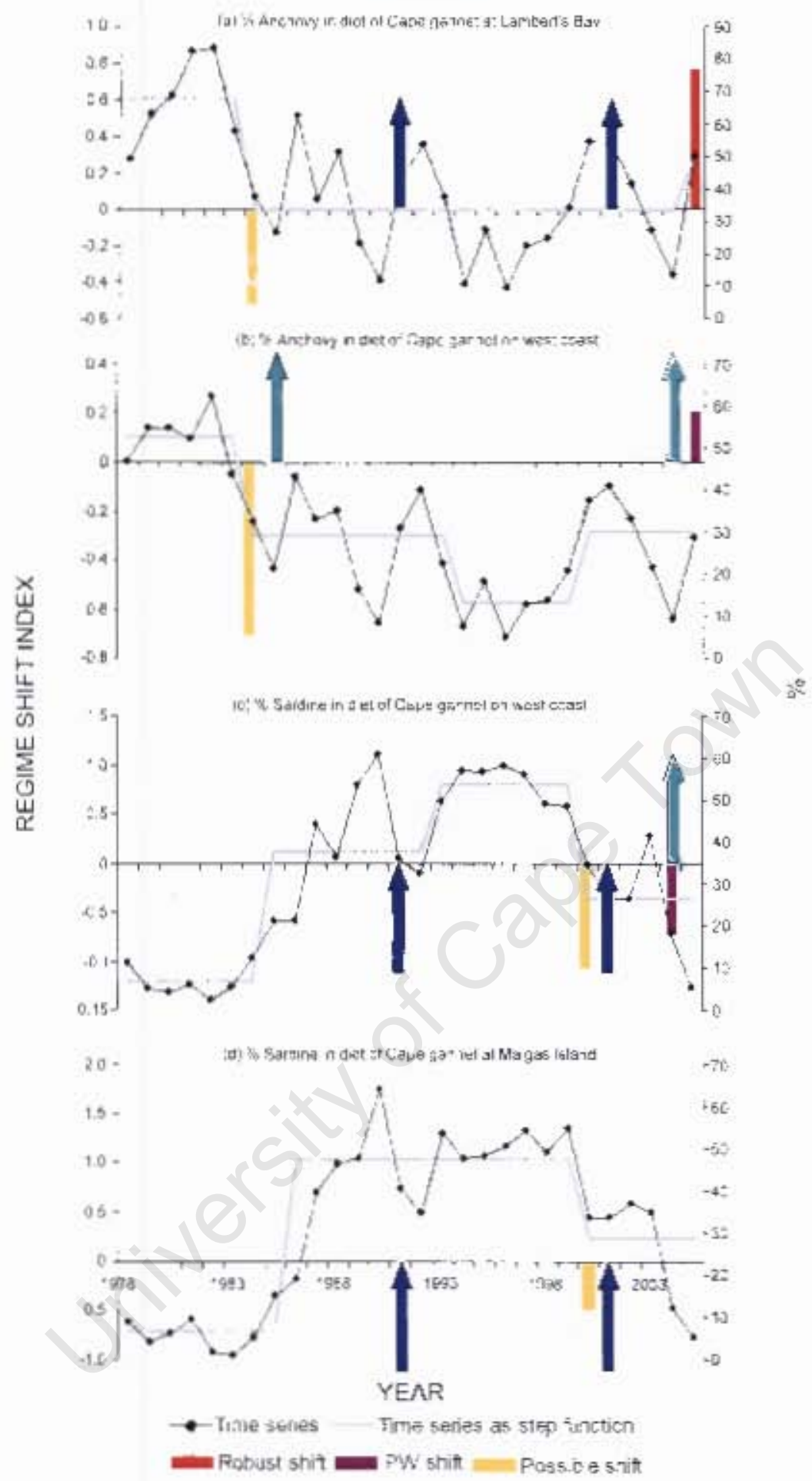

Figure 9: Results of STARS analysis showing the magnitude or shifts in RSI (coloured bars), the overall time serics (blach line) and the neighled netan of obsertution state variables (grey line) for the $\%$ anchovy in gannet tiet at (a) Lamberl's Bay and (b) the west const. Jhe \% sartine in: garnet dict is given for (c) the west chast and (d) Malgas Island. Dark and light biue arrows indicate robust. prewhitened and possible shifts in SST at $32^{n} \mathrm{~S}$ and at $30^{n} \mathrm{~S}$. L.p arrours indicate positive shitts in SST anomalies. Robust, prowhitened and possible stifts idertlifitd by the STARS analysis are showr. 

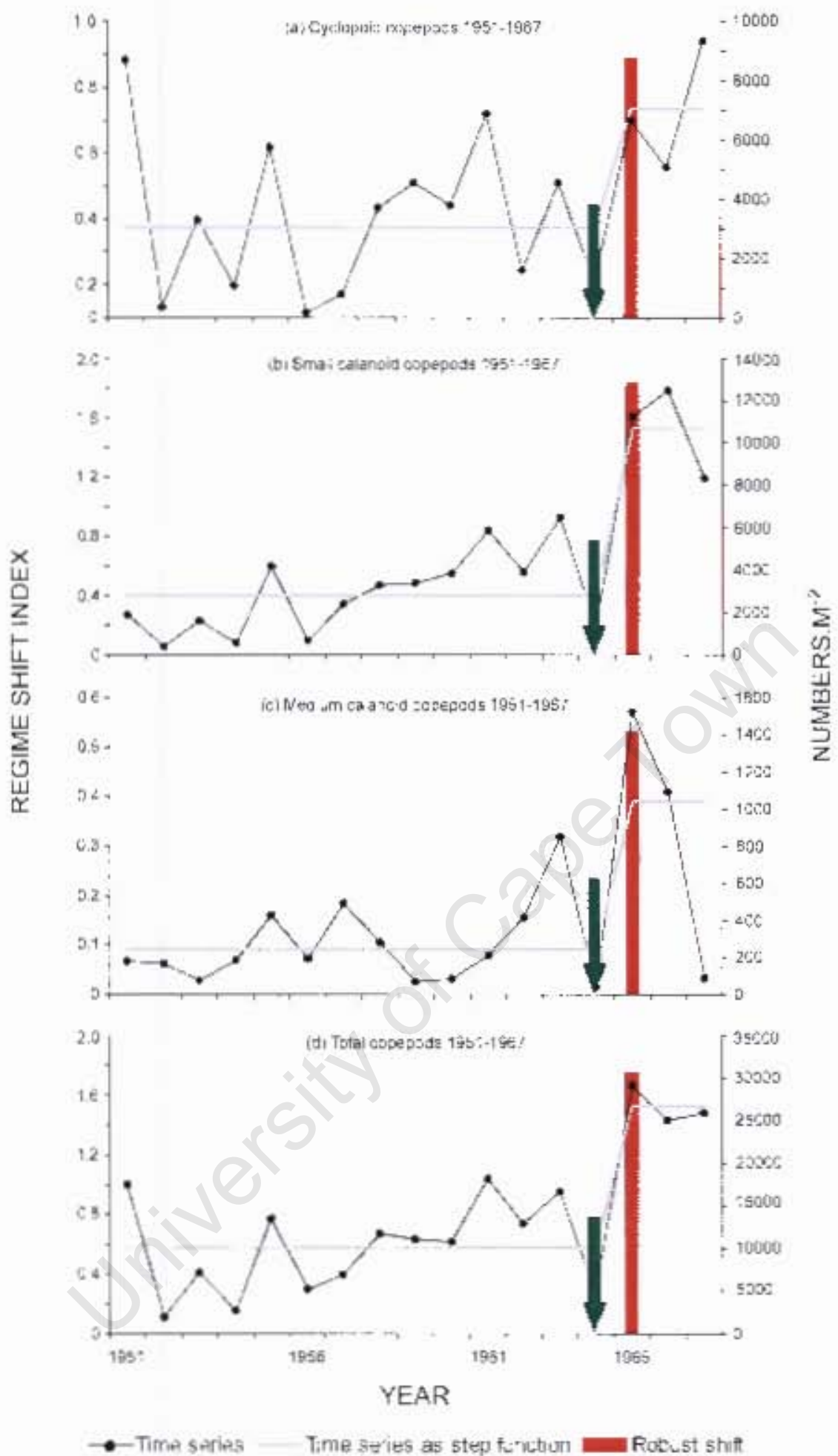

Figure 10: Results of STARS analysis showing th: mugnitude of shifts in R.ST foctourcd hars), the werall time scrits (black tinc) and the weighted mean of ohservarion state variables igrey lin:') for (a) cyctupoid copepods 1951-1\%\$7. (h) small calattuid copepods 1951-1967. (c) incdium calanoid cojepots 1951-1967 und (d) lutul copepods 1951-1967. Dark green arrons indjeate pussible shills in upwelling index unomatiss at $32^{\circ} \mathrm{S}$. Acruws pointing down indjestc regative shifts. 


\section{Observed state variables compared to upwelling index anomalies at $30^{\circ} \mathrm{S}$ and $32^{\circ} \mathrm{S}$}

\section{Copepod abundance (1951-1967 and 1988-2005)}

In 1964 a negative possible shift in upwelling at $32^{\circ} \mathrm{S}$ occurred within one year of a positive robust shift in four of the five groups of zooplankton in the data set (Figures 10a-d). A negative possible shift in upwelling at $32^{\circ} \mathrm{S}$ occurred in $2000 / 01$, the same year as a negative possible shift in the abundance of cyclopoid copepods (Figure 11a) and total copepods (Figure 11c), and a negative prewhitened shift in upwelling at $32^{\circ} \mathrm{S}$ occurred in 2004/05 when small calanoid copepods undergo a negative robust shift (Figure 11b) and a negative prewhitened shift was detected for total copepods (Figure 11c).

\section{$\%$ Anchovy in diet of Cape gannets}

From the STARS analysis, Cape gannets on the west coast and at Lambert's Bay increased the percentage of anchovy in their diet in 2004/05, which coincided with a negative prewhitened shift in upwelling at $30^{\circ} \mathrm{S}$ and $32^{\circ} \mathrm{S}$ (Figure 12a and b). The negative possible shift on the west coast and at Lambert's Bay in 1983/84 (Fig 12a and b) did not occur soon after a shift in upwelling. Shifts in gannet diet in Algoa Bay, as before, could not be compared directly to oceanographic data, which was collected off the west coast and not the south east coast.

\section{Anchovy recruit numbers and biomass surveyed}

A positive possible shift in upwelling at $30^{\circ} \mathrm{S}$ occurred in 1998 , one year before the positive possible shift in anchovy recruit numbers (Figure 13a) and biomass (Figure 13b). There were no robust or prewhitened shifts in upwelling at either $30^{\circ} \mathrm{S}$ or $32^{\circ} \mathrm{S}$ that could be linked to the possible shifts in anchovy recruits. 


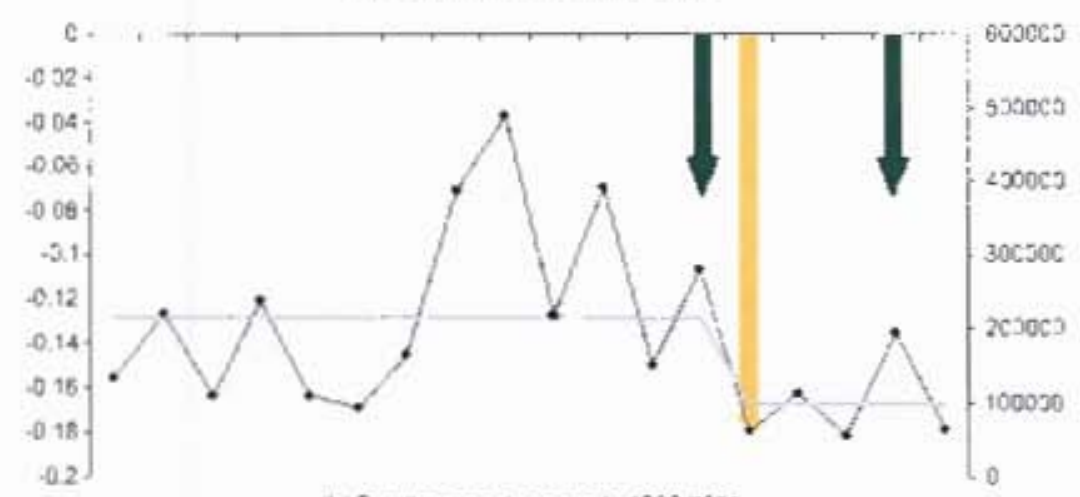

t) Small ca:ancij capepods $1988-7005$



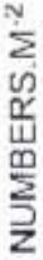

(c) Total ccoepods 198R-zวes

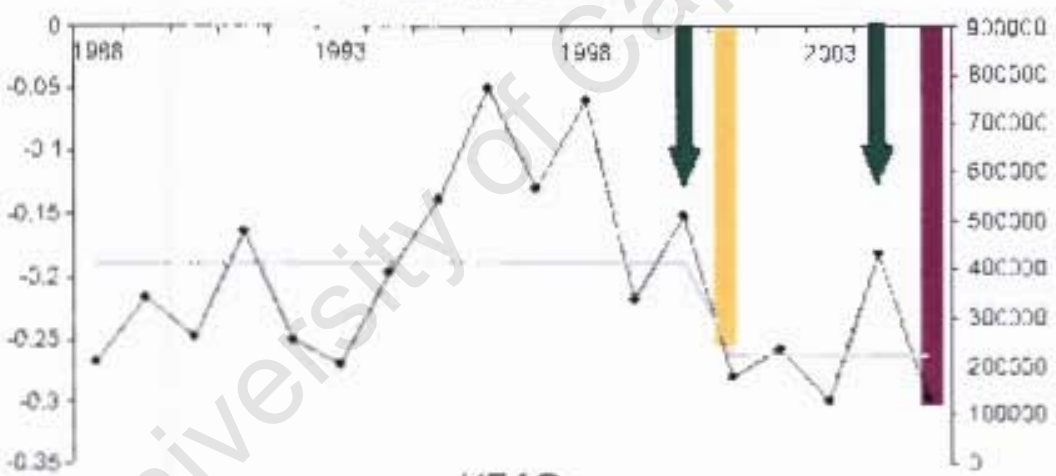

YEAR

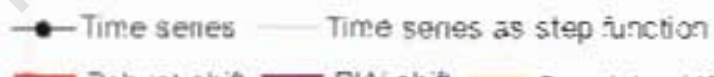

Robust shift PW shift Possible shift

Figure II: Results of STARS analyxis showing the magnitude of shilts in RSI (coloured hars), the overail time series (black line) and the weighued mean of obscrvation state variables (grey line) for (a) cyclopoid copepods 1988-2005, (h) small calanoid coptpods 1988-2005 and (cj tocal coppepods 14k8. 2005. 12arh green arrows indicute prewhitenod and pessible shifts in upwefling index anomalies at 32'S. Arrows pointing down indicate negative shifis in upwelling anomalies, Kubust. prewhikened and possihle shifts identilied by the STARS anuilysis doe shown. 


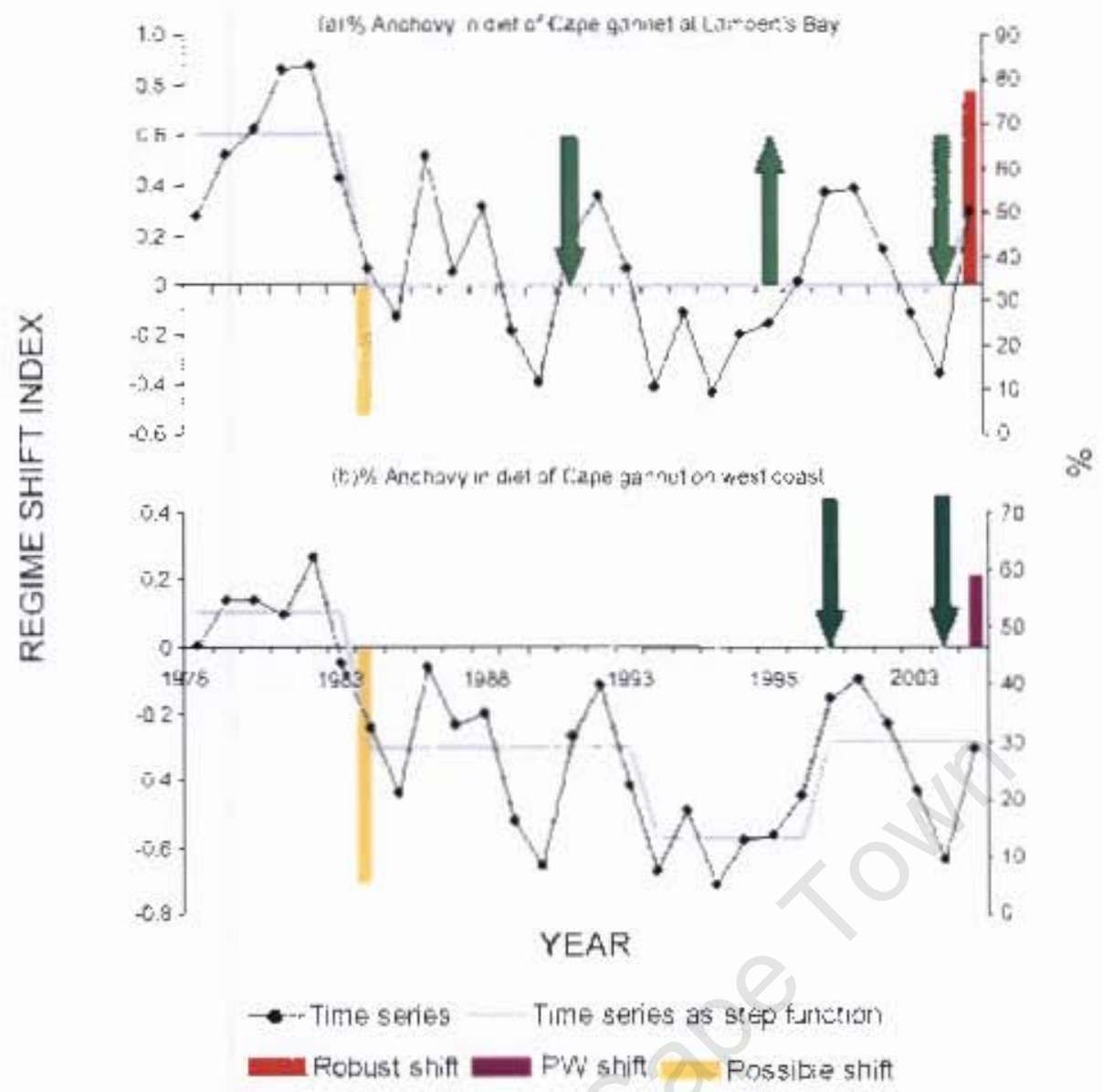

Figure 12: Restulis of STARS analy sis showing the magnitude of shifts in RSI (coloured hars), the overall time series (black line) and the weighted mean of obserwation state variables (grcy line) for the \% anchovy in gannel diel which is given liv (a) Lamberi's Bay and th) the west cnast. 1)ark green arrows indicate proutitened and possible shifts in upwelling index anomilies al $32 \% 5$ and light green arrows indicate prewhitened and possible shifts in upwelling index anomulies at 30 S. Amows pointing down indicace negative shitts in upwetling index aromalies and arrors pointing up indieate positive shitts. Robust, prewhitened and possible shits identified by the STARS analysis are shown. 
Modelled state variables compared to upwelling index anomalies at $30^{\circ} \mathrm{S}$ and $32^{\circ} \mathrm{S}$

\section{Sardine and anchovy model recruit numbers}

A positive possible shift in upwelling at $30^{\circ} \mathrm{S}$ occurred in 1998 , two years before the positive shift in anchovy model recruit numbers (Figure 13c) and the same year as the positive robust shift in sardine model recruit numbers (Figure 13d). There was no prewhitened or robust shift in upwelling at either $30^{\circ} \mathrm{S}$ or $32^{\circ} \mathrm{S}$ that preceded the sardine and anchovy positive shifts in recruitment.

\section{Observed state variables compared to sardine landings (1950-2005)} Copepod abundance (1951-67 and 1988-2005)

The negative prewhitened shift in sardine landings in 1963/64 occurred one year prior to the positive robust shift, which was detected in $1964 / 65$ in four of the five zooplankton groups within the data set (Figure 14a-d). However all four zooplankton groups dropped in abundance in 1964 before increasing dramatically in 1965 . A small negative possible shift in cyclopoid copepods (Figure 15a) and total copepods (Figure $15 b$ ) in 2000/01 occurred in the same year as the positive prewhitened shift in sardine landings. However it was clear that the abundance of all the zooplankton groups had been decreasing five or six years prior to the shift in sardine landings.

\section{$\%$ Sardine in diet of Cape gannets (1978-2005)}

At Malgas Island (Figure 16a) and on the west coast (Figure 16b), negative possible shifts in the percentage of sardine in gannet diet occurred in $2000 / 01$, one year before the positive prewhitened shift in sardine landings. In contrast, a positive robust shift in the percentage of sardine in gannet diet at Algoa Bay (Figure 16c) was detected two years after the increase in sardine landings. 

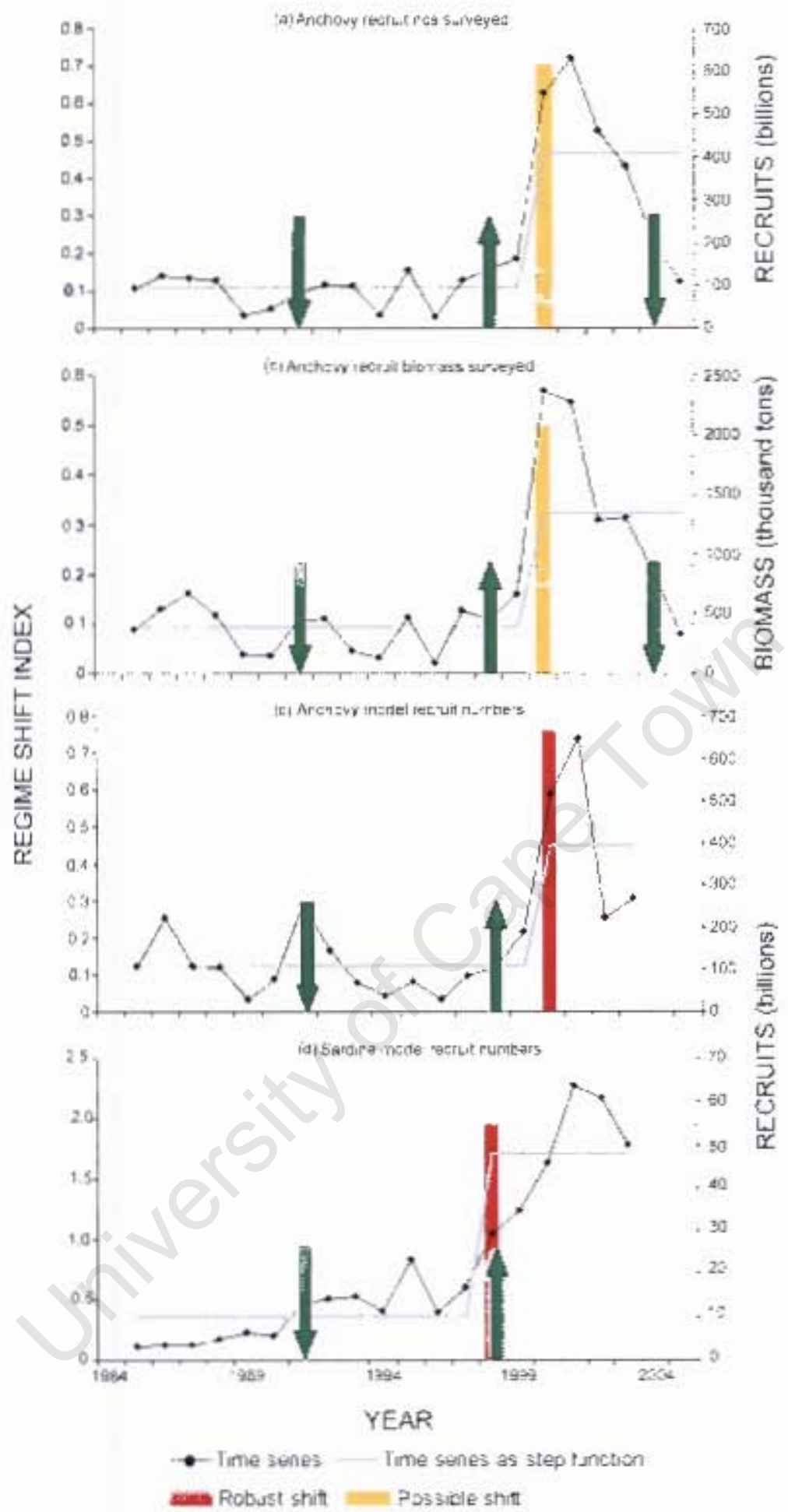

rigure 13: Results of SFARS analysis showing the nagnitade of shifts in RSI (Coloured hars), the overall time series (hlack line) and the weighted mean of observation state tariahies (grey line) for anchovy surveyed recruitment in terms of (a) numbers and (b) biomass, (c) model numbers and (d) sardine model recruit numbers. light green arrows indicate prewhicened and passible shifts in upwelling at $30 " \mathrm{~S}$, IJown arrows indicare negative shitts in upwelling anornaljes and vice versa. 


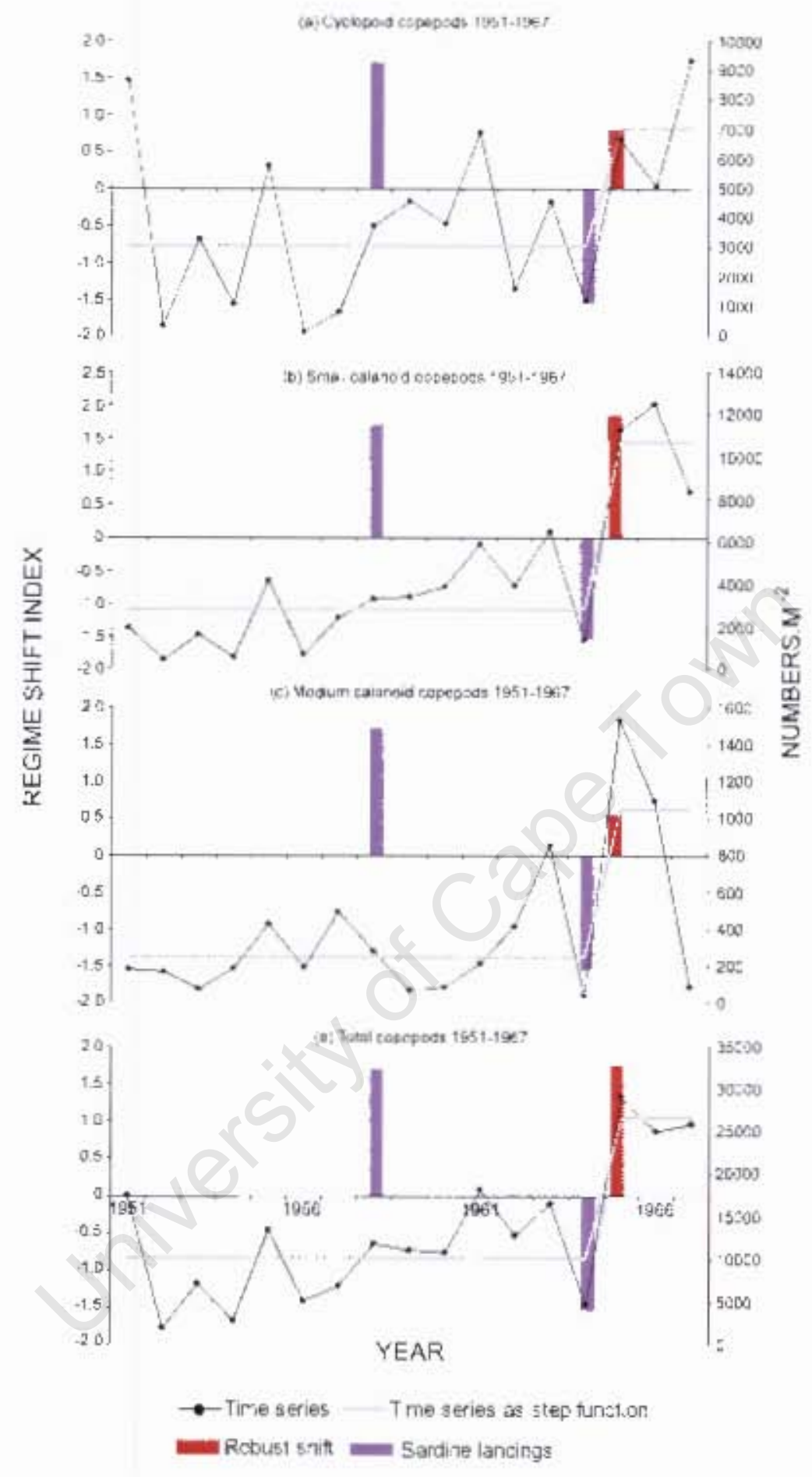

Figure 14: Resulls of STARS undysis shewing the magnitude of shifls in RS1 (coluured burs), the overall time series of observation scate variables (black line) and the weighted mean of observation state variables (grey line) for (a) cyclopoid copepords 1951-1967. (b) smatl cal anoid copepods 19511967. (c) medium calanoid copepods $1951-1967$ and (d) total copepods 1951-1\%67. Hoth rotust and possible shifts in sardine landings identified by the \&T ARS aralysis ure stown. 


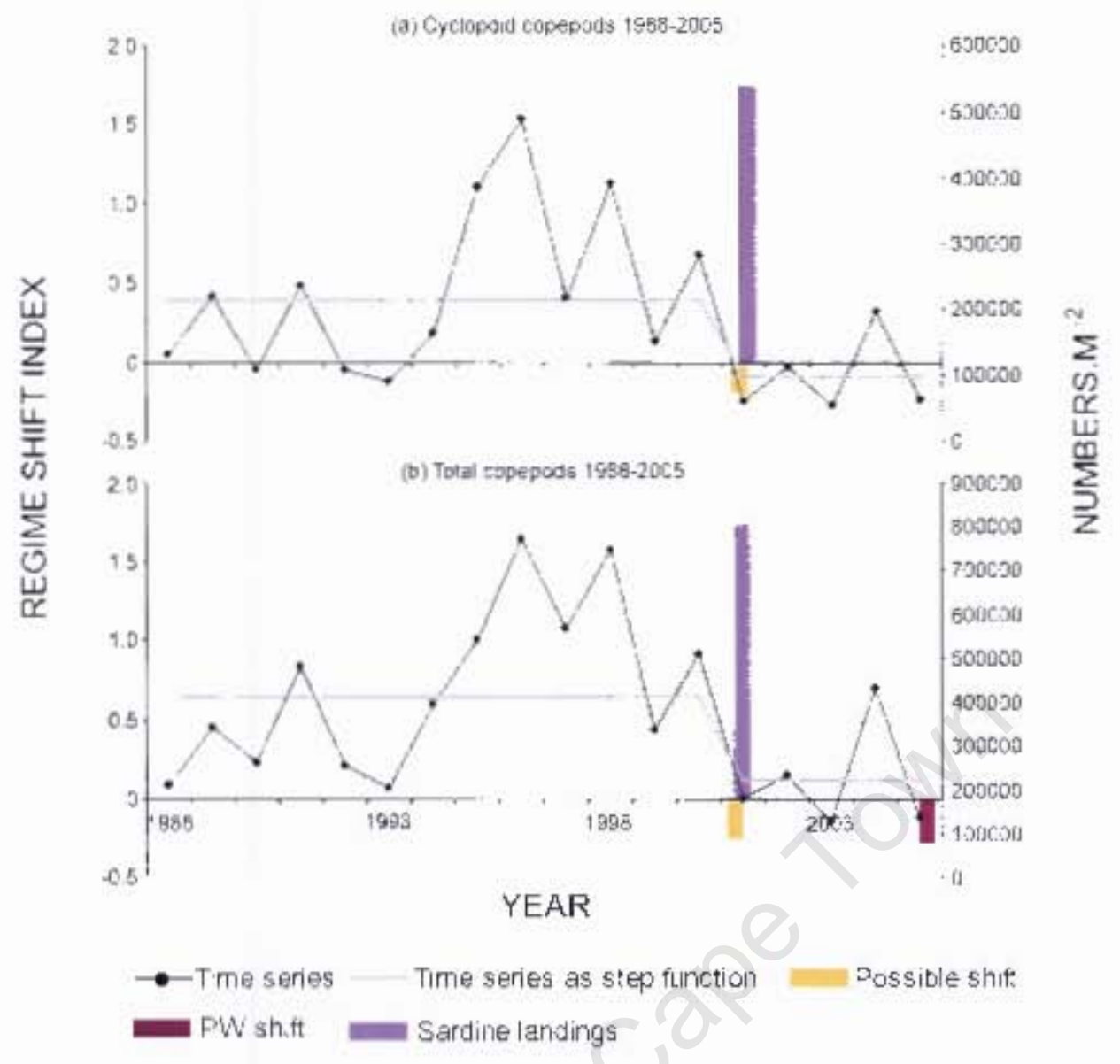

Figure 15: Results of STARS unalysis showing the inagnitude of shifts in RSI (eoloured bars), the overall time seris of observation state variahles (black line) and the seighted metn of observatien state varisbles (grey lines for (a) evetognaid cojepods 1988-2005 and (b) totsl copeperds 1988-2005. Boch prewhitened ( $P$ W) and possible shirls itcritifiod by the STARS analysis are shown. 

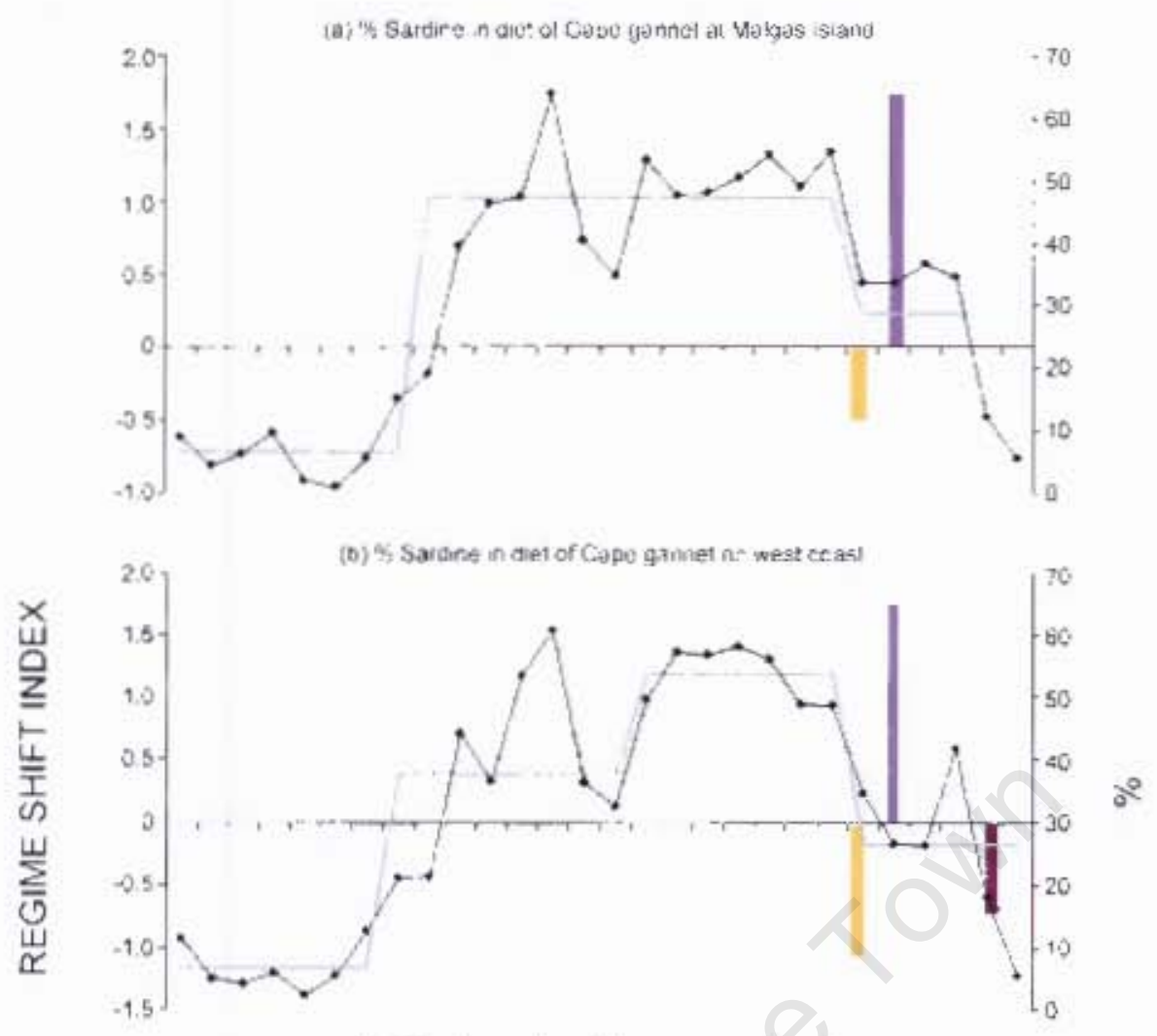

(c) D. Sardine n die: of Cape ganner at A.
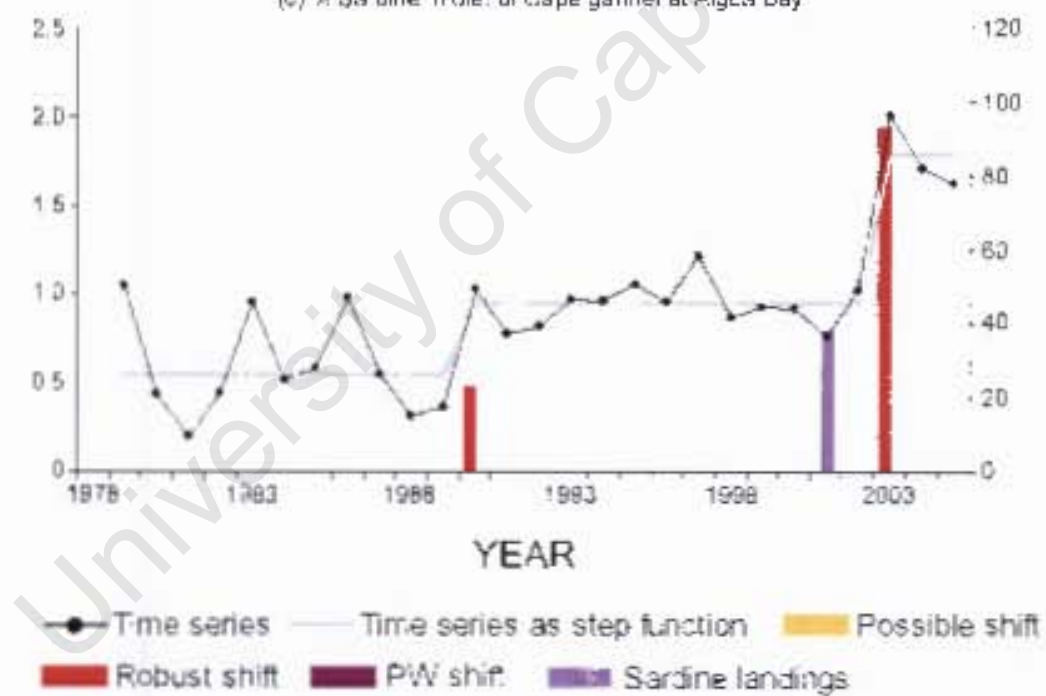

Figure 16: Results of STARS analyxis showing the magnitude of shifts in RSI (coloured bars), the overal] lime series of ebservation stake tariables (black fiac) und the weighted mean of obscrvation state varlables (grey line) for the \% sardine in gannet diei for (a) Mat gas lsland, (b) ihe west coast and (c) Algou Bay. Rubust, prewbitened (PW) and possible sbitts identified by the STARS analysis are shown. 
Modelled state variables compared to sardine landings (1950-2005) and sardine mean length (1987-2004)

Sardine stock size VPA

In $1959 / 60$ a positive prewhitened shift in sardine stock size was detected two years after the positive possible shift in sardine landings and this was then followed by a negative possible shift in sardine stock size in 1963/64 and a negative prewhitened shift in sardine landings in the same year (Figure 17a). One would expect the positive shift in landings to have occurred after the increase in sardine stock size. The negative shift in sardine landings was detected in the same year as the collapse of the sardine stock.

Sardine model recruit numbers and Sardine spawner biomass

The positive robust shift in sardine recruit numbers in 1997/98 (Figure 17b) occurred three years prior to the positive prewhitened shift in sardine landings. The shift in recruit numbers could explain the increase in landings but the landings could not explain the increase in sardine recruits. The robust shift in the mean length of sardine landed occurred in 1995/96 (Figure 17c) and preceded the positive possible shift in sardine spawner biomass by two years.

Observed state variables compared to horse mackerel purse-seine landings (1950-2005) and anchovy mean length landed (1987-2004)

Copepod abundance (1951-67)

A negative prewhitened shift in horse mackerel purse-seine landings in 1963 preceded the positive robust shift of the four zooplankton groups in 1964/65 (Figures 18a-d) by one to two years. 


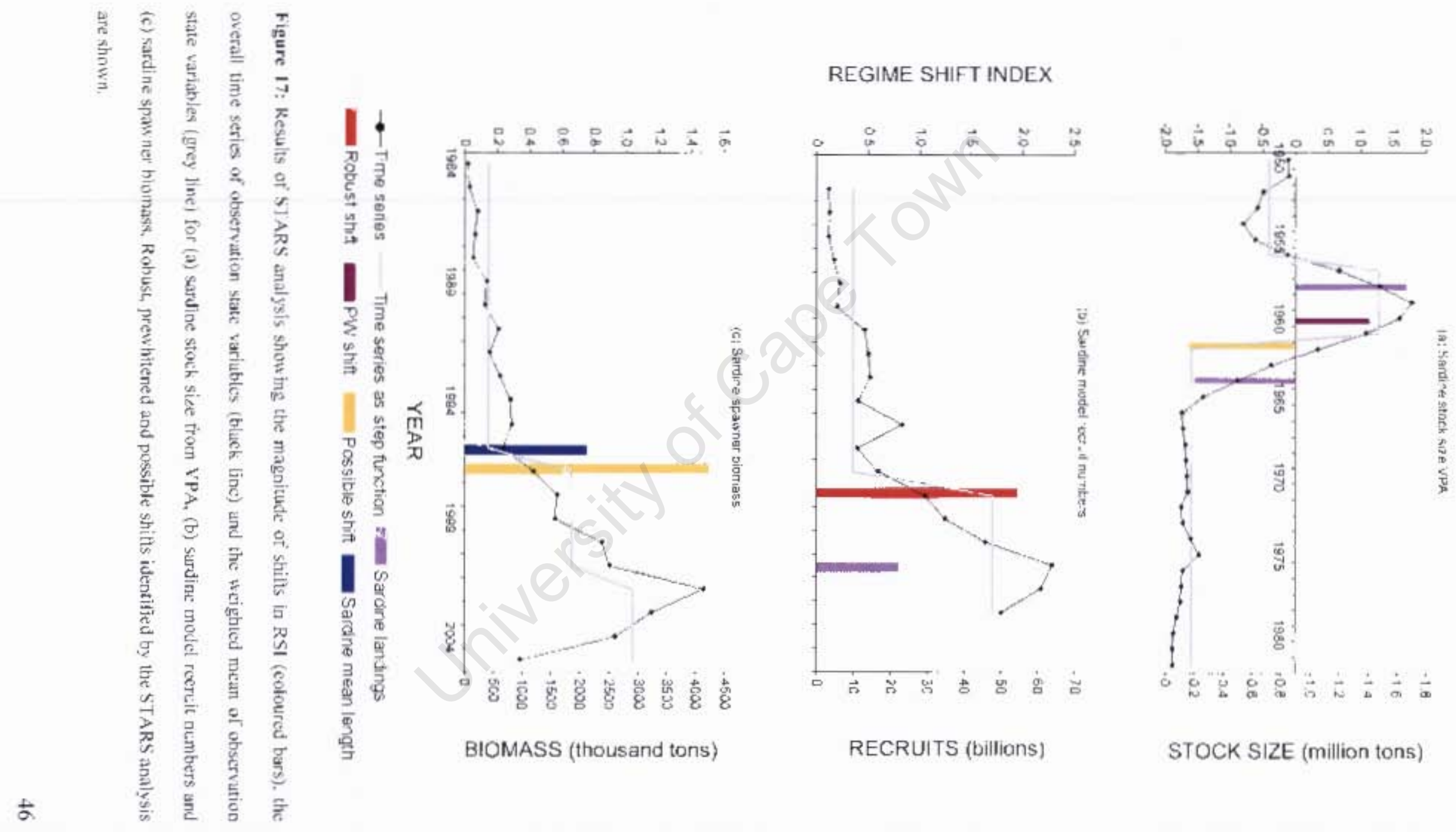




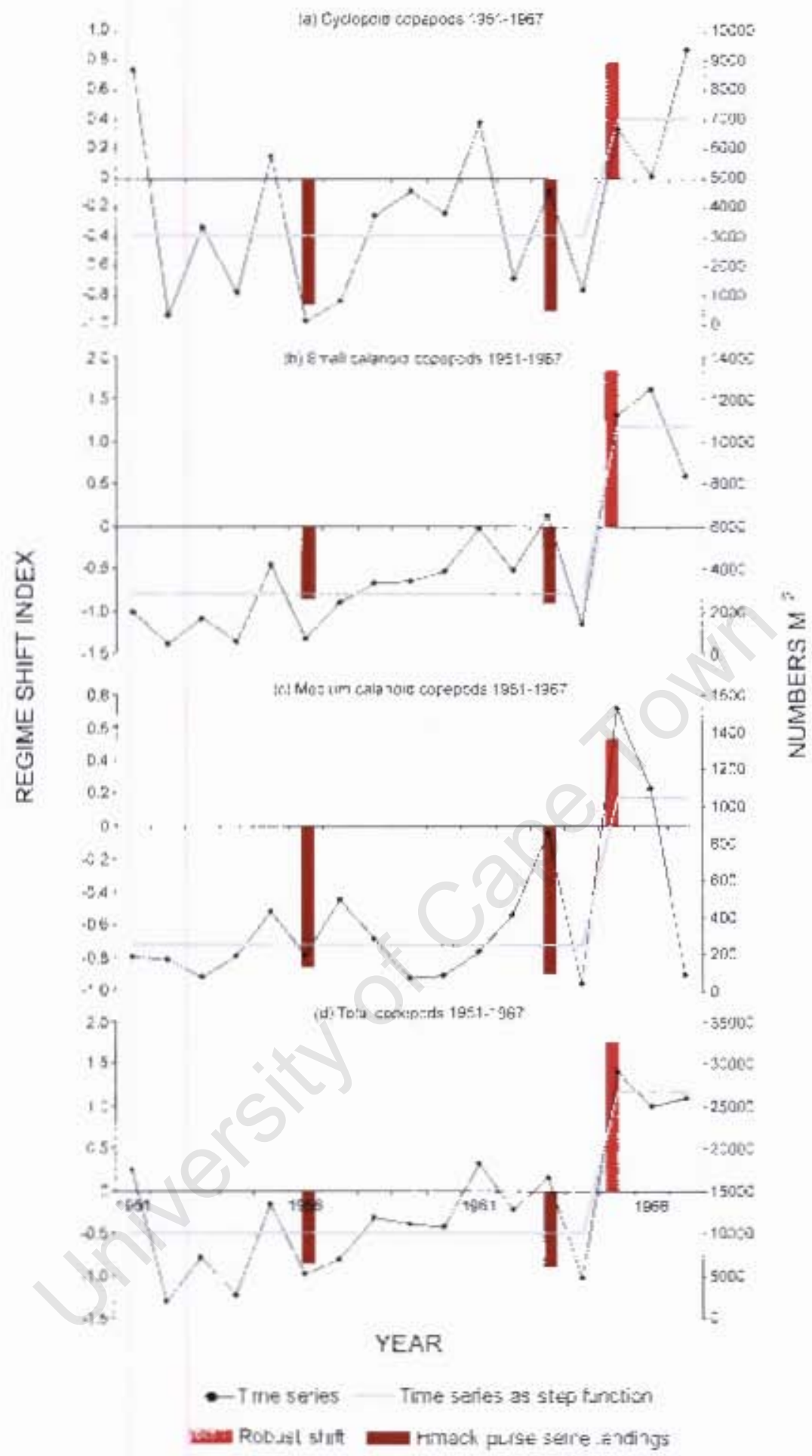

Figure 18: Results of STARS andysis shuving the cragnitude of shifts in RSI (coloured turs), the overall time series of ohservation stafe vuriables (black line) and the weighted ineall of ohservalion state variables (grey line) for (ut eyclopoid copepods 1951.1967, (bi small culanoid copepods 19511967. (t) medium calanoid copepods 1951-1967 and (d) tolal cupepods 1951-1967. 13oth prewhitened und pussible stifts is horse natherel landings identilied by the STA[z S analy sis are shown. 
Anchovy recruit numbers and biomass surveyed and Anchovy recruit numbers modelled

The negative prewhitened shift in the mean length of anchovy landed in 2001/02 was detected one to two years after the large positive possible shift in anchovy recruit numbers (Figure 19a) and biomass (Figure 13b) from surveyed data, and the large positive robust shift in anchovy recruit numbers modelled (Figure 19d).

Anchovy Nov L95 and Anchovy Nov mean weight

A negative possible shift occurred in 1999/00 in anchovy Nov L95 (Figure 19b) and anchovy Nov mean weight (Figure 19c). This was detected one to two years prior to the negative shift in anchovy mean length landed and within one year of the positive possible shift in anchovy recruits' abundance and biomass. 


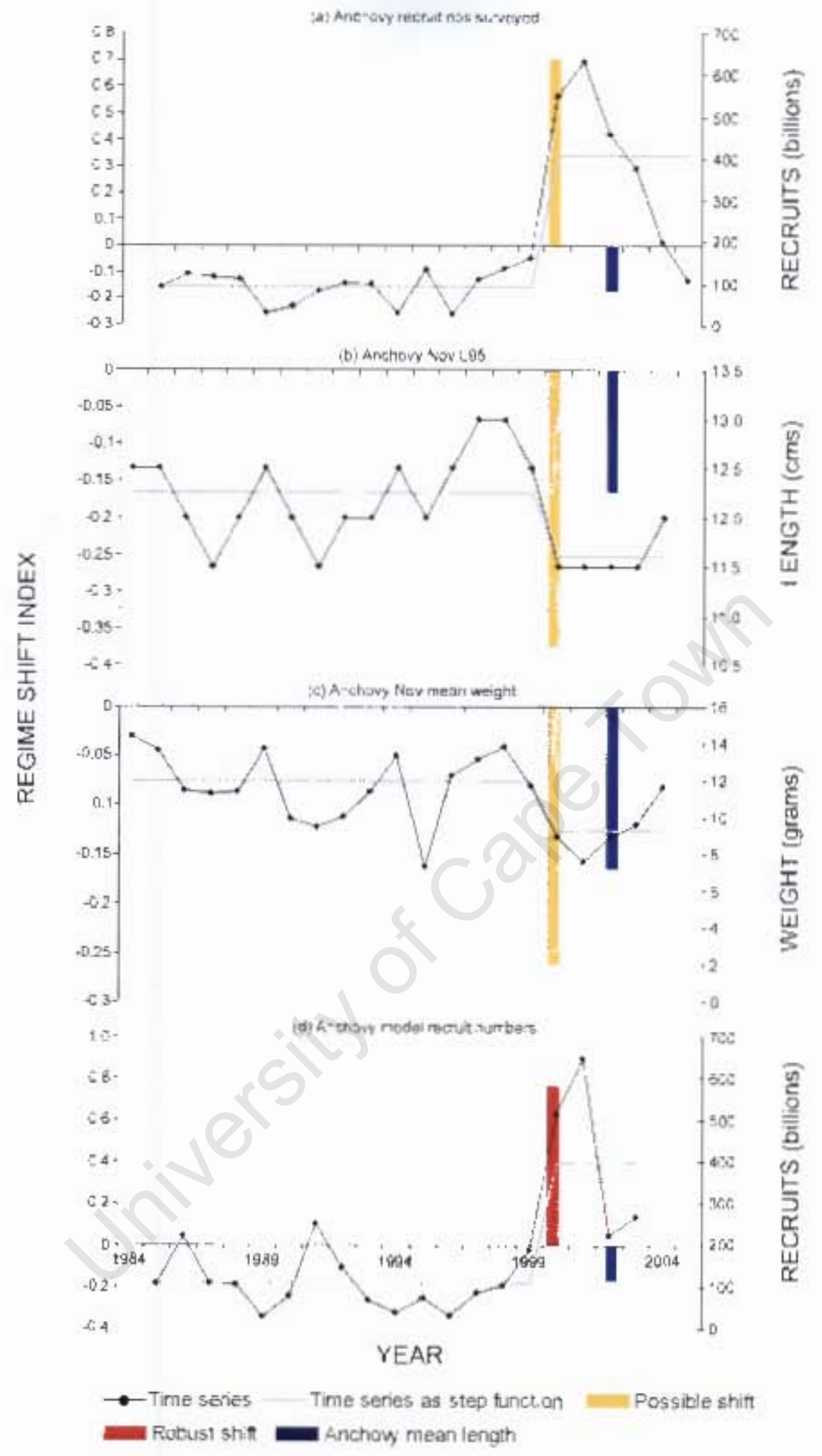

rigure 19: Results of SIARS analysis showing the magnitude of shifts in RSI (coloured hars). the ovcralt time scrics (black line) and the wcighted matan of observatisn state variables (grey line) for (a) anthovy recruit numbers surveyed, unchovy $\operatorname{Now}$ (b) 195, (c) mean weighe and (d) anchosy modet reuruit numburs. Buth rohust and possible shifts identified by the SIARS analysis are shown. 


\section{Discussion}

\section{Methods discussion}

Straight vs. prewhitened analyses

One quarter fewer shifts were detected by the prewhitening method than in straight analyses of the biological state variables and the anthropogenic forcing variables. Nearly twice as many shifts in environmental forcing variables were detected during straight analyses than prewhitened analyses, indicating that autocorrelation may be important and needs to be considered in future analyses.

\section{Cut off length, Huber parameter and significance level}

The cut off length was shown to cause differences in result outputs, with more shifts being detected for shorter cut off length times than longer cut off lengths. For all Huber parameter values tested $(\mathrm{H}=1,3,6)$, the results were the same or of negligible difference, hence the Huber parameter over this testing range has very little influence over the result of shift detection and regime lengths. The significance level was seen to have a greater effect than the Huber parameter on the results derived from the STARS analysis. Fewer shifts were detected if the significance level was set to $5 \%$ rather than $10 \%$, which was to be expected given the interannual variability in the time series. The significance level appeared to also affect the results to a larger extent than the cut off length did. The maximum significance level caused large variation in the year in which shifts were detected and variations in the groupings of variables that shift in the same year, more so than the cut off length or Huber parameter.

Although shifts were detected across various trophic levels by the STARS analysis, there were discrepancies in the timing of shifts when compared with those known from previous empirical or modelling studies, such as the environmental shifts described in Roy et al. (2001). The large shift in anchovy recruits that is known to 
have occurred in 2000 from surveys was detected by STARS, but only under straight analyses and not with prewhitening. This makes interpretation difficult, because the method of analysis can influence the kind of shift that is identified (see also Mantua 2004). In addition to this, prewhitened environmental shifts tended to be small shifts, detected at the $10 \%$ significance level. Many were detected within one to two years of straight environmental shifts. The prewhitening method, though essential to remove autocorrelation from time series, needs further development to provide for clearer interpretation. The STARS method was effective at detecting shifts near the end of time series, with many such examples in the variables tested. However, in some instances, positive shifts were detected in certain variables (e.g. anchovy recruit numbers and biomass surveyed), but a subsequent decrease in numbers or biomass towards the end of the time series, corresponding in magnitude to the previous positive shift, is not identified as a negative shift (Figure 8).

No single set of parameter values will identify with certainty the years in which shifts occur in all variables. Differences in ecosystems and data sets will require varying parameter inputs are tested, as in this study, to identify when large changes might occur in the data set. Both straight and prewhitened analyses should be performed until the prewhitening method has been developed further.

\section{Upwelling anomalies}

The upwelling anomalies at $30^{\circ} \mathrm{S}$ and $32^{\circ} \mathrm{S}$ were based on monthly data, and some preliminary analyses were carried out on these data using STARS. Three different STARS analyses were done using 1) the raw monthly data, with 12 data points per year, 2) annual averages (September - August), with one data point per year, and 3) seasonal averages (October- March), i.e. the upwelling season, with one data point per year. Each trial showed different signals in the shifts that were detected (results not 
shown). The STARS analyses run on averaged data tended to remove/hide many signals that were apparent in STARS analyses of the raw data, particularly post 1970 . It was therefore decided to use the raw monthly data series as the basis for comparisons between upwelling indices and the biological variables. Our decision was made in accordance with the findings of Roy et al. (2001), that there are subtleties within the upwelling signal which are removed when averaged, yet are important in driving bottom up control on ecosystems.

\section{Application to the southern Benguela ecosystem}

Having applied STARS analysis to time series of the southern Benguela ecosystem, it appears that this method detects the occurrence of long term changes in all aspects of the ecosystem considered: environmental forcings, anthropogenic forcings and biological shifts. This same method detected long-term changes and possible regime shifts in the Bering Sea from both biological and oceanographic/environmental data (Rodionov and Overland 2005). It is very difficult to discern concrete links or causal mechanisms from such a study, but patterns in the timing of shifts of forcing variables and biological variables make it possible to broadly portray the scope of interactions and fluctuations within the southern Benguela since 1950. Process studies carried out in the southern Benguela may suggest possible causal mechanisms.

$1950-1960$

Very few available biological datasets extend back in time prior to the late 1970s, but a major shift in environmental indices and fisheries landings was detected in 1956/57. The increase in upwelling intensity noted at that time may have been beneficial to sardine stocks and resulted in the subsequent shift in sardine gonad mass. During the 1950s the pelagic fishery was still developing, and was not at the same level as it is today. The shifts in sardine and demersal landings were the first recorded and can be 
attributed to improvements in fishing techniques, gear and effort, rather than increases in fish abundance. The increase in sardine landings in the mid 1950s was, however, indicative of high sardine biomass in the southern Benguela. The analysis detected a positive shift in sardine stock size in 1959/60, calculated from VPA modelling, and the next shift in sardine biomass was a decrease in 1963/1964 at the time of the collapse of the sardine fishery in the southern Benguela. This demonstrates that the STARS analysis detected shifts in separate types of data that are related, and the analyses accurately identified the years in which known stock changes occurred, as shown in commercial catch data (Table 3).

$1961-1970$

The next major shift in various components of the system is detected during the period 1963-65. Reduced upwelling intensity at $32^{\circ} \mathrm{S}$ as well as a Benguela Niño event (Table 3) would have resulted in more stratified conditions in coastal waters over this period, allowing zooplankton to feed maximally on phytoplankton blooms, and resulting in large increases in zooplankton biomass. This is not normally possible, as pulsed upwelling prevents zooplankton from taking full advantage of the phytoplankton blooms because the development of nauplii and copepodites in relation to the development of phytoplankton blooms is mis-matched (Hutchings 1992). The southern Benguela is characterised as having a lower copepod biomass than predicted from the relationship between phytoplankton biomass and copepod abundance. It is believed that ENSO-like decadal modes influences the oceanography of the south eastern Atlantic (Reason et al. 2006). At this time the sardine stock collapsed, the purse seine fishery began to target anchovy, and anchovy landings increased (Armstrong and Thomas 1989). The change in fishing practice and negative shift in sardine stock size appear to have contributed to the increase in copepod abundance at this time, supporting the hypothesis of Verheye et al. (1998). 


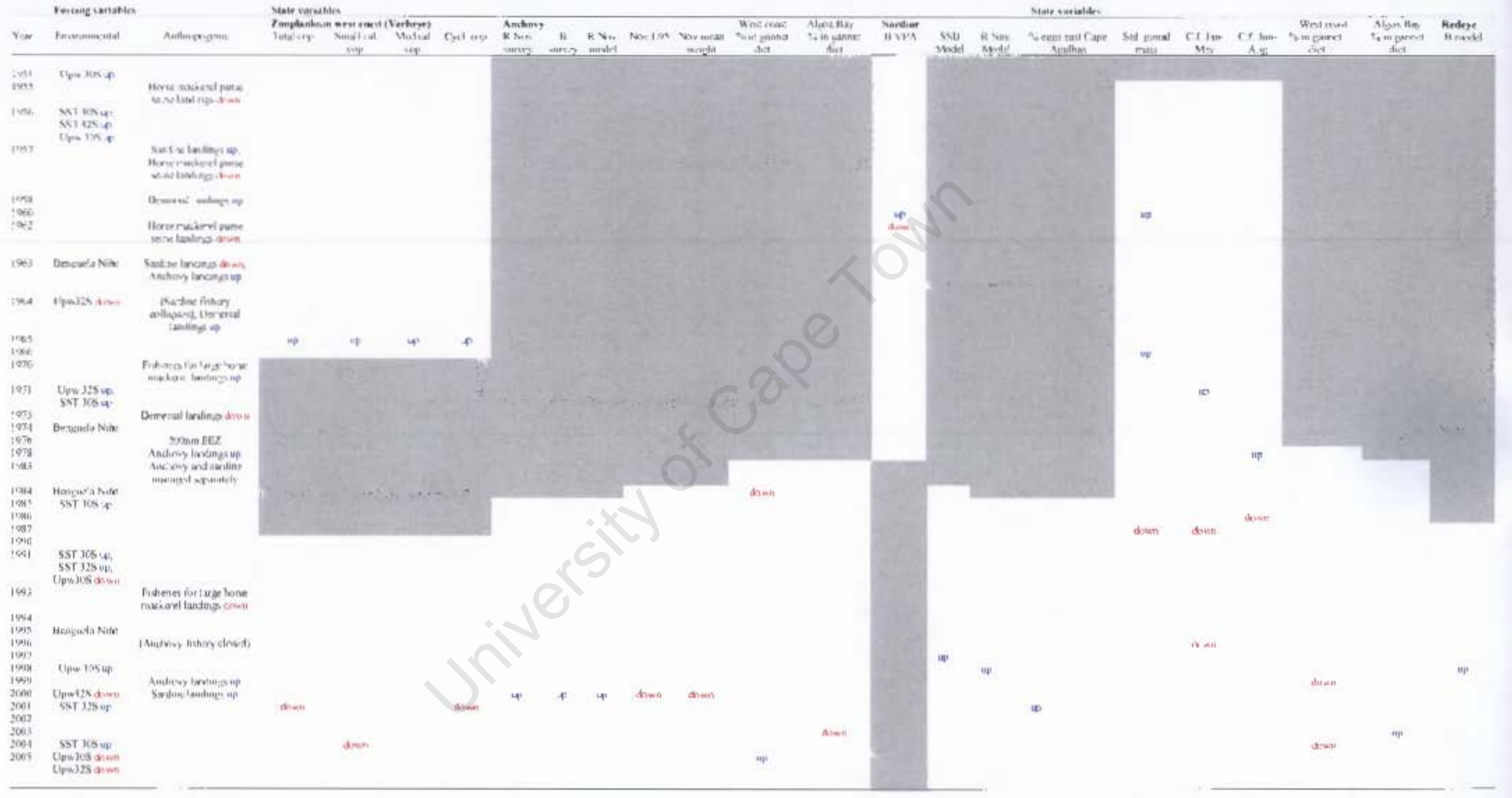

Table 3. Robust and poss ble changes found in foreng and state variables for the souttern Benguela ecosystem (1950 - 2005) Grey areas indicate periods with no data, up = an increase (blue), down - a decrease (red). cop = copepods: cal. = calanoid; med = medium. cycl = cyclopond; $\mathrm{R}$ Nos. surveyimodel - recruit nunibers surveyed or modelled; $\mathrm{B}$ survey/model - recrut biomass surveyed or modelled, Nov = November pelagic acouslic surveys: $B$ VPA = stock size from VPA; SSB = sardine spawner biomass: C. $f$ = condition faclor 
It is known that copepods in the southern Benguela have increased in abundance 100 fold between 1950 and 1990, and have increased in biomass 10 fold over the same period (Verheye et al. 1998). The discrepancy in the magnitudes of the increase for abundance and biomass has been explained as being due to a change in the species composition of zooplankton over the past 50 years, shifting from a system dominated by large zooplankton to one dominated by smaller species. It has been hypothesised that, in view of the diet preferences of sardine and anchovy, the shift from a sardine dominated system to an anchovy dominated system between the $1950 \mathrm{~s}$ and $1980 \mathrm{~s}$ is linked to this shift in zooplankton species assemblage (Verheye et al. 1998). The collapse of the sardine stock would have reduced predation pressure on the smaller zooplankton species. The increased catch of anchovy indicates there might have been increased biomass of anchovy, and thus heavier predation pressure on large zooplankton; anchovy prefer large species of zooplankton $(>580 \mu \mathrm{m})$ than do sardine (van der Lingen 2002, van der Lingen et al. 2006a).

The increase in zooplankton abundance may have initiated an increase in large horse mackerel abundance, as this is their predominant prey type. In 1969/70 a shift in large horse mackerel landings was detected, but this shift is considered to be due more to high fishing pressure by foreign fleets (which could then still fish in South African waters) than any increase in horse mackerel abundance. Heavy fishing from foreign fleets would also explain the increase in demersal landings in 1964, consisting mainly of hake, and so it is unlikely that the shift in these anthropogenic forcing groups can be linked to changes in state variables during this long term change in the system (Table 3).

STARS analysis indicates that during the period from the collapse of the sardine stock up to the late 1980 s sardine stock levels do not increase dramatically, but standardised 
gonad mass increases and condition factor improves. These changes are indicative of a reduction in density dependent effects among sardine due to low abundance observed during the slow recovery of the southern Benguela sardine stock (van der Lingen et al. 2006b). In support of this hypothesis, as sardine stock levels have recovered during the 1980s a negative shift in condition factor was detected (van der Lingen et al. 2006b). There are, however, changes in environmental forcing in the form of increased upwelling intensity and SSTs around the same period as the increases in sardine condition factor and sardine gonad mass (Table 3). An increase in upwelling was detected in the mid 1950s prior to an increase in sardine gonad mass, and a further increase in upwelling and SSTs in 1971 occurred at the same time as increases in sardine condition factor, but a decrease in upwelling was detected in 1964 around the time of a further increase in sardine gonad mass. It is believed that if there is a causal mechanism between the environment and sardine condition factor and gonad mass, then an increase in these biological state variables would occur at a time of increased productivity, i.e. increased upwelling and SSTs (van der Lingen et al. 2006b). Using the same upwelling index, which is used here as a proxy for productivity, it has been shown previously that increased upwelling from 1950-1989 matched increases in sardine condition factor and gonad mass up to 1980 (Shannon et al. 1992). However it did not match the decreases in condition factor recorded in the mid to late 1980s. This was true in this analysis as well; when condition factor decreased in the mid $1980 \mathrm{~s}$, there is only an increase in SST at $30^{\circ} \mathrm{S}$ at this time, and no changes in upwelling were identified. Furthermore, there were no recent changes in SST or upwelling before the decrease in condition factor in $1995 / 96$, but sardine biomass was shown to increase at this time and thus density dependent effects would have resulted in the decrease in condition factor at this time (van der Lingen et al 2006b). Perhaps upwelling increases have a strong effect on sardine condition factor 
and gonad mass, whereas decreases in upwelling do not have an equal and opposite effect. This hypothesis would need further testing. Zooplankton data from 1968-1984 do not exist for the southern Benguela, and it is not known whether shifts in zooplankton occurred during this period in accordance with the oceanographic shifts, which would ultimately affect sardine condition and gonad mass.

\section{$1971-1990$}

There is evidence that a long-term change occurred in 1971-74 within the environmental variables analysed, although there were no corresponding shifts in the available biological variables. In terms of anthropogenic forcing variables, a negative shift in demersal landings occurred in 1974, but this was probably largely due to the process of creating an economic exclusive zone (EEZ), extending $200 \mathrm{~nm}$ from the South African coast in 1976, resulting in foreign fleets seeking alternative waters in which to fish and a resultant decrease in demersal landings (Table 3). The intense fishing pressure on demersals prior to this exclusion resulted in low abundance of demersal species, especially hake. Hake is one of the primary predators of small pelagic fish and so reduced predation on small pelagic fish may have occurred before 1976 , and could have aided the increase in sardine biomass. However, this would only occur under the hypothesis of top down control rather than wasp-waist control. If this were the case an increase in sardine biomass would result in decreased mean condition factor of sardine due to density dependent effects (van der Lingen et al. 2006b). A decrease in sardine mean condition factor was not detected at this time and only decreased in the mid 1980s. Therefore changes in sardine biomass due to reduced hake predation from overfishing of hake seem to not be large enough to allow detection of a response in condition factor of sardines, and indicate that wasp-waist control in the system is a more probable hypothesis than top down control. 
No robust shifts in any variables were detected between 1974 and 1990. The Benguela Niño of 1984 might have caused changes to pelagic components over a short duration, as documented for anchovy and sardine by Le Clus (1990), who suggested that spatial changes in pelagic spawning distribution is affected more by large scale environmental anomalies rather than by changes in abundance. Other studies have shown that fish migrations southwards and large mortalities in the major pelagic fish species and seabirds resulted from the 1984 event (Shannon et al. 1984, Duffy et al. 1984, Glynn, 1988, Gammelsrod et al. 1998). A negative shift in \% anchovy in the diet of Cape gannets off the west coast was detected in 1983/84 whereas the sardine component of their diet increased (Table 3). This could be attributed to the lower levels of anchovy stocks during the 1980s, which fluctuated and remained relatively low in comparison to the 1970 s stock levels. Sardine was recovering well since the 1960s collapse, making them more available as a prey source to gannets on the west coast. Sardine are generally believed to thrive under warmer sea temperatures, such as Benguela Niños, whereas anchovy tend to decline (Bakun and Broad 2003, van der Lingen 2006a). It is possible that the $1983 / 84$ Benguela Niño event helped to increase sardine abundance, which would result in the negative shift in sardine gonad mass and condition factor detected in the late 1980 s, caused by higher densities of sardine than occurred in previous years. In 1983 separate management of sardine and anchovy stocks was introduced and sardine was fished extremely conservatively from then until 2004. The end of the 1980s was a period in which the largest anchovy landings by weight were recorded, resulting from successful recruitment of anchovy through the mid 1980s, and is linked to a decrease in the mean length of anchovy. The anchovy fishery targets recruits, so there would be increased recruits at this time. 
The STARS analysis detected a negative possible shift in upwelling and a small increase in SSTs in 1991, indicating decreased production, but no robust shifts in biological variables were detected around the same period.

Strong recruit year classes in sardine after the Benguela Niño in 1995 caused an increase in the abundance of recruits, and this increase can be linked to the reduction in sardine mean length from catches identified in 1996. Once again the sardine stocks seem to respond positively to the Benguela Niño. Sardine spawner biomass was detected as increasing in 1996/97 (Table 3), possibly linked to the warmer coastal waters in 1995, which would favour small phytoplankton cells, which in turn would favour small zooplankton, which is the preferred prey size of sardine (van der Lingen et al. 2006a). Sardine only spawn at two to three years of age (Armstrong and Thomas 1989), so the increase in spawner biomass could explain part of the positive shift in sardine modelled recruit numbers one to two years later in 1997/98 (Table 3).

$1999-2001$

The most extensive shift involving a wide range of variables tested occurred between 1999 and 2001. An increase in upwelling at $30^{\circ} \mathrm{S}$ in 1998 may have explained the increase in anchovy spawner biomass a year later, as heightened upwelling increases the standing stock of large phytoplankton and these are fed upon by large zooplankton, the preferred prey of anchovy. The shifts in pelagic stocks, especially recruits, detected during this period have been explained by anomalous oceanographic conditions, which occurred in the summer of 1999/00. These conditions manifested as a period of reduced upwelling and an increase in SST, followed by a period of moderate upwelling, and with a period of heightened upwelling only beginning in March 2000 (Roy et al. 2001). With an already elevated level of anchovy spawner 
biomass, these shifts in upwelling and SST are believed to have provided environmental conditions that favoured a large increase in anchovy recruitment. The decrease in upwelling intensity would reduce advective losses of eggs and larvae that are transported up the west coast by jet currents from the spawning grounds (Hutchings et al. 1998). The period of moderate upwelling, which followed is believed to have increased the retention of juveniles and larvae in coastal waters, where a plentiful food source was available. Thus with greater food availability, a large positive shift in anchovy recruits occurs (Roy et al. 2001). The same changes in coastal oceanographic conditions may have caused increases in redeye-modelled biomass, as this pelagic species would be similar to anchovy in its response to the environment. The STARS analysis detected a negative shift in upwelling and a positive shift in SST only in 2000/01, and these were not detected under prewhitened analyses (Table 3). These climatic events of the 1999/00 summer may not have been detected, as they were not long term changes in the mean upwelling intensity or SST, but small, short term changes about the mean, i.e. changes in the variance of the environmental signal with a timing favourable to small pelagics recruitment. STARS analyses were only run to detect shifts in the means of variables tested.

Another factor that could be linked to the record level of anchovy recruitment was the eastward shift in anchovy that began in 1996 (Roy et al. in prep.) A recorded shift in 1996 of surface atmosphere pressure and SSTs over the Agulhas Bank has been hypothesised as a reason for this eastward shift in anchovy. STARS type shifts have been shown to indicate that $80 \%$ of the anchovy spawning biomass occurred east of Cape Agulhas in 1998 compared to $20 \%$ in 1988 (Roy et al. in prep.). Better feeding conditions and parental conditions east of Cape Agulhas have been indicated as factors that may be ensuring successful recruitment of anchovy. Despite the eastward shift, recruitment is still predominantly on the west coast (Roy et al. in prep.). 
With the resulting high abundance of pelagic recruits during the 1999/00 long-term change, it is expected that this would affect zooplankton abundance (Cury et al. 2000). Both total copepods and cyclopoid copepods showed a decrease in 2000/01, this decrease was relative to their abundance in 1988 , not 1953 , as separate analyses were carried out on the two periods of zooplankton data, because of the data gap from 1963-88 (Table 3). The decrease may also be linked to the change in zooplankton species assemblage, because the smallest of the five groups analysed shows negative shifts. It appears that increased predation from increasing sardine stocks, which prefer small zooplankton (van der Lingen et al. 2006a), could be a major cause of this shift. The high abundance of pelagic species between 2000 and 2003 would also result in increases in density dependent effects, and this is noted in the reduction in anchovy and sardine L95 from catches. Anchovy spawners have been described as being in poorer condition and smaller since 2000 (van der Lingen et al. 2005). It is hypothesised that all three pelagic species are unlikely to remain at high biomass levels, and a shift towards a sardine dominated system, in accordance with the shift towards small zooplankton species assemblage, is predicted within the next few years (Shannon et al. 2004).

\section{Eastward shift of sardine stocks}

From previous analytical and empirical studies it has been noted that a south and eastward shift in sardine stocks has occurred since 2001, and continues to occur. Stocks are occurring and spawning east of Cape Agulhas to a far greater extent than ever before, resulting in reduced abundance from the west coast areas (Fairweather et al. 2006). It is known that sardine can change their distribution and have the ability to migrate; this has been recorded in large shifts in their distribution during Benguela Niño events (Lluch Belda et al. 1989). However these migrations have been 
temporary, unlike the current eastward shift. Several hypotheses have been proposed, but it is not clear at present what has caused this shift in distribution of sardine (van der Lingen et al. 2005). The shift in sardine eggs from west to east of Cape Agulhas in $2000 / 01$ is indicative of this eastward shift in sardine spawner stock. This movement of sardine is also crucial in explaining the shifts in the contributions of anchovy and sardine to Cape gannet diet on the west coast and at Algoa Bay on the south east coast. It is clear from the shift in gannet diet at Algoa Bay that gannets have replaced anchovy with sardine in their diets since $2002 / 03$, as the availability of sardine in this area has increased (Table 3). Cape gannets will preferentially feed on sardine (Crawford et al. 1991), and with the influx of sardine to this area on the south east coast, gannets will feed less on anchovy.

The emigration or depletion of sardine from the west coast has resulted in gannets at Lambert's Bay and elsewhere on the west coast switching their diet from one consisting of sardine to a diet predominantly consisting of anchovy, a less favourable, but more available prey source. The high anchovy recruitment of 2000/01 would result in high anchovy abundance off the west coast as anchovy recruit to the west coast from their spawning grounds on the western Agulhas Bank (Armstrong and Thomas 1989). A modelling study, of stock dynamics in the southern Benguela between 1978 and 2002, concluded that fishing accounted for only $2-4 \%$ of variability in the system (Shannon et al. 2004). Despite this, heavy fishing of sardine on the west coast has been postulated to be a factor in the south-eastward migration of sardine in recent years (van der Lingen et al. 2005).

There are three main hypotheses of the eastward shift in sardine stocks (Coetzee et al. 2006). One of these is that there are, in fact, two separate sardine stocks. The west coast stock has been under heavy fishing pressure, which has depleted that stock, 
whereas the south coast stock has not been under such heavy fishing pressure (Coetzee et al. 2006). The recovery of the sardine stocks, resulting in an increase in biomass, has resulted in an expansion of their range. The east coast areas may be more favourable because of reduced fishing, increased productivity and successful recruitment. Recruitment is possibly linked to changes in environmental forcing, which has resulted in changes in sardine spawning habitat selection (van der Lingen et al. 2001). It is unknown whether a decrease in fishing effort on the west coast will result in an increase in the biomass of sardine in that area (Coetzee et al. 2006), or whether this might reverse the changes seen in seabird diet compositions.

\section{Regime shifts in other marine ecosystems}

The effect on marine ecosystems of changes in environmental forcing can be important, as has been demonstrated in this study of the southern Benguela. The same links cannot be made between changes in environmental forcing and state variables in the northern Benguela over this fifty-year period. Ecosystem restructuring has been observed in the northern Benguela and recorded across many trophic levels. However, the large-scale shift from a sardine dominated system to an abundance and dominance of jellyfish, horse mackerel and pelagic goby preceded large-scale changes in the environment, indicating that anthropogenic forcing could have been the dominant factor changing this ecosystem. Further changes to the ecosystem since the $1960 \mathrm{~s}$ have followed changes in environmental forcing. Most large fish stocks, including horse mackerel, have declined since the 1980 s and jellyfish currently dominate the system. Seabird and mammal populations have experienced large decreases in size because of the reduction and absence of their preferred prey. For example, Cape gannets, which breed off the coast of Namibia, have exhibited substantial long-term population declines as a direct result of the decrease in sardine abundance (Crawford 1999). This is an example of how fishing can influence the relative abundance of 
species and be a major anthropogenic forcing on ecosystem structure (Crawford 1987). The long-term changes in the northern Benguela have been described as regime shifts by Cury and Shannon (2004). They are linked to changes in environmental forcing, but high fishing pressures on small pelagic species have compounded the negative impacts of environmental changes or events.

By employing a wide variety of methods, Mantua (2004) showed that a regime shift occurred in the Northern Pacific in 1977/78. This shift was caused by changes in climatic variables such as the Pacific Decadal Oscillation (PDO) and Arctic oscillation which instigated changes in biological variables in the Pacific basin. The changes only became apparent almost two decades after the event, because of the need for long time series of data. Rodionov and Overland (2005) used STARS analysis to show that this regime shift was also detected in the Bering Sea ecosystem in 1977 and, more interestingly, that smaller shifts also occurred in 1989 and 1998. The identification of the recent shifts reveals the potential of the STARS method to detect recent shifts without the need for long time series.

Schwartzlose et al. (1999) stated that changes in the environment are more likely to cause regime shifts than anthropogenic forcing, but that the latter would probably exacerbate the initial changes. There are two types of environmental changes that influence marine ecosystems: prolonged forcing (long term changes in pressure, SSTs, upwelling) and episodic events (ENSO or Benguela Niño events). Both of these are shown in this study to have influenced changes in the southern Benguela. For example, changes in upwelling and SSTs resulted in changes in the zooplankton community over many decades (Verheye et al. 1998), and short-term anomalies in environmental forcing resulted in strong year classes of pelagic fish recruits (Roy et 
al. 2001). To what degree each type of forcing impact the system is currently unknown (Shannon et al. 2004), but there are examples of their influence in causing shifts in a number of different marine ecosystems worldwide.

The shift in the PDO of 1977 was shown to cause shifts in calanoid copepod populations in the California current system in the mid 1970s. Shifts in calanoid copepods also occurred in the same years as strong ENSO events of the 1950 s and early 1980s (Rebstock 2002). A non-linear response between the environment and biological variables was shown, because some species of calanoid copepod responded at different time scales to environmental conditions that persisted for only a few years. ENSO events seem to have caused these changes in zooplankton communities, and it is possible that Benguela Niño events, despite being less severe than ENSO events, are a major forcing variable in shifting ecosystem components.

Zooplankton community structure and abundance were altered by ENSO events in the Humboldt current (Hays et al. 2005). Many other large scale shifts have been influenced by the environment, e.g. increasing SSTs in the North Sea have altered the zooplankton community, which has reduced cod larval survival (Beaugrand et al. 2003). Cod recruitment was also influenced by changes in the North Atlantic Oscillation during the North Sea regime shift in the 1980s (Stige et al. 2006). Miller and Sydeman (2004) concluded from a study on Common Murre (Uria aalge) diet in the Pacific that ENSO events, changes in the PDO and reductions in upwelling were more likely to be responsible for shifts in rockfish abundance rather than anthropogenic forcing. In the east Bering Sea it was shown that fishing and trophic interactions had a smaller impact than environmental forcing did on changes in the ecosystem (Trites et al. 1999). These results are in agreement with the results of this 
study using the STARS analysis; the environment appears to be the main driving factor in driving long-term changes in the southern Benguela.

\section{Conclusions}

The overall pattern emerging from the application of STARS analysis to the southern Benguela over the past 50 years, is that two major long-term changes have occurred. The first occurred in the early 1960s, and was mainly caused by overfishing, but with some environmental influence. This conclusion is similar to one recorded by Crawford et al. (unpublished manuscript). The second long-term change spanned the late 1990 s to the early 2000 s, and appears to be linked more to environmental shifts rather than to anthropogenic forcing. During both periods of change, large-scale shifts occurred in environmental forcing as well as in biological variables across several trophic levels. Pelagic fish species alternations have occurred, and are predicted to occur again in the future. Non-linear relationships indicated between environmental forcing and changes in biological state variables are apparent in the results. Changes in anthropogenic forcing, although not apparently primarily responsible for changes in biological variables, nonetheless can accelerate and magnify changes. The two longterm changes identified here can be termed regime shifts under the definition set out by de Young et al. (2004), which states that a regime shift comprises substantial changes in ecosystem structure, such that key pathways of energy flows or distribution are altered. In order to strengthen this finding, it would be beneficial to apply further analyses to detect these regime shifts.

Previous studies investigating ecosystem interactions within the southern Benguela have produced similar results to those described in this study. Jarre et al. (2006) proposed to combine the signals of several indicators into a "probability" of long-term change using rule-based expert systems. This study has defined indicators for use in 
such expert systems, and discussed mechanisms that may aid in their combination of the indicators in the rules underlying the decision whether long-term change is occurring. The STARS method is able to detect shifts from time series data, and to accurately place them within exact years or even months. The method was able to detect shifts in the same year that they were happening, which occurred in some of the time series analysed here. In addition to this, a modelling exercise would need to be applied to these data to conclusively prove the causality of the correlations identified between events. However the timing and correlations of shifts identified in this study provide starting points for such work. Further development is needed before this method can be adopted as a tool for adaptive management under an ecosystem approach to fisheries management. 


\section{Acknowledgements}

I am grateful to the Marine Biology Research Centre (MBRC) for funding part of this research. I would like to thank my supervisors for their assistance and guidance as well as their patience and time without which this project would not have been possible.

I would also like to thank Dr Claude Roy of IRD, France and Marine and Coastal Management (MCM) for permitting the use of their extensive data set in this project.

Lastly I would like to thank my parents and family without whose help and support, this Masters would not have become a reality. 


\section{References}

Alheit J and Niquen M (2004) Regime shifts in the Humboldt Current ecosystem. Progress in Oceanography 60: 201-222.

Armstrong MJ and Thomas RM (1989) Clupeoids. In: Oceans of Life off Southern Africa. Payne AIL and Crawford RJM (Eds), Cape Town, Vlaeberg: 105-121.

Bakun A (1996) Patterns in the ocean: Ocean processes and Marine Population Dynamics. University of California Sea Grant Program, San Diego, California, USA, in cooperation with Centro de Investigaciones Biologicas de Noroeste, La Paz, Mexico: 323pp.

Bakun A and Broad K (2003) Environmental 'loopholes' and fish population dynamics: comparative pattern recognition with focus on El Niño effects in the Pacific. Fisheries Oceanography 12(4\&5): 458-473.

Barange M, Hampton I and Roel BA (1999) Trends in the abundance of anchovy and sardine on the South African continental shelf in the 1990s, deduced from acoustic surveys. South African Journal of Marine Science 21: 367-391.

Beaugrand G (2004) The North Sea regime shift: evidence, causes, mechanisms and consequences. Progress in Oceanography 60: 245-262.

Beaugrand G, Brander KM, Lindley JA, Souissi S and Reid PC (2003) Plankton effect on cod recruitment in the North Sea. Nature 426: 661-664.

Boyer DC and Hampton I (2001) An overview of the living marine resources of Namibia. In: Payne AIL, Pillar SC and Crawford RJM (Eds), A decade of Namibian fisheries science. South African Journal of Marine Science 23: 5-35.

Boyer DC, Boyer HJ, Fossen I and Kreiner A (2001) Changes in abundance of the northern Benguela sardine stock during the decade 1990-2000, with comments on the relative importance fishing and the environment. In: Payne AIL, Pillar SC and Crawford RJM (Eds), A decade of Namibian fisheries science. South African Journal of Marine Science 23: 67-84.

Butterworth DS (1983) Assessment and management of pelagic stocks in the southern Benguela region. In: Sharp GD, Csirke J (Eds), Proceedings of the expert consultation to examine changes in abundance and species composition of neritic fish resources. San Jose, Costa Rica, April 1983. FAO Fisheries Report 291(2): 329-405.

Coetzee JC, van der Lingen CD, Fairweather T and Hutchings L (2006) Has fishing pressure caused a major shift in the distribution of South African sardine? ICES CM B:11 20p.

Collie JR, Richardson K and Steele J (2004) Regime shifts: Can ecological theory illuminate these mechanisms? Progress in Oceanography 60:281-302.

Crawford RJM (1987) Food and population variability in five regions supporting large stocks of anchovy, sardine and horse mackerel. In: Payne AIL, Gulland JA, Brink KH (Eds), 
The Benguela and Comparable Ecosystems South African Journal of Marine Science 5: $735-757$.

Crawford RJM, Ryan PG and Williams AJ (1991) Seabird consumption and production in the Benguela and western Agulhas ecosystems. South African Journal of Marine Science 11: 357-375.

Crawford RJM (1999) Seabird responses to long-term changes of prey resources off southern Africa. In: Adams NJ, Slotow RH (Eds), Proceedings of the 22nd ornithological congress pp 688-705 Durban, August 1998, Johannesburg, Birdlife South Africa.

Crawford RJM and Jahncke J (1999) Comparison of trends in abundance of guano producing seabirds in Peru and southern Africa. South African Journal of Marine Science 21: 145-156.

Crawford RJM, Shannon LJ, Kreiner A, van der Lingen CD, Alheit J, Bakun A, Boyer D, Cury P, Dunne T, Durand M-H, Field JG, Fréon P, Griffiths MH, Hagen E, Hutchings J, Klingelhoeffer E, Moloney CL, Mouton D, Roy C, Roux J-P, Shannon LV, Shillington FA, Underhill LG and Verheye HM Periods of major change in the structure and functioning of the pelagic component of the Benguela ecosystem, 19502000. Unpublished manuscript.

Cury P, Bakun A, Crawford RJM, Jarre-Teichmann A, Quinones R, Shannon LJ and Verheye HM (2000) Small pelagics in upwelling systems: patterns of interaction and structural changes in "wasp-waist ecosystems. ICES Journal of Marine Science 57: 603-618.

Cury PM and Shannon LJ (2004) Regime shifts in the Benguela ecosystem: Facts, theories and hypotheses. Progress in Oceanography 60:223-243.

Daskalov GM, Boyer DC and Roux J-P (2003) Relating sardine Sardinops sagax abundance to environmental indices in northern Benguela. Progress in Oceanography 59:257274.

de Young B, Harris R, Alheit J, Beaugrand G, Mantua N and Shannon L (2004) Detecting regime shifts in the ocean: Data considerations. Progress in Oceanography 60:143164.

Duffy DC, Berruti A, Randall RM and Cooper J (1984) Effects of the 1982-1983 warm water event on the breeding of South African seabirds. South African Journal of Marine Science 80: 65-68.

Fairweather TP, van der Lingen CD, Drapeau L, Booth AJ and van der Westhuizen JJ (2006) Indicators of sustainable fishing for the South African sardine (Sardinops sagax) and management implications. African Journal of Marine Science 28(3\&4): 661-680.

Gammelsroed T, Bartholomae CH, Boyer DC, Filipe VLL and O'Toole MJ (1998) Intrusion of warm surface water along the Angolan-Namibian coast in February-March 1995: The 1995 Benguela Niño. South African Journal of Marine Science 19: 41-56.

Glynn PW (1988) ENSO 1982-83: Nearshore population, community and ecosystem responses. Annual Review of Ecological Systematics 19: 309-345. 
Hare SR and Mantua NJ (2000) Empirical evidence for North Pacific regime shifts in 1977 and 1989. Progress in Oceanography 47: 103-145.

Hays GC, Richardson AJ and Robinson C (2005) Climate change and marine plankton. TRENDS in Ecology and Evolution 20: 337-344.

Hutchings L (1992) Fish harvesting in a variable, productive environment - searching for rules or searching for exceptions? In: Payne AIL, Brink KH, Mann KH and Hillborn R (Eds), South African Journal of Marine Science 12: 297-318.

Hutchings L, Barange M, Bloomer SF, Boyd AJ, Crawford RJM, Huggett JA, Kerstan M, Korrubel JI, De Oliveira JAA, Painting SJ, Richardson AJ, Shannon LJ, Schulein FH, van der Lingen CD and Verheye HM (1998) Multiple factors affecting South African anchovy recruitment in the spawning, transport and nursery areas. In: Pillar SC, Moloney CL, Payne AIL and Shillington FA (Eds), Benguela Dynamics: impacts of variability on shelf-sea environments and their living resources. South African Journal of Marine Science 19: 211-225.

Jarre A, Moloney CL, Shannon LJ, Fréon P, van der Lingen CD, Verheye H, Hutchings L, Roux JP and Cury P (2006) Detecting and forecasting long-term ecosystem changes. p. 239-272. In: Shannon LV, Hempel G, Malanotte-Rizzoli P, Moloney CL and Woods J (Eds), The Benguela: Predicting a large marine environment, Elsevier, Amsterdam, $410 \mathrm{p}$.

Kendall MG (1954) Note on bias in the estimation of autocorrelation. Biometrika 41: 403404.

Larkin PA (1996) Concepts and issues in marine ecosystems management. Review of Fish Biological Fisheries 6: 139-164.

Le Clus F (1990) Impact and implications of large-scale environmental anomalies on the spatial distribution of spawning of the Namibian pilchard and anchovy populations. South African Journal of Marine Science 9: 141-159.

Lluch-Belda D, Crawford RJM, Kawasaki T, MacCall AD, Parrish RH, Schwartzlose RA and Smith PE (1989) World wide fluctuations of sardine and anchovy stocks: the regime problem. South African Journal of Marine Science 8: 195-205.

Lluch-Belda D, Schwartzlose RA, Serra R, Parrish RH, Kawasaki T, Hedgecock D and Crawford RJM (1992) Sardine and anchovy regime fluctuations of abundance in four regions of the world oceans: a workshop report. Fisheries Oceanography 1(4): 339347.

Mantua N (2004) Methods for detecting regime shifts in large marine ecosystems: A review with approaches applied to North Pacific data. Progress in Oceanography 60 (2-4): 165-182.

Marriott FHC and Pope JA (1954) Bias in the estimation of autocorrelations. Biometrika 41: $390-402$. 
Miller AK and Sydeman WJ (2004) Rockfish response to low-frequency ocean climate change as revealed by the diet of a marine bird over multiple time scales. Marine Ecology Progress Series 281: 207-216.

Moloney CL, van der Lingen CD, Hutchings L and Field JG (2004) Contributions of the Benguela Ecology Programme to pelagic fisheries management in South Africa. African Journal of Marine Science 26: 37-51.

Overland JE, Percival DB and Mofjeld HO (2006) Regime shifts and red noise in the North Pacific. Deep Sea Research I 53: 582-588.

Reason CJC, Florenchie P, Roualt M and Veitch J (2006) Influences of large-scale climate modes and Agulhas system variability on the BCLME region. In: Shannon LV, Hempel G, Malanotte-Rizzoli P, Moloney CL and Woods J (Eds), The Benguela: Predicting a large marine environment, Elsevier, Amsterdam, $410 \mathrm{p}$.

Rebstock GA (2002) Climatic regime shifts and decadal scale variability in calanoid copepod populations off southern California. Global Change Biology 8: 71-89.

Rodionov SN (2004) A sequential algorithm for testing climate regime shifts. Geophysical Research Letters 31: L09204.

Rodionov SN and Overland JE (2005) Application of a sequential regime shift detection method to the Bering Sea ecosystem. ICES Journal of Marine Science 62: 328-332.

Rodionov SN (2006) Use of prewhitening in climate regime shift detection. Geophysical Research Letters 33:L12707.

Roux J-P and Shannon LJ (2004) An ecosystem approach to fisheries management in the northern Benguela. The Namibian experience. African Journal of Marine Science 26: 79-93.

Roy C, Weeks S, Rouault M, Nelson G, Barlow R and van der Lingen C (2001) Extreme oceanographic events recorded in the Southern Benguela during the 1999-2000 summer season. South African Journal of Marine Science 97: 465-471.

Roy C, van der Lingen CD and Coetzee JC (in prep) Environment-fish relationships: processes and variability. A focus on anchovy life history and recent changes. Presented at BCLME Southern Boundary Workshop, May 2006.

Scheffer M, Carpenter S, Foley JA, Folke C and Walker B (2001) Catastrophic shifts in ecosystems. Nature 413: 591-596.

Schwartzlose RA, Alheit J, Bakun A, Baumgartner TR, Cloete R, Crawford RJM, Fletcher WJ, Green-Ruiz Y, Hagen E, Kawasaki T, Lluch-Belda D, Lluch-Cota SE, MacCall AD, Matsuura Y, Nevarez-Martinez MO, Parrish RH, Roy C, Serra R, Shust KV, Ward MN and Zuzunaga JZ (1999) Worldwide large-scale fluctuations of sardine and anchovy populations. South African Journal of Marine Science 21: 289-347.

Shannon LV, Crawford RJM and Duffy DC (1984) Pelagic fisheries and warm events: a comparative study. South African Journal of Science 80: 51-60. 
Shannon LV (1985) The Benguela ecosystem. 1. Evolution of the Benguela, physical features and processes. In Oceanography and Marine Biology. An Annual Review 23: Barnes M (Ed), Aberdeen: University Press: 105-182.

Shannon LV, Boyd AJ, Brundrit GB and Taunton-Clark J (1986) On the existence of an $E l$ Niño-type phenomenon in the Benguela system. Journal of Marine Research 44(3):495-520.

Shannon LV, Crawford RJM, Pollock DE, Hutchings L, Boyd AJ, Taunton-Clark J, Badenhorst A, Melville-Smith R, Augustyn CJ, Cochrane KL, Hampton I, Nelson G, Japp D and Tarr RJQ (1992) The 1980s - a decade of change in the Benguela ecosystem. In: Benguela Trophic functioning. Payne AIL, Brink KH, Mann KH, and Hillborn R (Eds), South African Journal of Marine Science 12: 271-296.

Shannon LJ and Jarre-Teichmann A (1999) Comparing models of trophic flows in the northern and southern Benguela upwelling systems during the 1980s. In: Ecosystem Approaches for Fisheries Management. University of Alaska Sea Grant, AK-SG-9901, Fairbanks: 527-541.

Shannon LJ (2001) Trophic models of the Benguela upwelling system: Towards an ecosystem approach to fisheries management. (319pp + appendices pp. i-xxxv) Ph.D. thesis, University of Cape Town.

Shannon LJ, Moloney CL, Jarre A, Field JG (2003) Trophic flows in the southern Benguela during the 1980s and the1990s. Journal of Marine Systems 39: 83-116.

Shannon LJ, Field JG and Moloney CL (2004) Simulating anchovy-sardine regime shifts in the southern Benguela ecosystem. Ecological Modelling 172: 269-281.

Steffen W, Sanderson A, Jager J, Tyson PD and Moore B III (2004) Global Change and the Earth System: A Planet Under Pressure. Heidelberg: Springer-Verlag. 336 pp.

Stige LC, Ottersen G, Brander K, Chan K-S and Stenseth NC (2006) Cod and climate: effect of the North Atlantic Oscillation on recruitment of North Atlantic. Marine Ecology Progress Series 32: 227-241.

Trites AW, Livingston PA, Vasconcellos MC, Mackinson S, Springer AM and Pauly D (1999) Ecosystem change and the decline of marine mammals in the eastern Bering Sea: testing the ecosystem shift and commercial whaling hypotheses. Fisheries Centre Research Reports 7, 106pp.

van der Lingen CD, Hutchings L, Merkle D, Van der Westhuizen JJ and Nelson J (2001) Comparative spawning habitats of anchovy (Engraulis capensis) and sardine (Sardinops sagax) in the southern Benguela upwelling ecosystem. In: Spatial Processes and Management of Marine Populations. Kruse GH, Bez N, Booth T, Dorn M, Hills S, Lipcius RN, Pelletier D, Roy C, Smith SJ and Witherell D (Eds), University of Alaska Sea Grant, AK-SG-01-02, Fairbanks: 185-209.

van der Lingen CD (2002) Diet of sardine Sardinops sagax in the southern Benguela upwelling ecosystem. South African Journal of Marine Science 24: 301-316. 
van der Lingen CD, Coetzee JC, Demarcq H, Drapeau L, Fairweather TP and Hutchings L (2005) An eastward shift in the distribution of southern Benguela sardine. GLOBEC International Newsletter 11: 17-22.

van der Lingen CD, Hutchings $L$ and Field JG (2006a) Comparative trophodynamics of anchovy Engraulis encrasicolus and sardine Sardinops sagax in the southern Benguela: are species alternations between small pelagic fish trophodynamically mediated? African Journal of Marine Science 28(3\&4): 465-477.

van der Lingen CD, Freon P, Fairweather TP and Van der Westhuizen JJ (2006b) Density dependent changes in reproductive parameters and condition of southern Benguela sardine Sardinops sagax. African Journal of Marine Science 28(3\&4): 625-636.

Verheye HM, Richardson AJ, Hutchings L, Marska G and Gianakouras D (1998) Long-term trends in the abundance and community structure of the coastal zooplankton in the southern Benguela system, 1951-1996. In: Pillar SC, Moloney CL, Payne AIL and Shillington FA (Eds), Benguela dynamics: impacts of variability on shelf-sea environments and their living resources. South African Journal of Marine Science 19: $317-332$. 


\section{Appendix A}

\section{Observation State variables compared to Benguela Niños}

\section{Anchovy recruit numbers and biomass surveyed}

A positive possible shift was detected in 2000 , which is too long a lag time for the Benguela Niño of 1995 to be linked with shifts in these two variables. Since 1985, anchovy recruits have been at low levels until the successful recruitment year in 2000, which was outside the maximum lag times of Benguela Niños affecting anchovy recruitment (Figure 1a and b). There was also no indication of successful recruitment after the 1984 Benguela Niño.

\section{\% Sardine eggs west and east of Cape Agulhas}

A negative robust shift in the \% of sardine eggs west of Cape Agulhas occurred in $2000 / 01$ with a positive robust shift in \% of sardine eggs found east of Cape Agulhas in the same year (Figure 1c and d). The Benguela Niño of 1995 occurred outside of maximum acceptable lag times between changes in environmental forcing and a response in biological variables (Table 2).

\section{Copepod abundance (1988-2005)}

A negative possible shift in cyclopoid copepods occurred in $2000 / 01$, small calanoid copepods undergo a negative robust shift in 2004/05. There were two shifts detected for numbers of total copepods, a negative possible shift in $2000 / 01$ and a negative prewhitened shift in 2004/05 (Figure 1e, $\mathrm{f}$ and $\mathrm{g}$ ). All these shifts in all three groups occurred outside acceptable lag times after the Benguela Niño event of 1995 , for it to be a causal factor. 

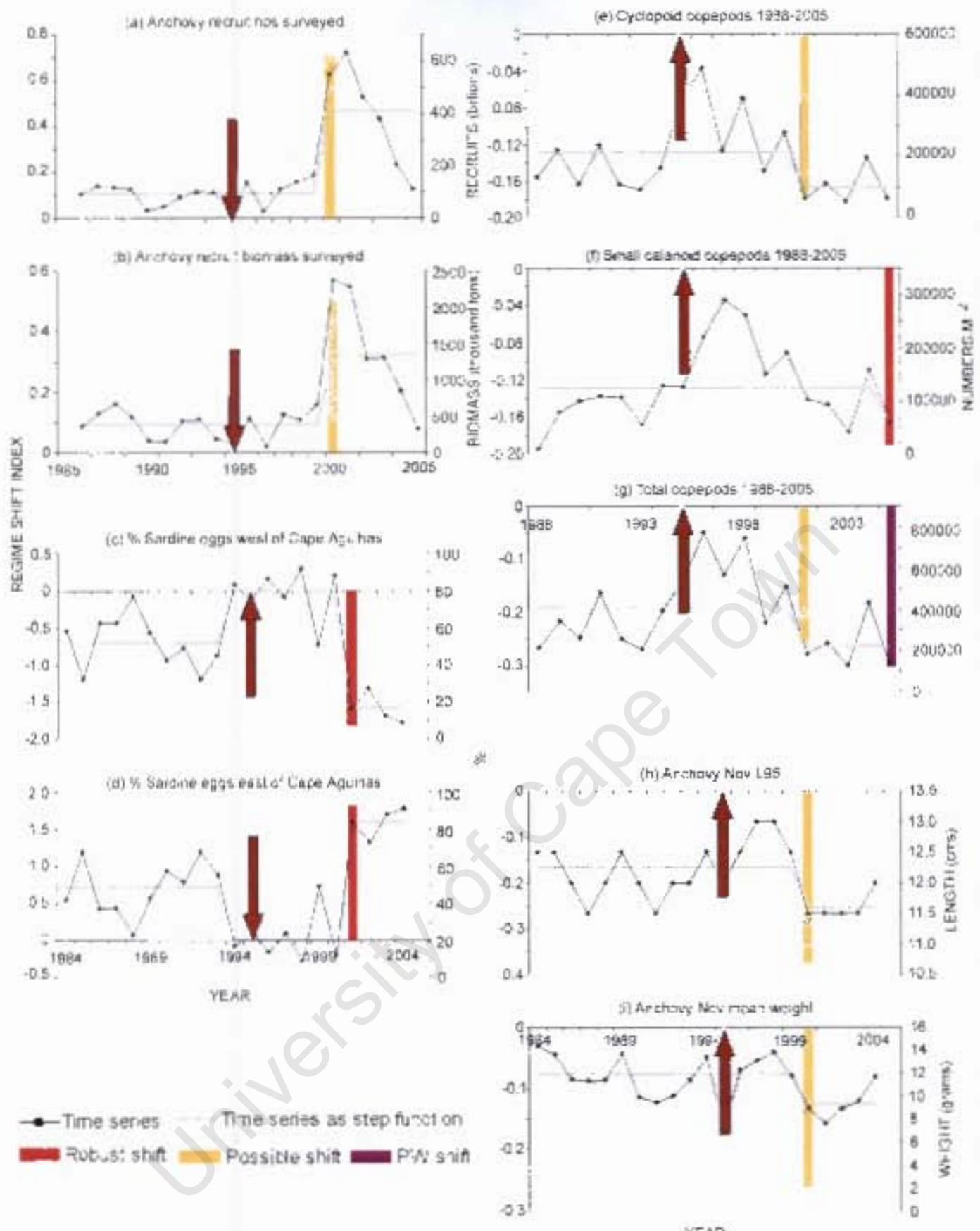

VFAR

Figure I: Results of STARS analysis showing the magnilude of shills in RSI (coloursd bars), the overall time series (black tine) and the weighed mean of obstruation slate varjables (grey line) for surveyed anchovy recruitmenl in terns of $(\mathrm{a})$ numbrs and (b) biomass. The \% sardine eges, (c) west of Cape Aguhas und (d) cast of Capc Agulhas arc given. Copepod abundance (198x-20)(55) is given til terms of (e) cyclopoid copepods, (t) sinall calanoid copepods, (g) lowat copepods. Surveyed anchusy (h) 195 and (i) mean weight are given. Isrown arows indieate Jeng uela Nino events (Table 1 ). 
Anchovy Nov L95 and Anchovy Nov mean weight

A negative possible shift in anchovy November surveyed L95 and anchovy November surveyed mean weight, occurred in 1999/00 (Figure 1h and i). This could be due to unfavourable prey availability, which may have been affected by the 1995 Benguela Niño. However, there was no shift in either L95 or mean weight between the 1984 event and the 1995 event.

\section{Observed State variables compared to SST anomalies at $30^{\circ} \mathrm{S}$ and $32^{\circ} \mathrm{S}$}

Sardine mean condition factor and standardised gonad mass

Positive possible shifts in SST anomalies at $30^{\circ} \mathrm{S}$ were identified in 1956,1971 and 2001, (Figure $2 \mathrm{a}, \mathrm{b}$ and $\mathrm{c}$ ) however positive prewhitened shifts in SST at $30^{\circ} \mathrm{S}$ were only detected in 1991 and 2004/05 (not shown in Figure 2). The prewhitened shifts cannot be linked to any of the shifts in sardine gonad mass or sardine condition factor, whereas the possible shift in 1971 occurred in the same year as a positive robust shift in sardine condition factor (Jan-May) (Figure 2b). At $32^{\circ} \mathrm{S}$, positive robust shifts were detected in SSTs in 1956 and 2000/01 and a positive possible shift occurred in 1991. These robust shifts in SST occurred too late to be linked to the shifts detected in sardine gonad mass and condition factor.

\section{Anchovy Nov L95 and Anchovy Nov mean weight}

The negative possible shifts in anchovy L95 and mean weight in 1999/00 cannot be explained by the shifts detected in SST at either $30^{\circ} \mathrm{S}$ or $32^{\circ} \mathrm{S}$; lag times between these SST shifts and the shifts in anchovy L95 and mean weight were too great and the other SST shifts occurred after the 1999/00 shifts (Figure 2d and e). 

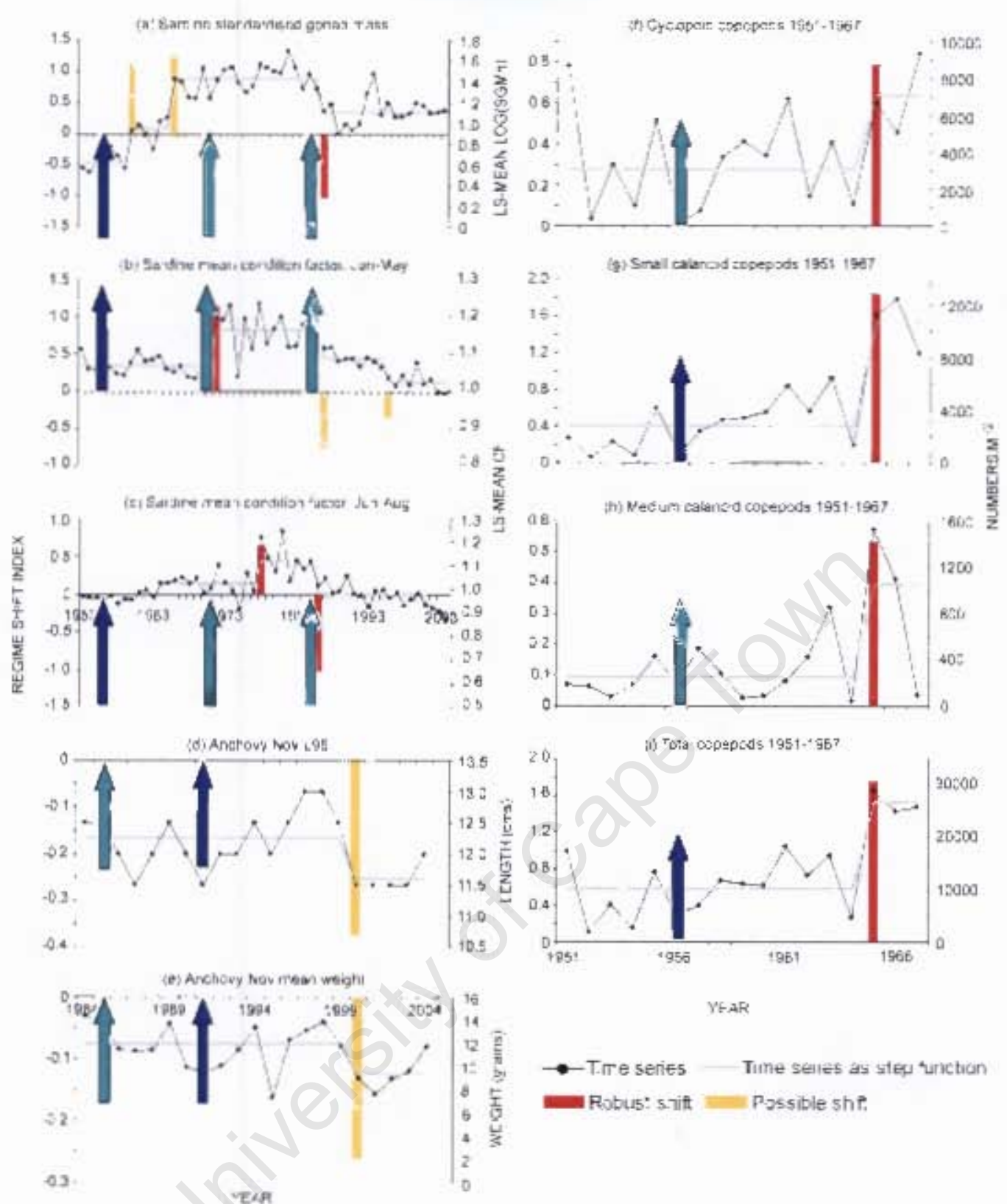

Figure 2: Results of STAKS analysis shonsing the magnitude of sbifts in RSI (coloured bars). the overall time stries (black line) and the weighted mean of ubservation state variables fgrey line) for (a) sardine standarufised gonad mass (b) sardine mean condition factor, Jan-May. (c) sardine mean condition factar, Jun-Aug. Surveyed anchory (d) L95 and (e) mean weight are shuwn. Copepud abundance is given in terms of (i) cyclopoid copepods 1951-1967, (g) small calanoid copepods 1951. 1967, (h) medium calanoid copepods 1951-1967 and (i) cotal copepods 1951-1967. 13oth robust and possible shifts identified hy the SI AIRS analysis are shown. 
Copepod abundance (1951-1967)

The positive robust shift in $1964 / 65$ that was detected in four of the five groups of zooplankton cannot be attributed to shifts in SST anomalies, as the only robust shift in SSTs occurred in 1956 at $32^{\circ} \mathrm{S}$, (Figure $2 \mathrm{f}-\mathrm{i}$ ), too long a lag time to be a contributing factor.

\section{Observed State variables compared to Upwelling index anomalies at $30^{\circ} \mathrm{S}$ and $32^{\circ} \mathrm{S}$}

Sardine mean condition factor and standardised gonad mass

A negative robust shift in upwelling at $30^{\circ} \mathrm{S}$ and at $32^{\circ} \mathrm{S}$ was detected in 1964 , one year before a positive possible shift in sardine gonad mass (Figure 3a). The negative robust shift in sardine gonad mass in $1986 / 87$ had no recently preceding shifts in upwelling at either $30^{\circ} \mathrm{S}$ or $32^{\circ} \mathrm{S}$. The positive robust shift in sardine mean condition factor (Jan-May) in 1971/72 occurred in the same year as a positive robust shift in upwelling at $32^{\circ} \mathrm{S}$, however the negative possible shifts in condition factor that occurred in 1986/87 and 1995/96 were not preceded by any significant changes in upwelling (Figure 3b). Sardine mean condition factor (Jun-Aug) showed robust shifts in $1977 / 78$ and $1985 / 86$, however the nearest preceding robust shift in upwelling was at $32^{\circ} \mathrm{S}$ in $1971 / 72$ (Figure $3 \mathrm{c}$ ), which would be greater than the maximum acceptable lag time for such a response.

\section{Anchovy Nov L95 and Anchovy Nov mean weight}

No robust or prewhitened shifts in upwelling at $30^{\circ} \mathrm{S}$ or $32^{\circ} \mathrm{S}$ preceded the negative possible shifts in anchovy L95 and anchovy mean weight in 1999/2000 (Figure 3d and e). 

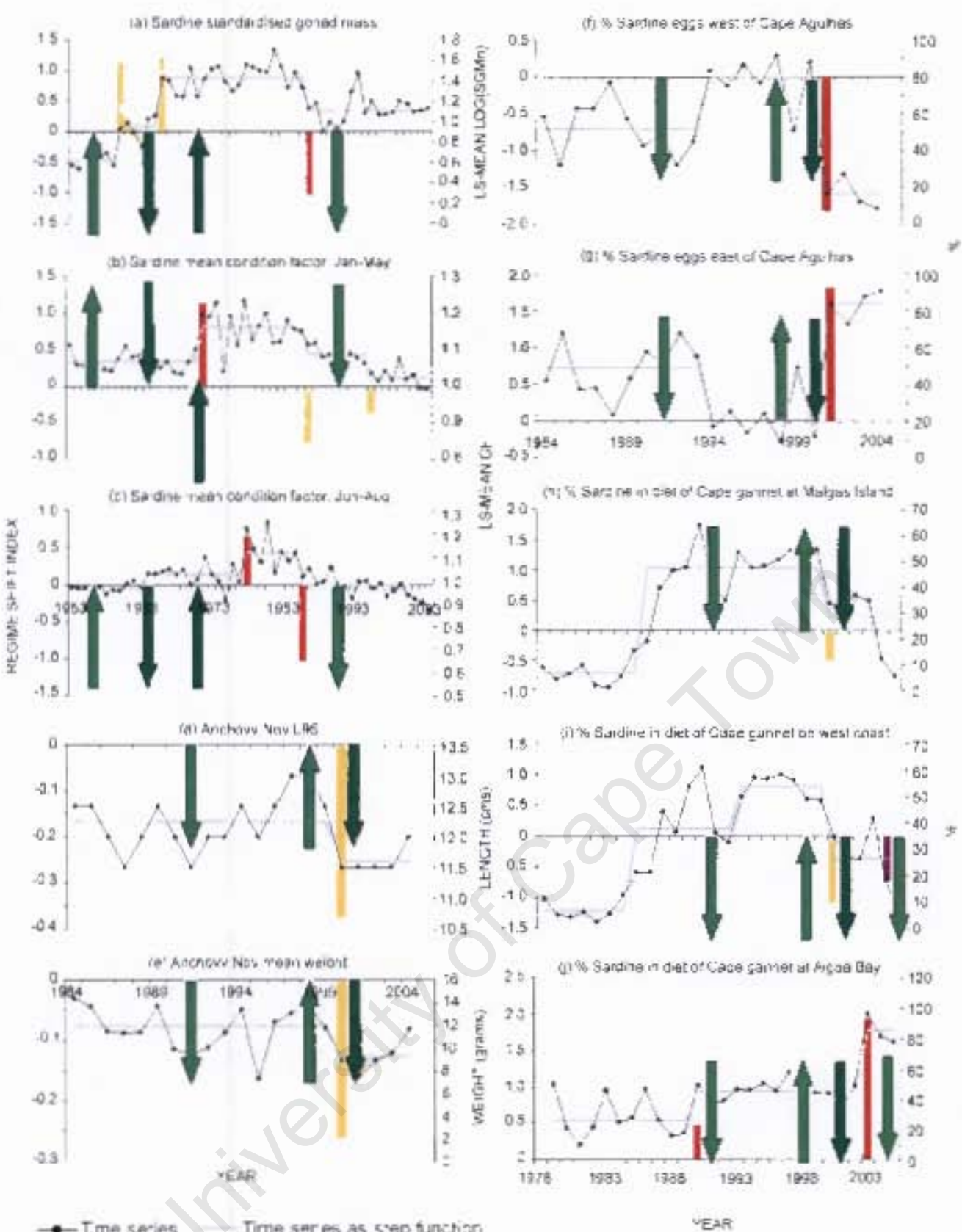

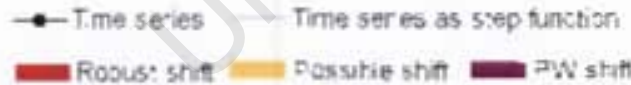

Figure 3: Results of STARS analysis showing the magnitude of shilts in RSI feoloured harsi, the ovenall time series (hlack line) and the weighted moth of obscrvalion state variahles (grey line) for (a) sardine standardiead gonad mass, sardine mears condition factor in (bi Jar-May and (c) Jurr-Aug. Surveyed anchovy (d) $L 95$ and (t) mean weiglt are giver. The $\%$ sardine cgess. (f) west and (g) cast of Cape Agulhas is shown. The \% sardixe in gannet diet is shown for (h) . Walgas [sland. (i) the west coast and (j) Algoa Bay. Light and dark greer arrows indicate prewhilened and possible shifts in upwelling at $30^{\prime \prime} S$ and at $32^{\circ} S$ respectiv thy. Down arrows jodicate negative shitts and vice versat. 
The positive possible shift in upwelling at $30^{\circ} \mathrm{S}$ was the only closely preceding upwelling shift, yet it is unlikely that this would be an explanatory factor.

\section{$\%$ Sardine eggs west and east of Cape Agulhas}

The positive possible shifts in upwelling at $30^{\circ} \mathrm{S}$ in 1998 may have been a factor in causing the 2000/01 negative shift in the \% of sardine eggs west of Cape Agulhas (Figure 3f). A negative possible shift at $32^{\circ} \mathrm{S}$ was detected in $2000 / 01$, though this was a very minor change in upwelling intensity so is unlikely to affect the spawning behaviour of sardine. No robust shifts in upwelling at $30^{\circ} \mathrm{S}$ or $32^{\circ} \mathrm{S}$ occurred before this shift in egg distribution.

\section{\% Sardine in diet of Cape Gannets}

There was no shift in upwelling that closely preceded the negative possible shifts in $\%$ sardine in gannet diet at Malgas Island (Figure 3h) and on the west coast, however there was a negative prewhitened shift in the $\%$ sardine in gannet diet on the west coast in $2003 / 04$ that follows the negative shift in upwelling at $32^{\circ} \mathrm{S}$ in $2000 / 01$ (Figure 3i). The robust shift in Algoa Bay cannot be compared to upwelling intensities recorded off the west coast (Figure 3j). 


\section{Appendix B}

\section{Modelled State variables compared to Benguela Niños}

\section{Sardine stock size VPA}

The positive prewhitened shift in sardine stock size occurred in 1959/60 ad cannot be linked to the Benguela Niño event in 1963. The 1963 event occurred one year after the 1962 negative possible shift in sardine stock size however the decline in sardine stock size had begun before 1962 (Figure 4a). The Benguela Niño was not the only factor causing the decrease in stock size. The Benguela Niño may have accelerated the decline. In contrast, the Benguela Niño of 1974 has no effect on sardine stock size, however the stock size is relatively constant at this time and not in a state of decline.

\section{Anchovy stock size VPA}

A positive robust shift in anchovy stock size was detected in 1972/73 and a negative robust shift in anchovy stock size occurred in 1979/80. The Benguela Niño of 1974 occurred between these two shifts but anchovy stock size remained relatively constant during that period (Figure 4b), therefore there appears to be little link between this Benguela Niño event and the shifts in anchovy stock size calculated by VPA.

\section{Anchovy spawner biomass}

A positive possible shift in modelled anchovy spawner biomass is detected in 1999/2000 (Figure 4c). The Benguela Nino of 1995 may have affected food availability and contributed to this large increase in spawner biomass, however the lag time is outside of maximum acceptable limits. 

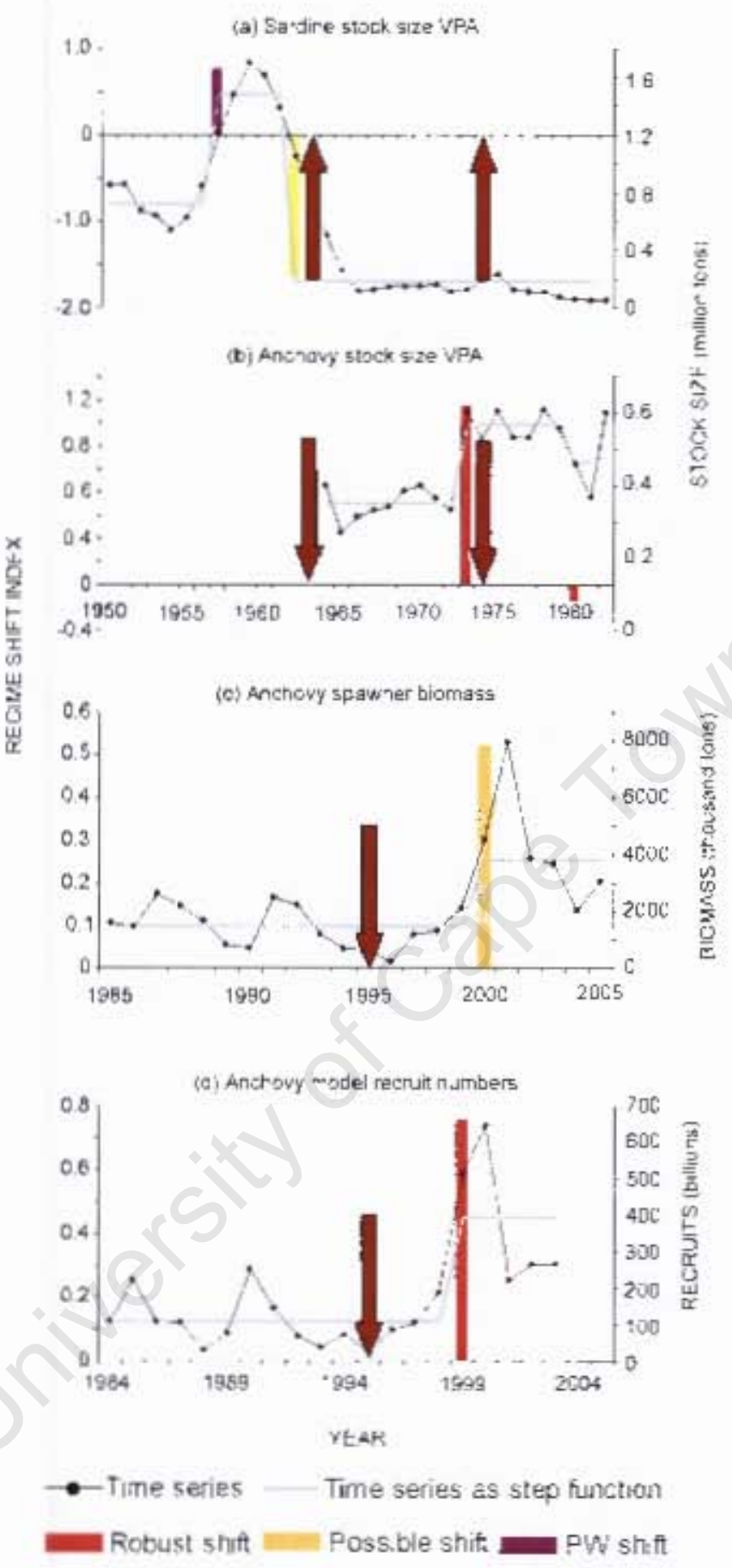

Figure 4: Results of S7ARS analysis stowing the magnitude of shilts in RS1 (coloured bars), the overall time series tblack line) and the weighted mean of observation state tariables (grey linel for (a) sardine stock size, (b) anchowy stock size, 4 c) anchovy spawner biutnass and (d) unchovy thodel recrujl numhers. 13rown arrows indicate Benguela Nino events (Table 1). Robust. prewhitened (PW) und possible shifts iclentitied by the STARS analysis are strowr. 


\section{Anchovy model recruit numbers}

Anchovy modelled recruit numbers showed a positive robust shift in $1999 / 2000$, too long after the 1995 Benguela Niño to be a causal factor (Figure 4d). There was no corresponding increase in anchovy recruit numbers after the 1984 Benguela Niño.

\section{Modelled State variables compared to SST anomalies at $30^{\circ} \mathrm{S}$ and $32^{\circ} \mathrm{S}$}

\section{Sardine stock size VPA}

A positive shift in SSTs occurred in 1956 at $30^{\circ} \mathrm{S}$ and $32^{\circ} \mathrm{S}$ and these shifts were three to five years prior to the positive prewhitened shift in sardine stock size, too large a lag time to be an explanatory factor (Figure 5a). Further positive shifts in SSTs later in the time series do not cause further negative shifts in sardine stock size.

\section{Anchovy stock size VPA}

A positive possible shift in SSTs in 1971 at $30^{\circ} \mathrm{S}$ was detected and was followed by a positive robust shift in anchovy stock size two years later, which was an acceptable lag time between an SST increase and a pelagic species responding (Figure 5b). There were no preceding shifts in SSTs at $32^{\circ} \mathrm{S}$ to the $1972 / 73$ stock size increase or the negative robust shift in stock size in 1979/80.

\section{Sardine and Anchovy model recruit numbers}

In 1991, a positive possible shift in SSTs at $32^{\circ} \mathrm{S}$ and a positive prewhitened shift at $30^{\circ} \mathrm{S}$ were detected, yet these shifts preceded the change in modelled sardine recruit numbers by six to seven years and this was too great a lag time for SST shifts to be an acceptable explanatory factor (Figure 5c). The SST shifts in 1991 were the only shifts prior to the robust positive shift in anchovy model recruit numbers and the lag time could not be accepted either (Figure 5d). 


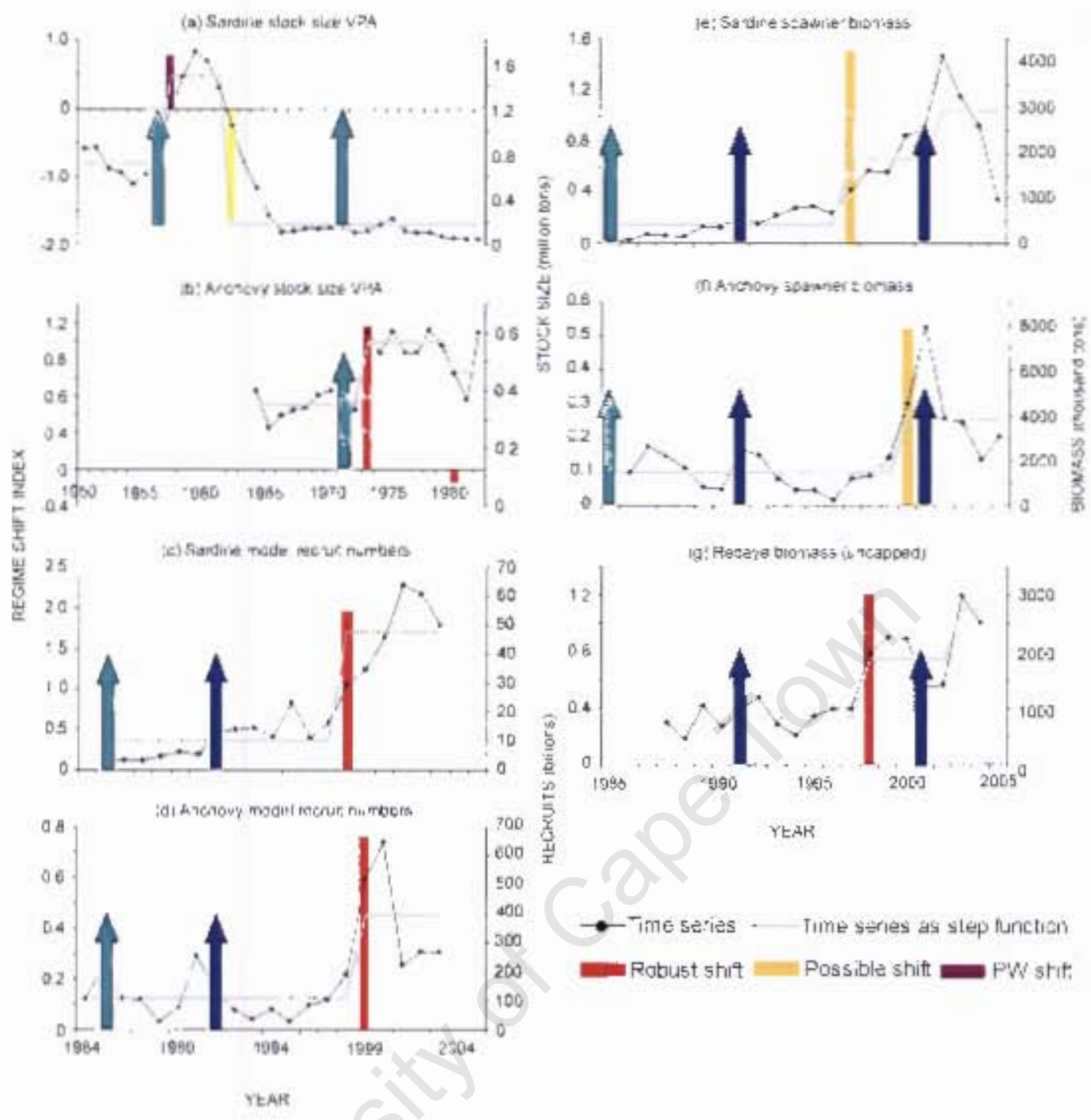

Figure 5: Results of SIARS analysis showing the maynitude of shifls in RSI (coloured bars). the overall time series (black line) and the weighted mean of observation state variahles (grcy linc) for (a) sardine slock sire irom VPA and (b) anchory slock siez from VPA. Model recruit numbers are given for (c) sardine and (di anchovy. Spawnur biomrass is shown for (e) sardine, (1) anchovy and (g) redeye. Dark bluc arrows indieate robust and possible shifits in SST at $32^{\circ} \mathrm{S}$ and light blue arrows indicate prewhitened shifts in SST at $30^{\circ} \mathrm{S}$. Arrows pointing up indicate positive shitts in SSI anomalies. Robust, prewhitened (PW) and possible shifts identified by the SI ARS analysis are shown. 


\section{Sardine, Anchovy and Redeye spawner biomass}

The positive possible SST shift at $32^{\circ} \mathrm{S}$ and the positive prewhitened SST shift at $30^{\circ} \mathrm{S}$ both occurred in 1991. The lag time between both these SST shifts and the positive possible shift in sardine spawner biomass that occurred in 1996/97 (Figure 5e), the possible shift in anchovy spawner biomass in 1999/2000 (Figure 5f) and the positive robust shift in redeye biomass of $1997 / 98$ (Figure $5 \mathrm{~g}$ ) was too long a period to be an explanatory factor in causing these shifts in pelagic species spawner biomass.

\section{Modelled State variables compared to Upwelling intensity at $30^{\circ} \mathrm{S}$ and $32^{\circ} \mathrm{S}$}

\section{Sardine stock size VPA}

A prewhitened shift in upwelling intensity at $30^{\circ} \mathrm{S}$ occurred in 1956 , three years before the positive prewhitened shift in sardine stock size (Figure 6a). All other shifts detected in upwelling anomalies occurred after the negative possible shift in sardine stock size in $1962 / 63$ except a possible shift at $30^{\circ} \mathrm{S}$, which preceded it by over ten years and so was disregarded in terms of a possible explanatory factor in causing this shift in sardine stock size.

\section{Anchovy stock size VPA}

None of the shifts in upwelling at $30^{\circ} \mathrm{S}$ occurred within an acceptable lag time before the positive robust shift in anchovy stock size, however a positive robust shift in upwelling intensity at $32^{\circ} \mathrm{S}$ was detected in $1971 / 72$ and preceded the shift in anchovy stock by one to two years (Figure 6b). This shift in upwelling falls within an acceptable lag time between oceanographic forcing and a response from the biological variable. However, a positive possible shift in upwelling at $30^{\circ} \mathrm{S}$ in 1979 was followed by a negative shift in anchovy stock size in 1979/80. 


\section{Anchovy spawner biomass}

A positive possible upwelling shift in 1998 at $30^{\circ} \mathrm{S}$ preceded the positive shift in anchovy spawner biomass by one to two years but a negative possible shift in upwelling which occurred in 1991, of equal magnitude to the 1998 possible shift, did not appear to have caused any change in anchovy spawner biomass (Figure 6c). Again there were no prewhitened or robust shifts in upwelling at $30^{\circ} \mathrm{S}$ or $32^{\circ} \mathrm{S}$, which preceded the increase in spawner biomass. 

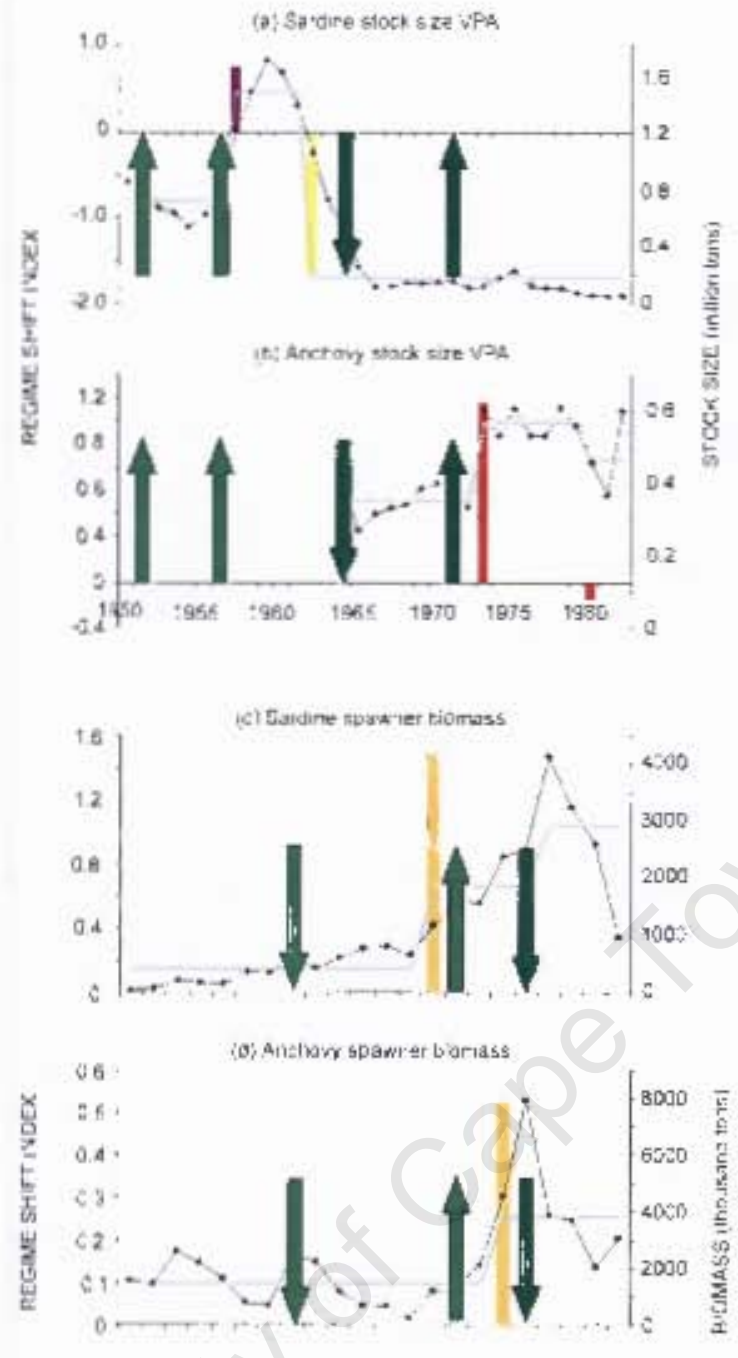

jel Redeye burrass liuntapped |

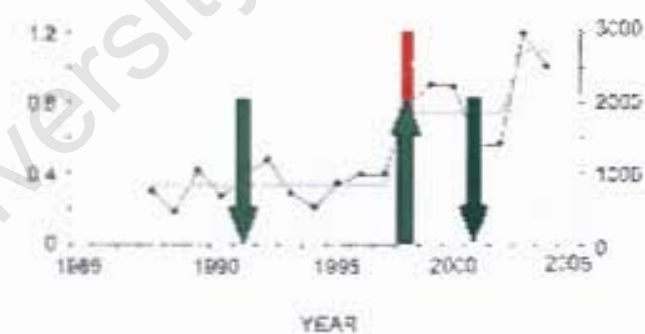

- Time seres Time senes as stef functian

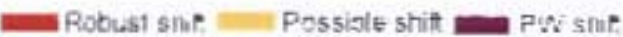

Figure 6: Results of STARS analysis shosing the magnitude of shifts in RSI (coloured bars), the overall time series (black line) and the weighted mesn of observation state variables (grey line) for stock size Irom VPA for (a) surdine und (b) unchowy. Spawner bionass is shown for (c) sardine, (d) ancbovy and (e) redeyc. Dark und light gren urrows indicalc robust and possible shifts in upwelling at $32^{\circ} \mathrm{S}$ and $30^{\circ} \mathrm{S}$ respectively. Arrows pointing up indicate positive slifts and vice versa. 


\section{Sardine spawner biomass}

In 1998, the positive possible shift in sardine spawner biomass occurred before the positive possible shift in upwelling at $30^{\circ} \mathrm{S}$, therefore this shift could not be linked to the sardine spawner biomass increase (Figure 6d). No robust or prewhitened shifts in upwelling at either $30^{\circ} \mathrm{S}$ or $32^{\circ} \mathrm{S}$ were detected within an acceptable lag time response between these environmental and biological variables.

\section{Redeye biomass (uncapped)}

The positive possible shift in upwelling in 1998 at $30^{\circ} \mathrm{S}$ occurred in the same year as the robust shift in redeye biomass (Figure 6e), this is a rapid response for a pelagic species to increase its biomass within the same year as a change in oceanographic conditions. All robust and prewhitened upwelling shifts at $30^{\circ} \mathrm{S}$ or $32^{\circ} \mathrm{S}$ occurred many years prior, or some years after, this shift in redeye biomass. 


\section{Appendix C}

\section{State variables compared to Anthropogenic forcing variables}

\section{Observed state variables compared to sardine landings (1950-2005)}

A positive possible shift in sardine landings occurred in 1957/58 and a negative prewhitened shift occurred in 1963/64 and a positive prewhitened shift occurred in $2000 / 01$

\section{Sardine mean condition factor and standardised gonad mass}

The positive possible shift in sardine landings in $1957 / 58$ occurred two years prior to the positive possible shift in sardine gonad mass, however the negative prewhitened shift in sardine landings in 1963/64 also occurred two years before a possible positive shift in sardine gonad mass (Figure 7a), this removed sardine landing shifts as an explanatory factor affecting sardine gonad mass. There was no recently preceding shift in sardine landings to the negative robust shift in sardine gonad mass in 1986/87. There were no recent preceding shifts in sardine landings prior to the positive or negative robust shifts in sardine condition factor (Jan-May) or (Jun-Aug) (Figure 7b and $\mathrm{c}$ ).

\section{$\%$ Anchovy in diet of Cape Gannets}

The positive prewhitened shift in sardine landings in 2000/01 occurred two years before a decrease in \% anchovy in the diet of Cape gannets in Algoa Bay (Figure 7d). On the west coast and at Lambert's Bay, a positive prewhitened and robust shift in \% anchovy in the diet of Cape gannets was detected four years after the increase in sardine landings (Figure $7 \mathrm{e}$ and $\mathrm{f}$ ). This difference in response makes it clear that sardine landings alone were not the cause of such shifts in gannet diet. 

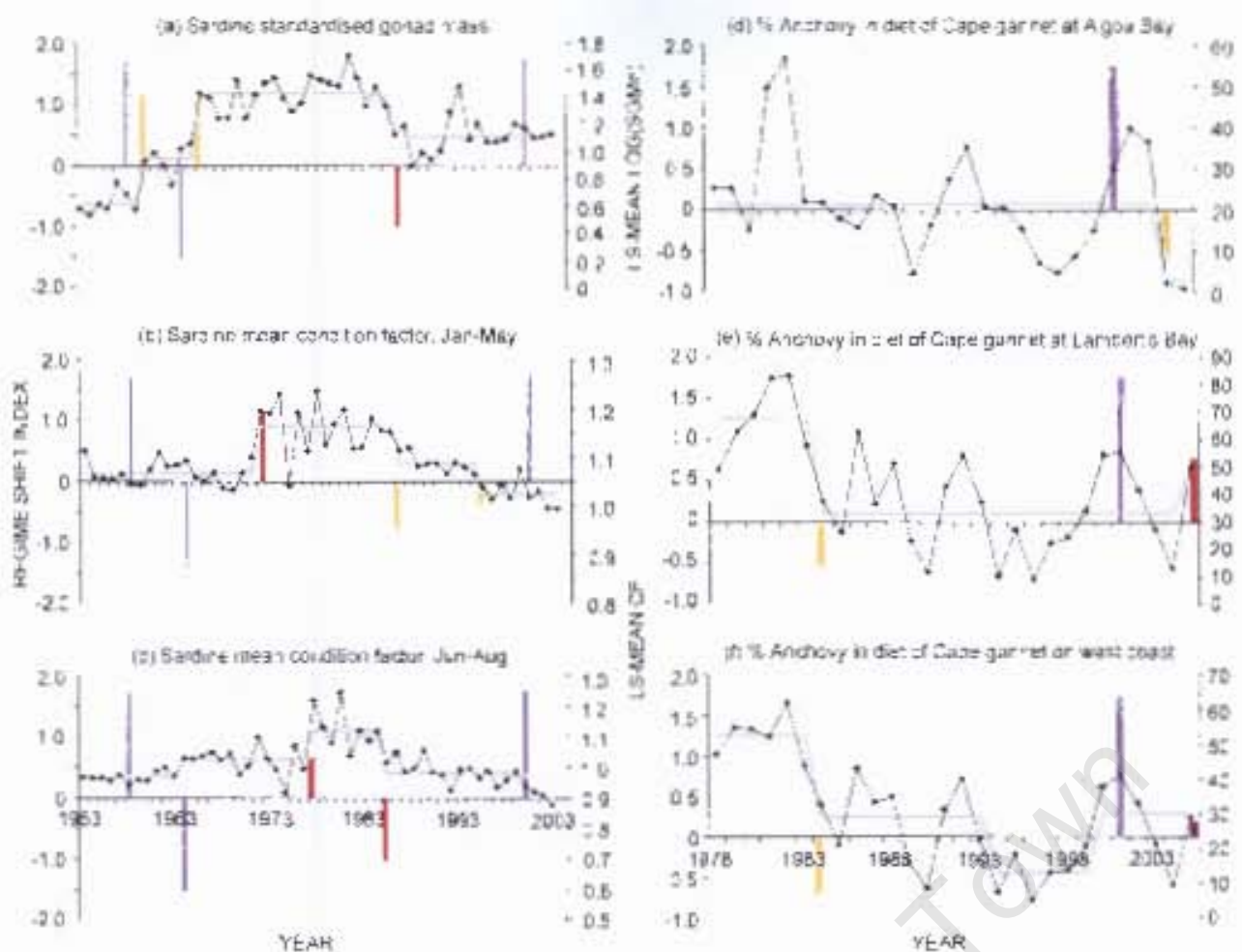


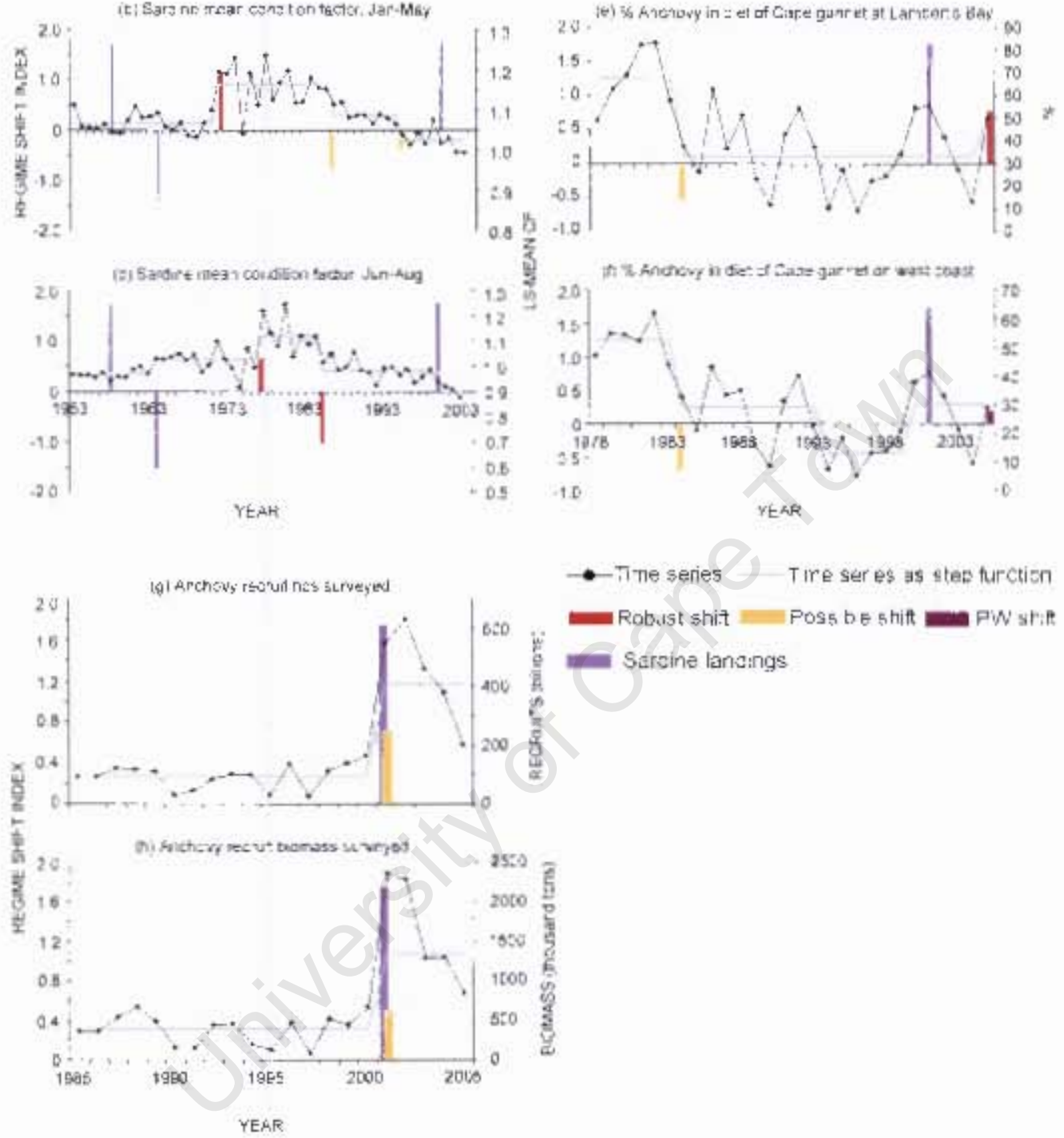

- Titne series - Tire ser es as stes furction

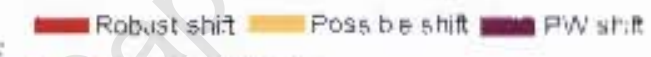
warsine lansings

Figure 7: Results of STARS unalysis khowing the magnitude of shitls in RSI (cotourud hurs), the overabl time serics thlack line) and the weighted inean of obserwulion slate sariables (grey line) for (a) sardine stundardised gonad mass, (b) sardine mean condition tactor, lan-May and (c) sardine meun condition factor, Jar-Aug. The $\%$ anchovy in Cape gannet diet is given for (d) Algoa Bay. fc) Lumbert's Bay and (f) the west coast. Anchovy surveyed recruicment is given in terms of (g) numbers and (h) biounass. Robuce pretshitened (PW) and possible shilis idencified by the SIARS anabysis are shown. 


\section{Anchovy recruit numbers and biomass surveyed}

The positive possible shift in anchovy recruit biomass and numbers in 1999/2000 occurred one year before the increase in sardine landings in 2000/01 (Figure $7 \mathrm{~g}$ and h). Since then, both recruit variables have decreased to similar levels as those before the positive shift of 2000 .

\section{$\%$ Sardine eggs west and east of Cape Agulhas}

The positive prewhitened shift in sardine landings in 2000/01 occurred in the same year as the negative shift in the \% of sardine eggs west of Cape Agulhas (Figure 8a). This appears too short a lag time to have directly affected egg distribution in the same year, however it is still unclear what has influenced the shift in egg distribution.

\section{Anchovy Nov L95 and Anchovy Nov mean weight}

The negative possible shifts in anchovy L95 and mean weight in 1999/00 and the positive prewhitened shift in sardine landings in 2000/01 cannot be linked, as the anchovy shifts occurred prior to the shift in this pressure variable (Figure $8 \mathrm{c}$ and d). Both anchovy L95 and mean weight were decreasing several years prior to the sardine landings shift.

\section{Modelled state variables compared to sardine landings (1950-2005)}

\section{Anchovy stock size VPA}

The negative prewhitened shift in sardine landings in 1963/64 cannot be linked to the positive robust shift in anchovy stock size in $1972 / 73$ or the negative robust shift in anchovy stock size in $1979 / 80$ and therefore was not a factor in explaining such shifts (Figure 8e). 

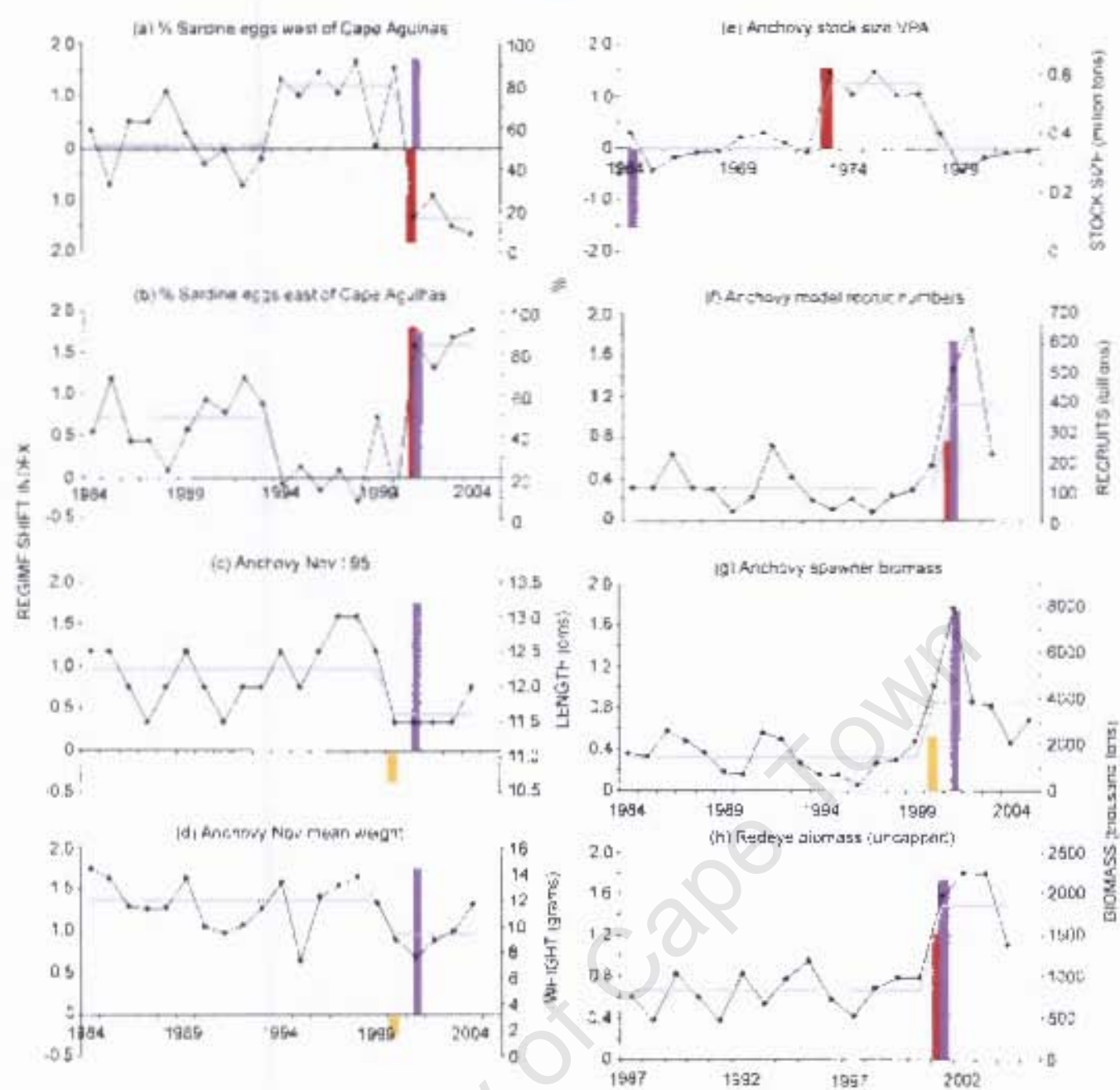

- Time senes Time series as step s. vchan

Easbust snith Wassible shiff ans Sarding landings

Figure 8: Results of STARS analysis showing the magnitude of shifls in RSI tcoloured hars), the ovcrall time scries (black line) and the weighted ncan of ubscrvation statc variables (grey line) for the \% of sardine egg (ii) west of Cupe Agulbas and (b) east of Cape Agulthas, Suryeyed unchuvy, (c) L95 and (d) mean weight are given. Anchosy stock size from VPA, fe) and anchory model recruit numbers, ( $f$ ) are given. Spawner biomass is sbown for $(\mathrm{g})$ anchovy and (h) redeye, Robust, prewhitened (I'W) and possible shifis ident ilied by the STARS analysis are shown. 


\section{Anchovy model recruit numbers}

There was no link between the shift in sardine landings and anchovy model recruit numbers as the shift in landings occurred after the shift in recruit numbers (Figure 8f).

\section{Anchovy and redeye spawner biomass}

There was no link between sardine landings and anchovy and redeye spawner biomass as no robust shift occurs during this time period and the prewhitened shift in sardine landings of 2000/01 occurs after shifts in the spawner biomass of these two species (Figure $8 \mathrm{~g}$ and $\mathrm{h}$ ).

\section{Observed state variables compared to anchovy landings (1950-2005)}

No robust or prewhitened shifts were detected in anchovy landings data using STARS analysis, however possible shifts were detected in 1963/64, 1978/79 and 1999/00.

\section{Sardine mean condition factor and standardised gonad mass}

A positive possible shift in anchovy landings occurred in $1963 / 64$, two years before a positive possible shift in sardine gonad mass (Figure 9a). There were no other closely occurring shifts in anchovy landings and shifts in sardine gonad mass or mean condition factor (Figure $9 \mathrm{~b}$ and $\mathrm{c}$ ).

\section{$\%$ Sardine and Anchovy in diet of Cape Gannets}

There appears to be no link between the increase in anchovy landings in 1999/00 and the negative possible shift in $\%$ sardine in gannet diet on the west coast and the negative prewhitened shift at Malgas Island (Figure 9d and e), both of which occurred in 2003/04. At Algoa Bay a positive shift in \% sardine in gannet diet was detected in 2002/03 (Figure 9f). A positive possible shift in anchovy landings was detected in $1999 / 00$, however this shift appears to not be linked with the \% anchovy in gannet 

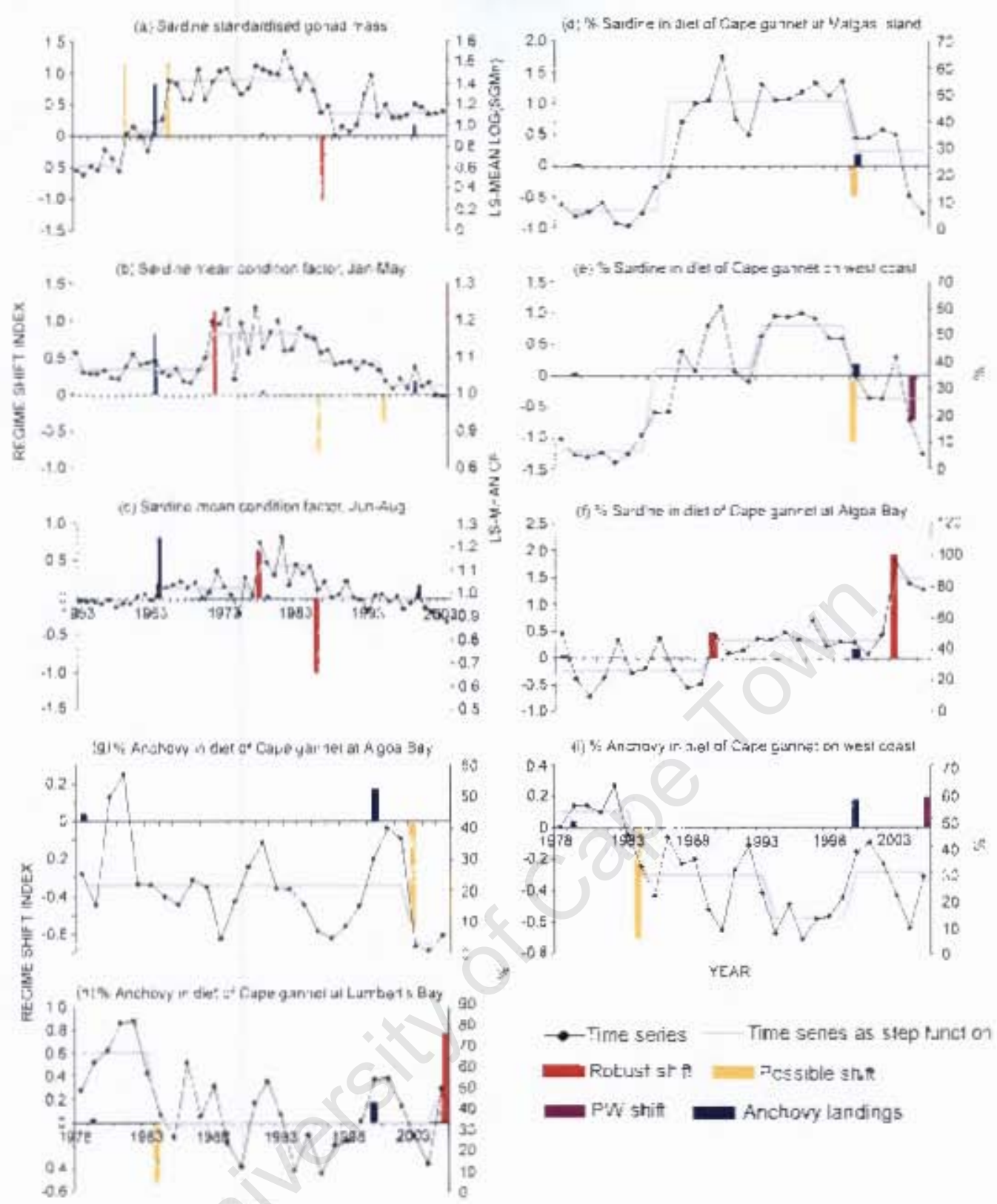

Figure 9: Results of STARS analysis showing the mugnitude of shitts in RSI (colourcd bars), the overall time series (black line) and the weighed mean of (obscrvation state variaties (grey line) for (a) sardine standardised gonad mass, sardine mcan condition tactor. (b) Jan-May and (c) Jum-Aug. The \% sardine in Cape gannet diet is given for (d) Malgas lsland. (e) the west coasl and (1) Algoa Bay. The \% anchevy in gannet diet is given for (L) Alyou Bay, (h) Lambert's Bay and (i) the vest coast. Robust, prewhitened $(P W)$ and possible shitts identifled by the STARS analysis ure shour. 
diet on the west coast or at Algoa Bay (Figure $9 \mathrm{~g}$ and i). On the west coast and specifically at Lambert's Bay, a positive prewhitened and a positive robust shift in gannet diet of anchovy occurred in 2004/05, respectively (Figure 9h and i). In Algoa Bay a negative possible shift in gannet diet of anchovy occurred in 2002/03 (Figure $9 \mathrm{~g})$.

Copepod abundance (1950-1967) and (1988-2005)

The positive possible shift in anchovy landings in 1963/64 occurred one year before a positive robust shift in four of the five zooplankton groups (Figure 10a-d). A positive possible shift in anchovy landings in 1999/00 was followed a year later by a negative possible shift in cyclopoid copepods and total copepods (Figure 10e and g). Other shifts in copepods occurred after too great a lag time for there to be any links (Figure $10 f)$.

\section{Anchovy Nov L95 and Anchovy Nov mean weight}

The negative shift in anchovy L95 and mean weight in 1999/00 occurred in the same year as the positive possible shift in anchovy landings (Figure 10h and i), however a longer lag time between the changes in the two variables would be expected. After the negative possible shift in anchovy landings in 1989/90 there was no corresponding shift in anchovy L95 or mean weight.

\section{Anchovy recruit numbers and biomass surveyed}

A positive possible shift in both variables occurred in $1999 / 00$, the same year as a smaller positive possible shift in anchovy landings (Figure 11a), which is assumed to be due to good year classes, resulting in the shift at this time. Therefore the positive shift in anchovy recruits has possibly caused the positive shift in anchovy landings. 

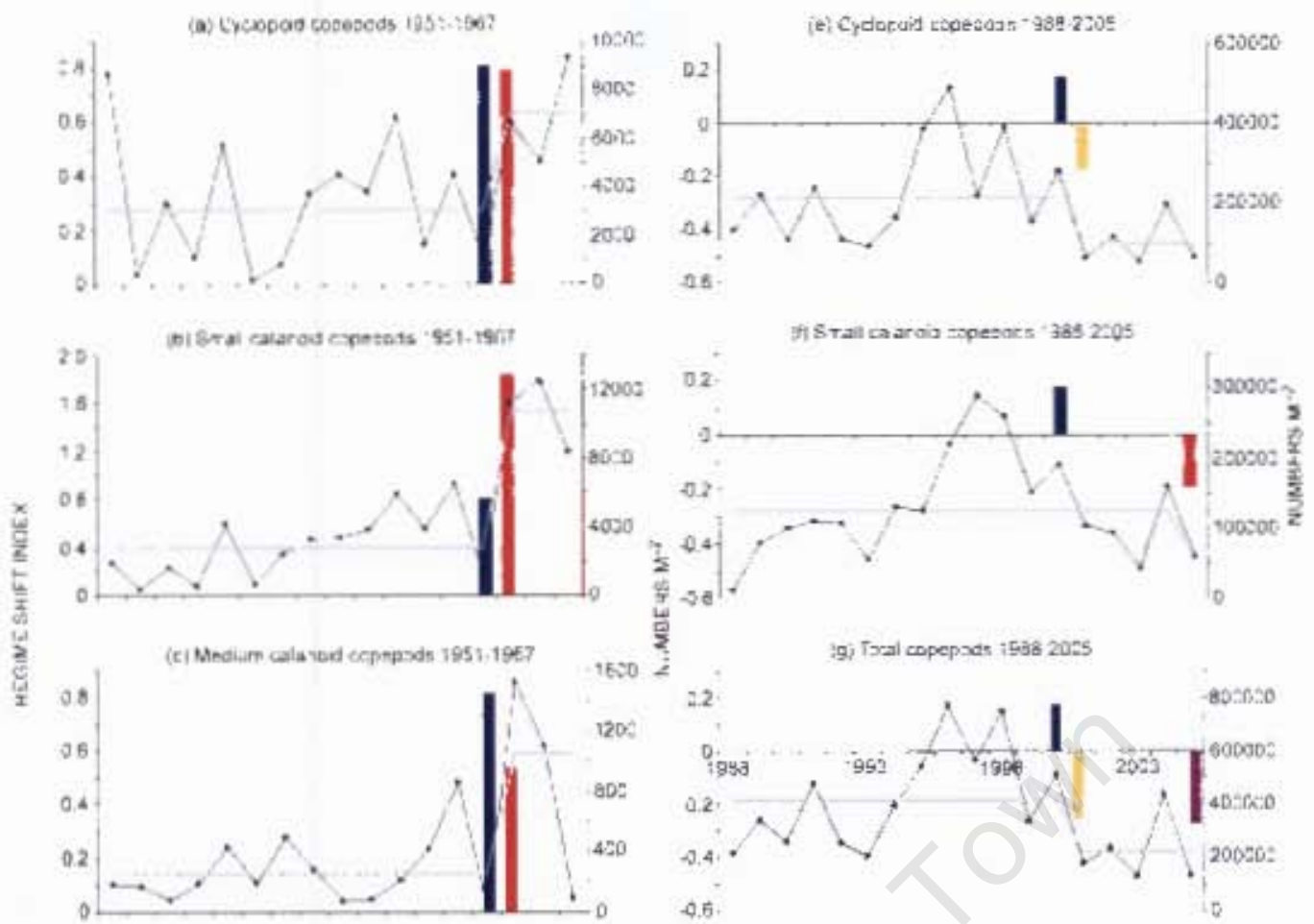
$\frac{1}{2}$
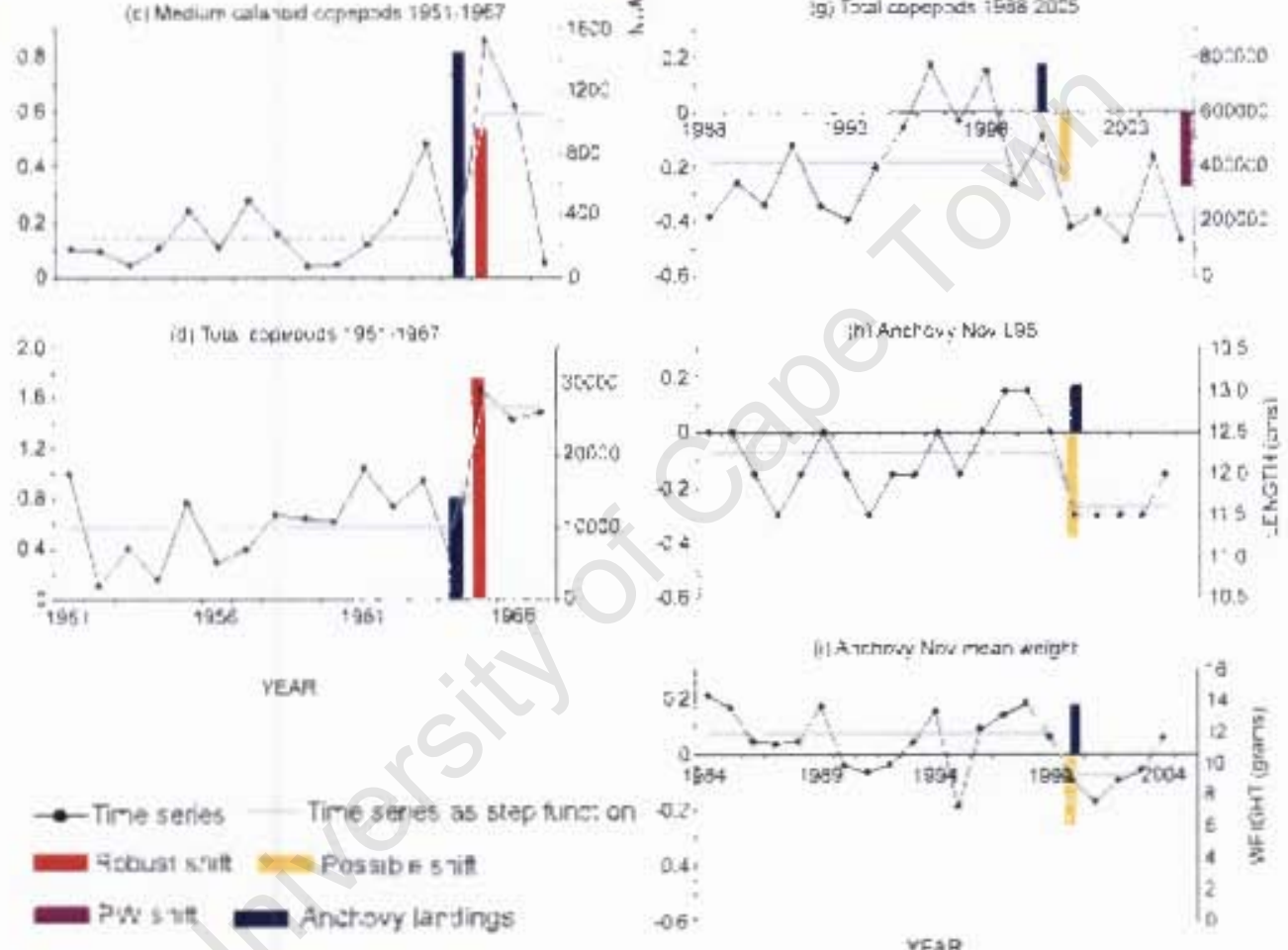

Figure 10: Results of STARS analysis showing the magnitude of shifts in RSI (coloured bars), the werall time series (black line) and the weighted mean of absersation state variables tgrey line) for (a) cyclopois copupods 1951-1967, (b) small cadunoid copepods 1951-1967, (c) medium talanoid copepods 1951-1967 and (d) tolal copcpods 1951-1967, Copepod abundance (1988-2005) is given in terns of (c) cyclopoid copepods, (f) small ealanoid copeponds and (g) toral copepords. Surveyod

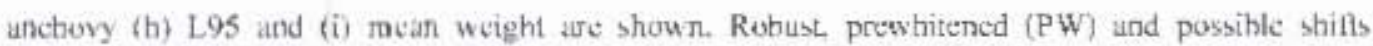
identitied by the STARS analysis ure shown. 
$\%$ Sardine eggs west and east of Cape Agulhas

The possible increase in anchovy landings in 1999/00 occurred one year before the change in distribution of sardine eggs from west of Cape Agulhas to east of Cape Agulhas (Figure 11b). However if anchovy landings were affecting sardine egg distribution it would affect the distribution both east and west of Cape Agulhas.

\section{Modelled state variables compared to anchovy landings (1950-2005)}

\section{Sardine and Anchovy stock size VPA}

The shift in anchovy landings occurred after the shifts in sardine stock size, therefore no link could be made (Figure 11c). There is no recently preceding shift in anchovy landings that could be linked to the positive robust shift in anchovy stock size in 1972/73. A positive possible shift in anchovy landings occurred in 1978/79, five years after a positive robust shift in anchovy stock size and one year after the positive shift in landings, anchovy stock size was shown to undergo a negative robust shift (Figure 11d).

\section{Sardine and Anchovy model recruit numbers}

There was no link between anchovy landings and sardine model recruit numbers (Figure 1le). The positive shift in anchovy model recruit numbers in 1999/00, may have caused the positive shift in anchovy landings in the same year (Figure 11f).

\section{Sardine Anchovy and Redeye spawner biomass}

There was no link between anchovy landings and shifts in sardine or redeye spawner biomass (Figure $11 \mathrm{~g}$ and i). In 1999/00, a positive possible shift in anchovy spawner biomass occurred and may have been linked to the positive possible shift in anchovy landings (Figure $1 \mathrm{lh}$ ). 

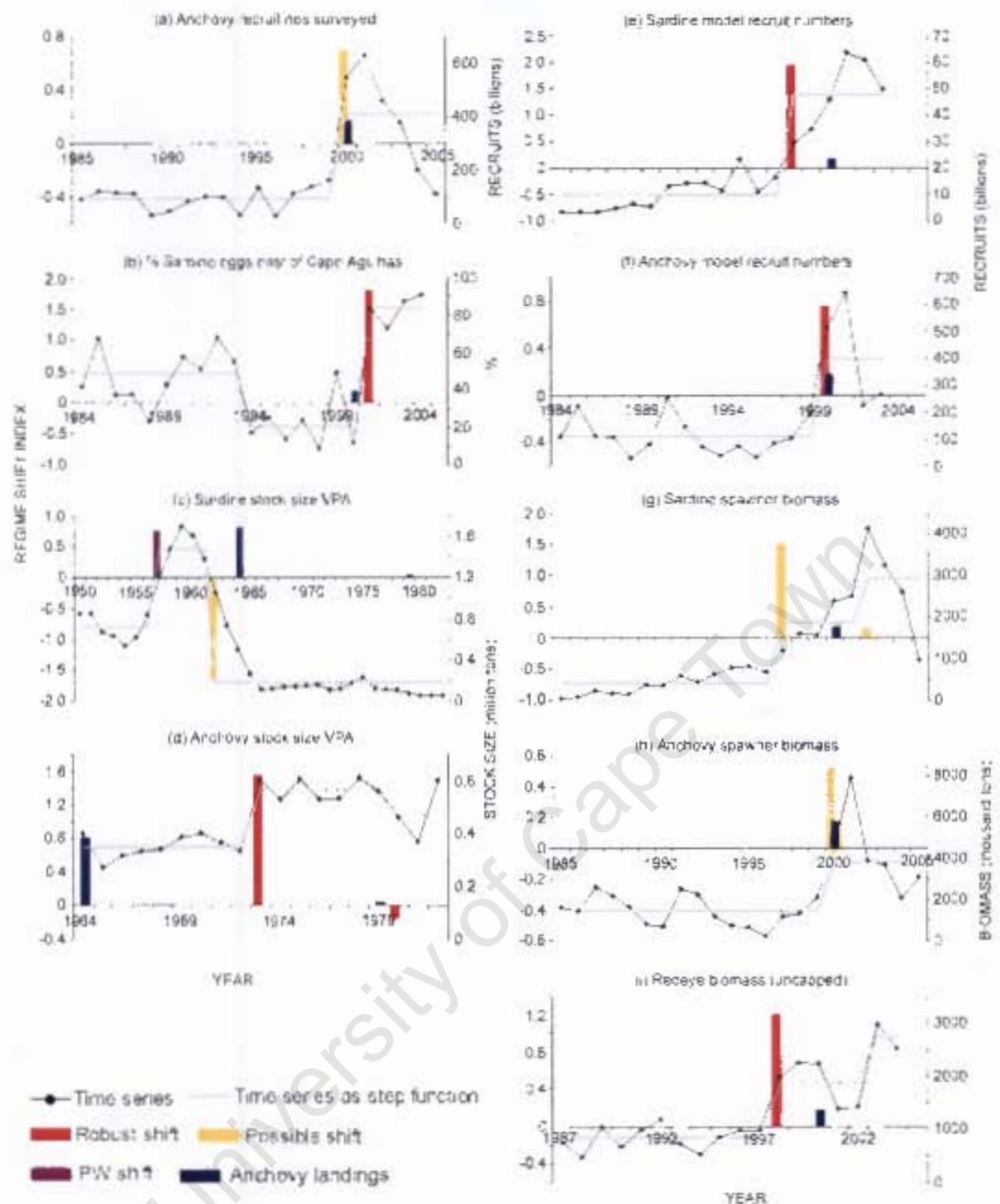

Figure 11: Results of STARS analysis shosing the magnitude of shitts in RSI (coloured bars), the overall time series (black line) and the weighted mean of observation slate variables (grey line) for (u) anchory surveyed recruit numbers and (b) the $\%$ of sardine eggs cast of Cape Agulhas. Stock size from VPA is given for (e) sirdine and (d) unchovy. Model recruit nurnhers are giten for ( $e$ ) sardine and (t) anchovy. Spuwner bionass is shown for (2) sardine, (h) anchovy and (i) redeye. Robust. prewhitened (PW) and possible shifts identified by the STARS analysis are shown. 


\section{Observed state variables compared to Horse mackerel purse-seine landings (1950-2005)}

Negative prewhitened shifts in horse mackerel purse-seine landings were detected in $1955 / 56$ and 1962/63. A negative possible shift was detected in 1957/58.

\section{Sardine mean condition factor and standardised gonad mass}

The two negative prewhitened shifts in horse mackerel purse-seine landings in $1955 / 56$ and 1962/63 precede positive possible shifts in sardine standardised gonad mass in $1959 / 60$ and $1965 / 66$, yet appear to have little linkage (Figure 12a). There appears to be little link between the negative shifts in horse mackerel purse-seine landings and the robust shifts in sardine mean condition factor which occurred in $1971 / 72,1977 / 78$ and 1979/80 and occurred outside of maximum acceptable lag times between the two variables (Figure 12b and c).

All other observed state variables time series do not overlap with the prewhitened shifts in horse mackerel pelagic landings, therefore no comparisons can be made.

\section{Modelled state variables compared to Horse Mackerel purse-seine landings (1950-2005)}

\section{Sardine stock size VPA}

The shift in horse mackerel purse-seine landings occurred after the shifts in sardine stock size and therefore cannot be an explanatory factor (Figure 12d).

All other modelled state variables time series do not overlap with the shifts detected in horse mackerel purse-seine landings, and so comparisons cannot be made. 


\section{Observed state variables compared to Fisheries on large Horse Mackerel (1950-2003)}

Two possible shifts were detected in landings from fisheries on large horse mackerel, a positive possible shift in 1969/70 and a negative prewhitened shift in 1992/93.

\section{Sardine mean condition factor and standardised gonad mass}

The 1969/70 positive possible shift in landings from fisheries on large horse mackerel occurred after the shifts in sardine gonad mass so cannot be a contributing factor to this variable (Figure 12e). There is no shift in large horse mackerel catches recently preceding the negative robust shift in sardine gonad mass in 1986/87. The 1969/70 shift in large horse mackerel catches precedes the positive robust shift in sardine condition factor (Jan-May) by two years (Figure 12f).

A political explanation caused the shift in large horse mackerel landings in 1992/93, and the positive possible shift in large horse mackerel landings in 1969/70 does not overlap with the time series of all other observed state variables and so cannot be compared.

\section{Modelled state variables compared to Fisheries on large Horse Mackerel (1950-2003)}

\section{Sardine and Anchovy stock size VPA}

A negative possible shift in sardine stock size occurred in 1963, six years before the positive robust shift in large horse mackerel landings (Figure 12h). The lag time is too great for a link to be derived. Three years after the positive possible shift in landings of large horse mackerel in 1969/70, a positive robust shift was detected in anchovy stock size (Figure 12i). 

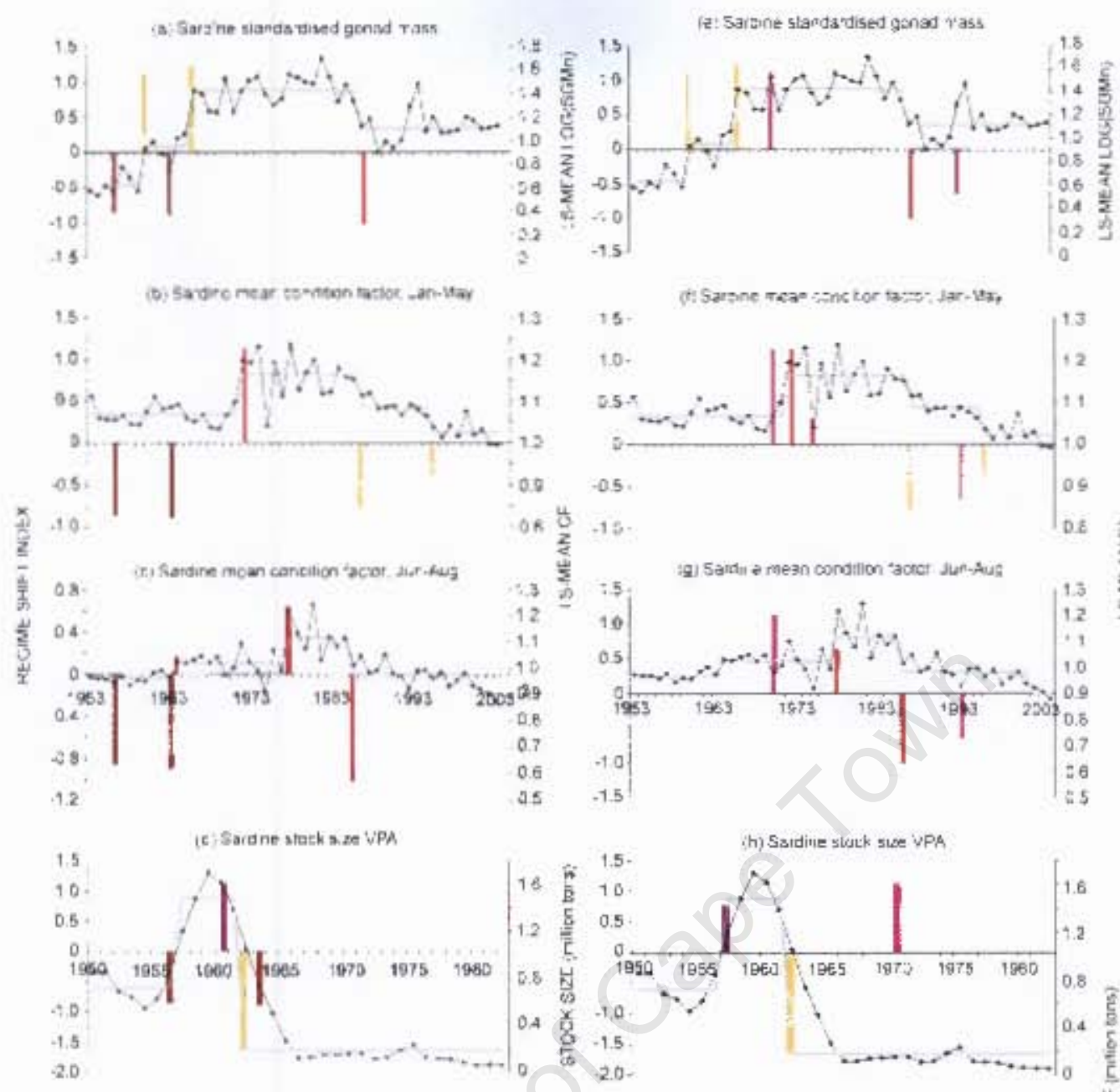

EAR

in Anithery stack sas WFA
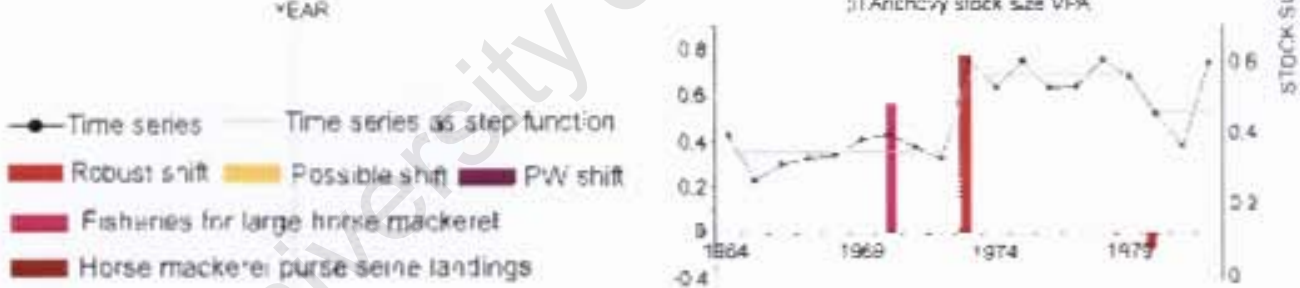

YEAF

Figure 12: Results of STARS unalysis showing the magnitude of shifts in RSI (coloured hars), the overall time series (black line) and the weighted mean of ubservation slate variables (grey lins) for (a) sandine standardised gonad muss, (b) surdine muan condition Eactor, Jan-May, (c) sardine mean condition fuctor, Jum- $A$ ug and (d) sardine stock size from v'P. These are compared to horse mackerel purse scine lunding shifts. Sardine standardised gonad mass (e), sardine mean condition factor, Jar)Muy (f), sardint mean condition factor, Jun-Aug (g), sardine stock size from VPA (h) and anchovy stock size ltom VPA (i) are compared to fisheries for large horse mackerel. Robust, prewhitened (PW) and possible shifts identifed by the STARS analysis are show' 
All other modelled state variables time series are too recent to overlap with the robust shifts in large horse mackerel landings, and so comparisons cannot be made.

\section{Observed state variables compared to demersal landings (1950-2003)}

Two robust shifts in demersal landings were detected in $1964 / 65$ and $1973 / 74$. A possible shift was detected in 1958/59.

\section{Copepod abundance (1950-1967)}

The positive robust shift in demersal landings in $1964 / 65$ occurred in the same year as the positive robust shift in copepods (Figure 13a-d), which would be a more rapid reaction time than would be expected if changes in demersal landings was affecting copepod abundance.

\section{Sardine mean condition factor and standardised gonad mass}

A positive possible shift in $1958 / 59$ and a positive robust shift in $1964 / 65$ in demersal landings preceded two positive possible shifts in sardine standardised gonad mass by one year (Figure 13e). Positive robust shifts in sardine mean condition factor occurred in $1971 / 72$ (Jan-May) and $1977 / 78$ (Jun-Aug), and so appear not to be linked to changes in demersal landings (Figure $13 \mathrm{f}$ and $\mathrm{g}$ ). There are no shifts in demersal landings in the mid 1980s when shifts in sardine gonad mass and condition factor occurred.

No shifts in demersal landings were detected after 1973/74, therefore no comparisons can be made with all other observed state variables, as the time series of these variables do not overlap. 
Modelled state variables compared to demersal landings (1950-2003)

Sardine and Anchovy stock size VPA

There was no link between demersal landings and sardine stock size as shifts in demersal landings occurred three and 13 years after the shift in sardine stock size (Figure 13h). The negative robust shift in demersal landings in 1973/74 occurred one year after the positive robust shift in anchovy stock size (Figure 13i), and may have been caused by a decline in demersal species.

All other modelled state variables time series do not overlap with the shifts in demersal landings, and so comparisons cannot be made. 

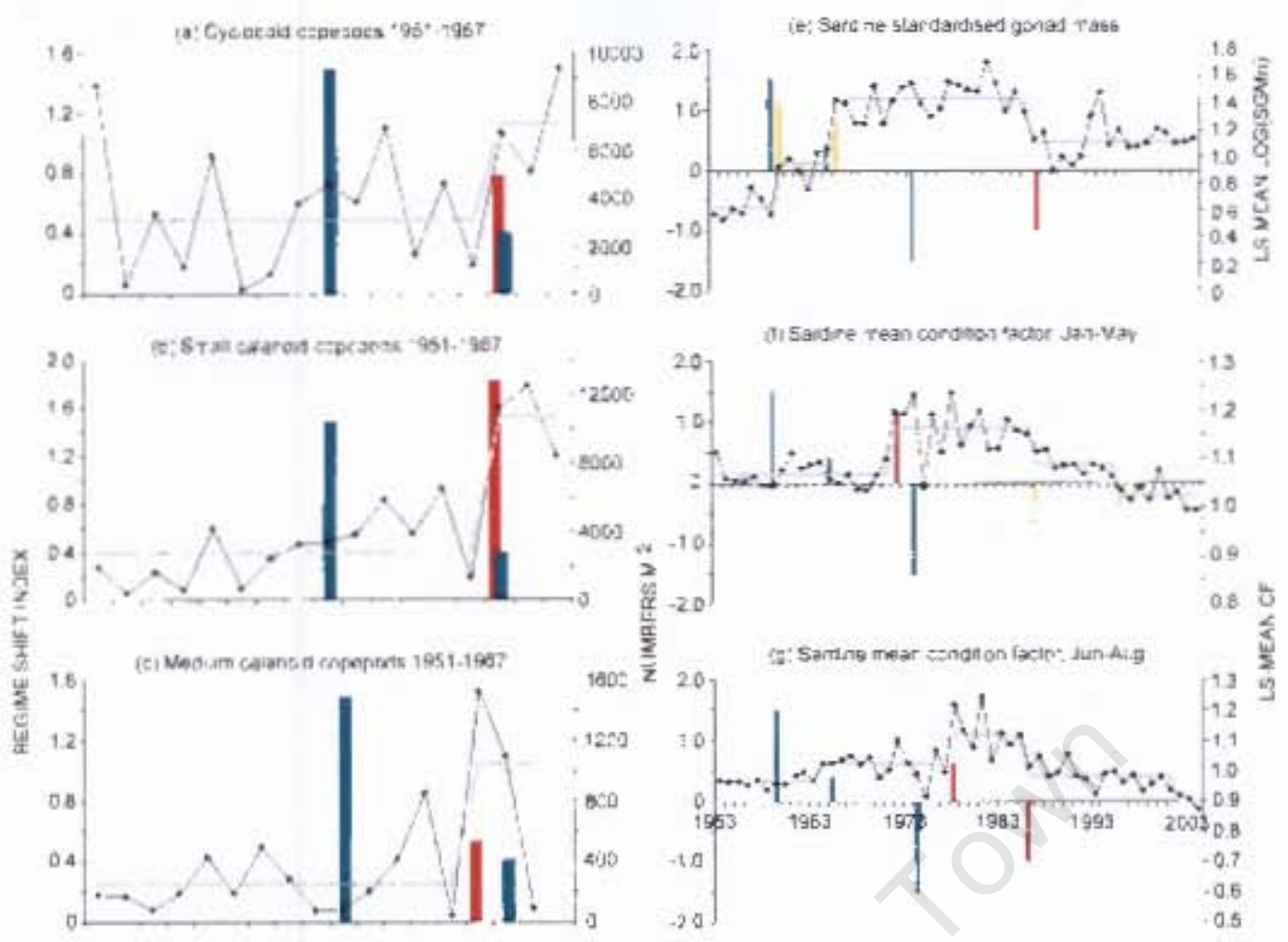

il Saidre tean condhos tactor Ja-7-Vay
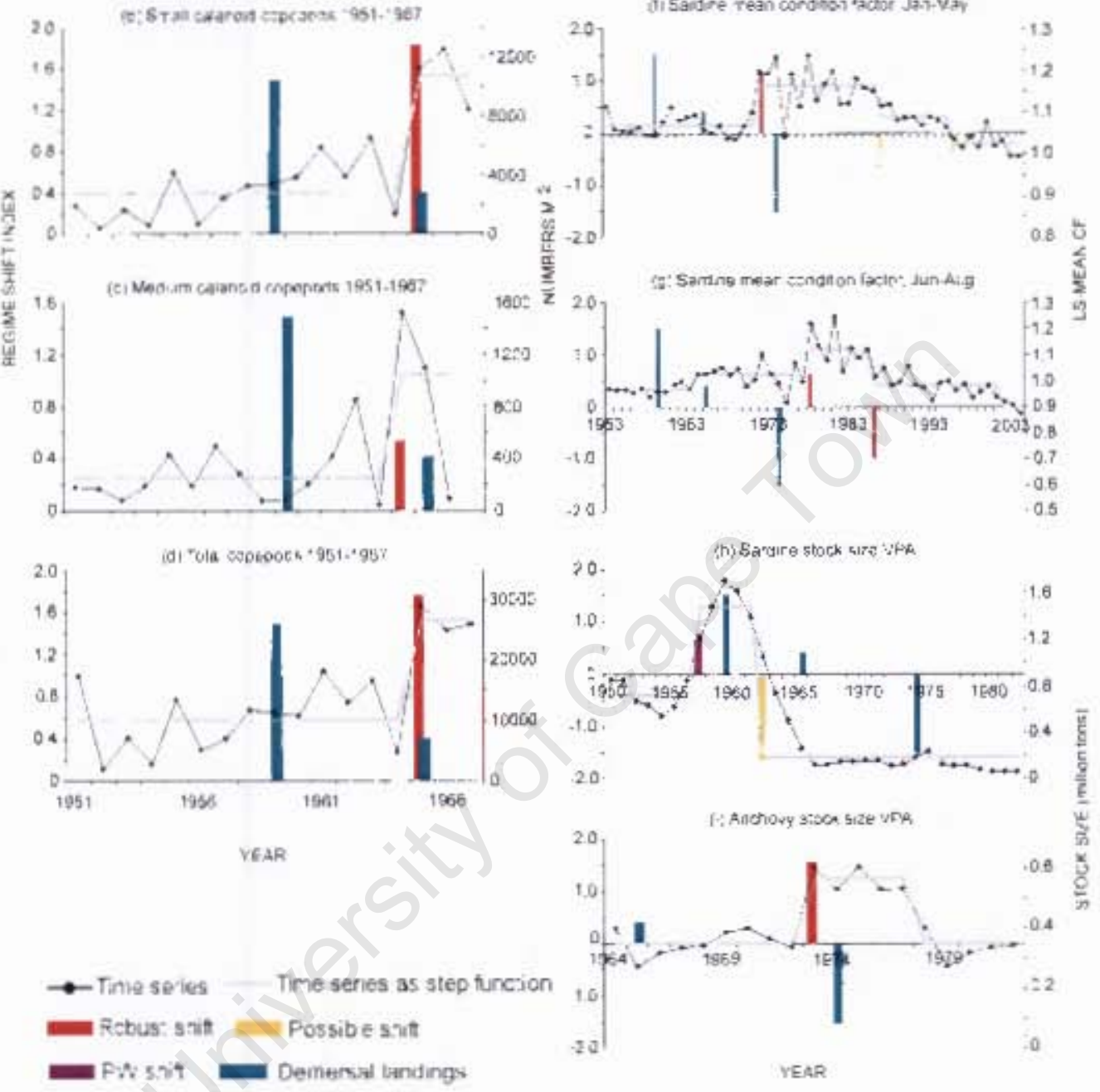

Figure 13: Results of STARS analysis showing the magnitude of shifts in RSI (coloured bars), the overull cime seties (black line) and the neightid meart of observationt slate variables (grey line) for (a) cyclopoid conepads 1951.1967, (b) senall calanoid copopods $1951 \cdot 1967$, (c) medium calanoid copepods 1951-1967 and (d) total copepods 1951-1967. Sardine standardised gonad mass (e), sardine mean condition factor, Jan-May (f). sardine mean condition factor. Jun-Aug (g), sardine stock size from VPA (h) and anchowy stoch size from VPA (i) are shown. Robush, prewhitened (IיW) and possible shifts identified by the SI ARS analysis are shown. 


\section{Appendix D}

\section{Observed and modelled state variables compared to Sardine and}

Anchovy mean length and L95 (1987-2004)

\section{Observed state variables compared to Sardine mean length landed}

\section{Sardine mean condition factor and standardised gonad mass}

A positive robust shift in the mean length of sardine landed occurred in 1995/96, seven years after the negative robust shift in sardine gonad mass (Figure 14a). A negative possible shift in sardine mean condition factor (Jan-May) occurred in the same year as the positive robust shift in the mean length of sardine landed (Figure 14b), however the lag time between these two variables is too short to be an explanatory factor. There were no shifts in the mean length of sardine landed at the time of the robust shifts in sardine mean condition factor (Jun-Aug) (Figure 14c).

\section{$\%$ Sardine eggs west and east of Cape Agulhas}

The positive robust shift in 1995/96 in the mean length of sardine landed occurred six years before the negative robust shift in the $\%$ of sardine eggs west of Cape Agulhas (Figure 14d). It is unlikely that this forcing variable would be an explanatory factor in this case.

\section{$\%$ Sardine in diet of Cape Gannets}

The positive robust shift in $1995 / 96$ in the mean length of sardine landings occurred four years before the negative possible shifts in the \% sardine in gannet diet at Malgas Island and on the west coast (Figure $14 \mathrm{f}$ and $\mathrm{g}$ ). The positive shift in mean length of sardine landings occurred seven years before the positive robust shift in $\%$ sardine in 



Figure 14: Resules of STARS analysis showsing the magnilude of shifts in RSI (coloured hars), the overall time series (black linc) and the weighted mean of obscrvation slate variubles (grcy lines for (a) sardine standardised gonad mass. (b) Sardine mean condition factor, lan-May and (c) sardinc mean condition factor. Jun-Aug. The 96 sardine egges lor (d) wesl of Cape Agulbas and (e) east of Cape Agulhus are shown. The $\%$ surdine in Cape gannet diet is given for (f) Malgus Island (g) the west coust and (h) Algna Bay. Sardine model recruit numbers (i) is sbown. Robust, prewthitined (PW) and possible shifts identified by the ST ARS analysis are shown. 
gannet diet in Algoa Bay (Figure 14h). It is unlikely that increased sardine mean length landed is a factor in influencing gannet diet.

\section{Modelled state variables compared to Sardine mean length landed}

\section{Sardine model recruit numbers}

The robust positive shift in the mean length of sardine landed occurred two years before the positive robust shift in sardine model recruit numbers (Figure 14i). An inverse response would have been expected between these two variables. Therefore a link could not be made between these two variables.

\section{Observed state variables compared to Sardine L95 catch}

Sardine mean condition factor and standardised gonad mass

A shift in L95 of sardine catch occurred in 1999/2000 and was a negative possible shift and occurred after all the shifts in sardine mean condition factor and gonad mass and so no links could be made (Figure 15a-c).

\section{\% Sardine eggs west and east of Cape Agulhas}

The negative possible shift of sardine L95 catch preceded the robust shift of the \% of sardine eggs west of Cape Agulhas by one year (Figure 15d), however the positive shift in the \% of eggs east of Cape Agulhas (Figure 15e) indicated that fishing pressure was not the cause of this shift in egg distribution.

\section{$\%$ Sardine in diet of Cape Gannets}

The negative possible shift in sardine L95 in 1999/00 occurred in the same year as the negative possible shift in the $\%$ of sardine in gannet diet at Malgas Island and the west 

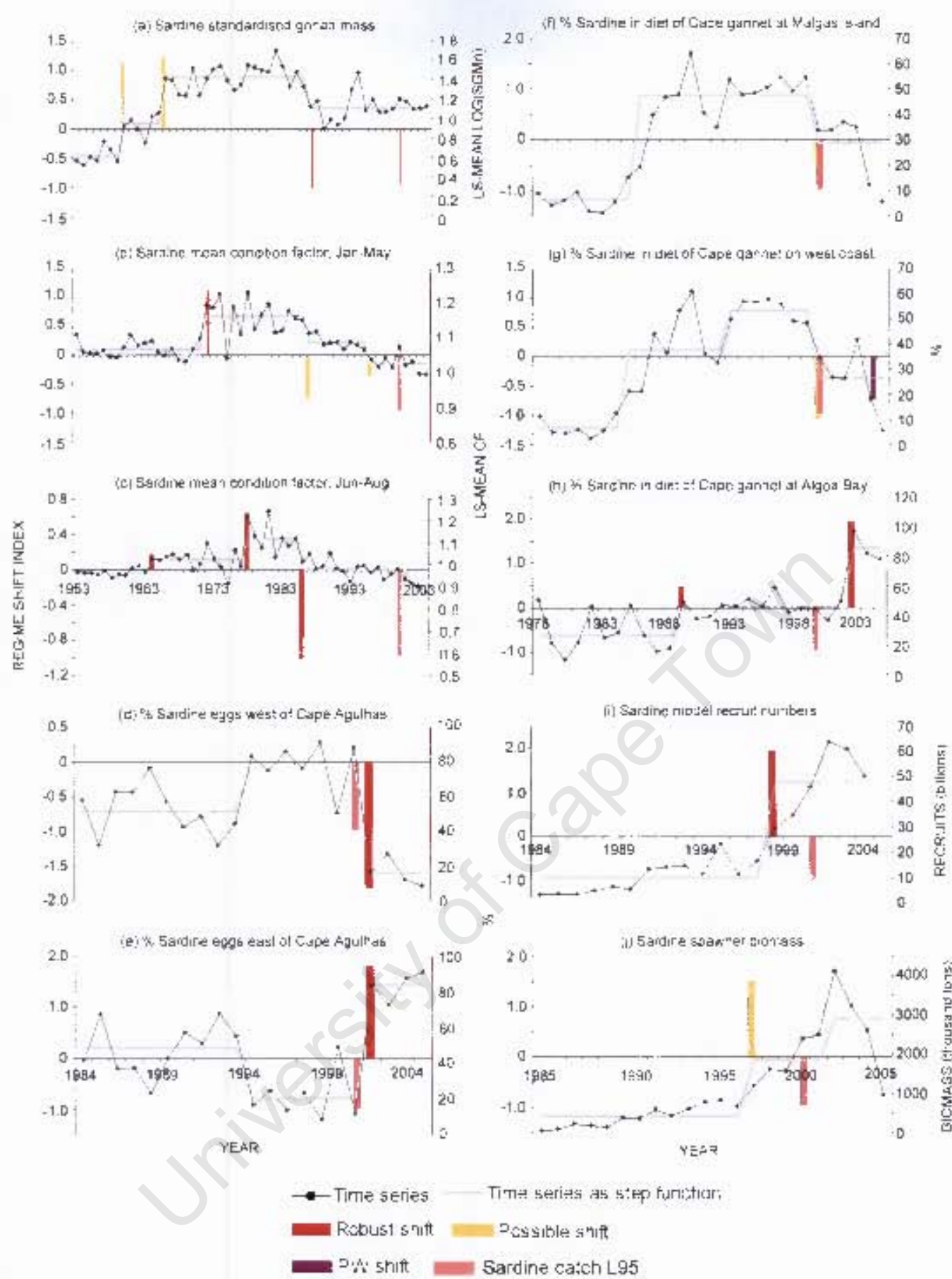

Figure 15: Rebults of STARS amalysis showing the magnitude of shitis in RSI (coloured bars). the overal] sime series (black line) and the weighted mean of obsertution state variables (grey line) fin (a) sardine standardised gonad mass. (b) sardine mean condition faccor. Jan-May and (c) sardine mean

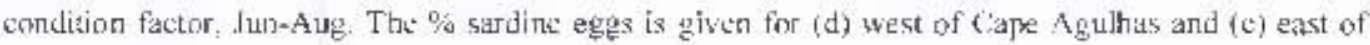
Cupc Agulhus. The "o sardine in Cape gannct diet is given for (f) Mfulgas Island, (g) the west conast and (h) Algua Bay. Surdint mode] rturuil numbers, (i) and spawner biomass, (j), are shown, 
coast (Figure $15 \mathrm{f}$ and $\mathrm{g}$ ). This shift however was unlikely to be the explanatory factor in the change in gannet diet.

\section{Modelled state variables compared to Sardine L95 catch}

Sardine model recruit numbers and spawner biomass

The shift in sardine catch L95 occurred after the robust shift in sardine model recruit numbers and spawner biomass (Figure $15 \mathrm{i}$ and $\mathrm{j}$ ), and so appears unlikely to be linked to the shift in this state variable.

\section{Observed state variables compared to Anchovy mean length landed}

\section{$\%$ Anchovy in diet of Cape Gannets}

The negative shift in mean length of anchovy landed was followed at Algoa Bay by a negative possible shift in \% anchovy in gannet diet (Figure 16a). A negative possible shift in the mean length of anchovy landed occurred in 1989/90 and there are no closely following shifts in \% anchovy in gannet diet at Lambert's Bay or on the west coast (Figure $16 \mathrm{~b}$ and $\mathrm{c}$ ). It is unlikely that any link can be made between these shifts in variables.

\section{Modelled state variables compared to Anchovy mean length landed}

\section{Anchovy spawner biomass}

There was a ten-year gap between the shift in mean anchovy length landed and the positive possible shift in anchovy spawner biomass of 1999/00 (Figure 16d), therefore there is also no link between these two shifts. 

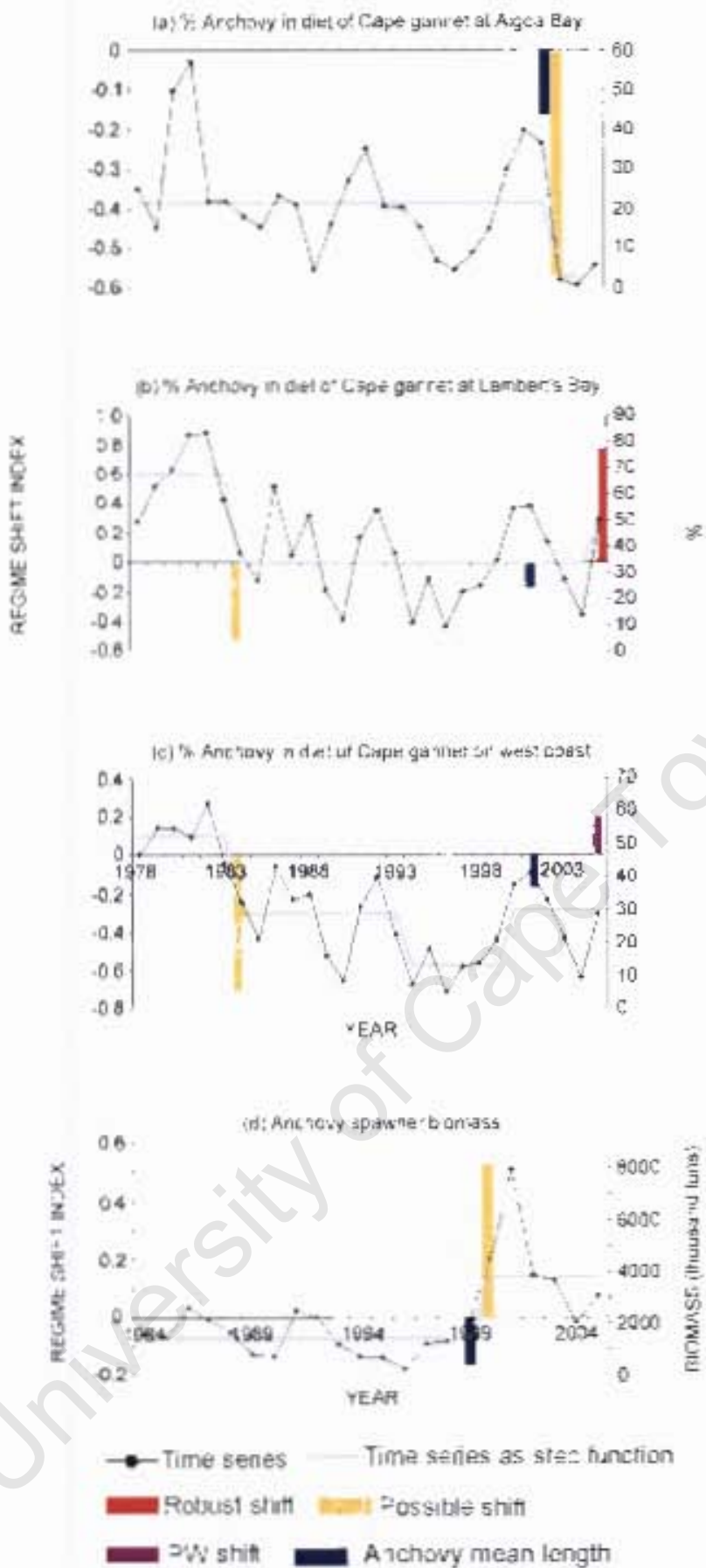

Figure 16: Results of SI ARS analysis showing the magnitude of shifes in RSI (colourid bars). the overail :ime series (black. line) and the weiglued mean of ohservation state variables (grcy lisc) for the $\%$ anchory in Cape gannet diet at (a) Aleoa Bay, (b) l,amberts Bay and (e) thit west coast. Anchovy spawner bionass (d) is shown. Rulsust, prewinitened (PW) and possible shifts identificd by the STARS arnalysis are showtw. 


\section{Observed state variables compared to Anchovy L95 catch}

$\%$ Anchovy in diet of Cape Gannets

A negative possible shift in anchovy L95 landed was detected in 1994/95. The period between this shift and a response in Cape gannets diet was too long to consider this an explanatory factor (Figure 17a-c).

\section{Anchovy recruit numbers and biomass surveyed}

These two state variables showed a positive possible shift five years after the negative possible shift in anchovy L95 landed in 1994/95 (Figure 17d and e). It appears there is no link between these shifts.

\section{Anchovy Nov L95 and Anchovy Nov mean weight}

The negative shift in anchovy L95 from catch data occurred five years prior to the negative shift in surveyed anchovy L95 (Figure 17f). The negative shift in anchovy mean weight also occurred five years after the negative shift in anchovy L95 (Figure $17 \mathrm{~g})$.

\section{Modelled state variables compared to Anchovy L95 catch}

Anchovy model recruit numbers and spawner biomass

There is no link between the negative shift in anchovy L95 in 1994/95 and the positive shift in anchovy model recruit numbers that occurred five years later (Figure 17h). A positive possible shift in anchovy spawner biomass occurred in 1999/00, five years after the negative shift in anchovy L95 (Figure 17i), there is no link between these two shifts. 


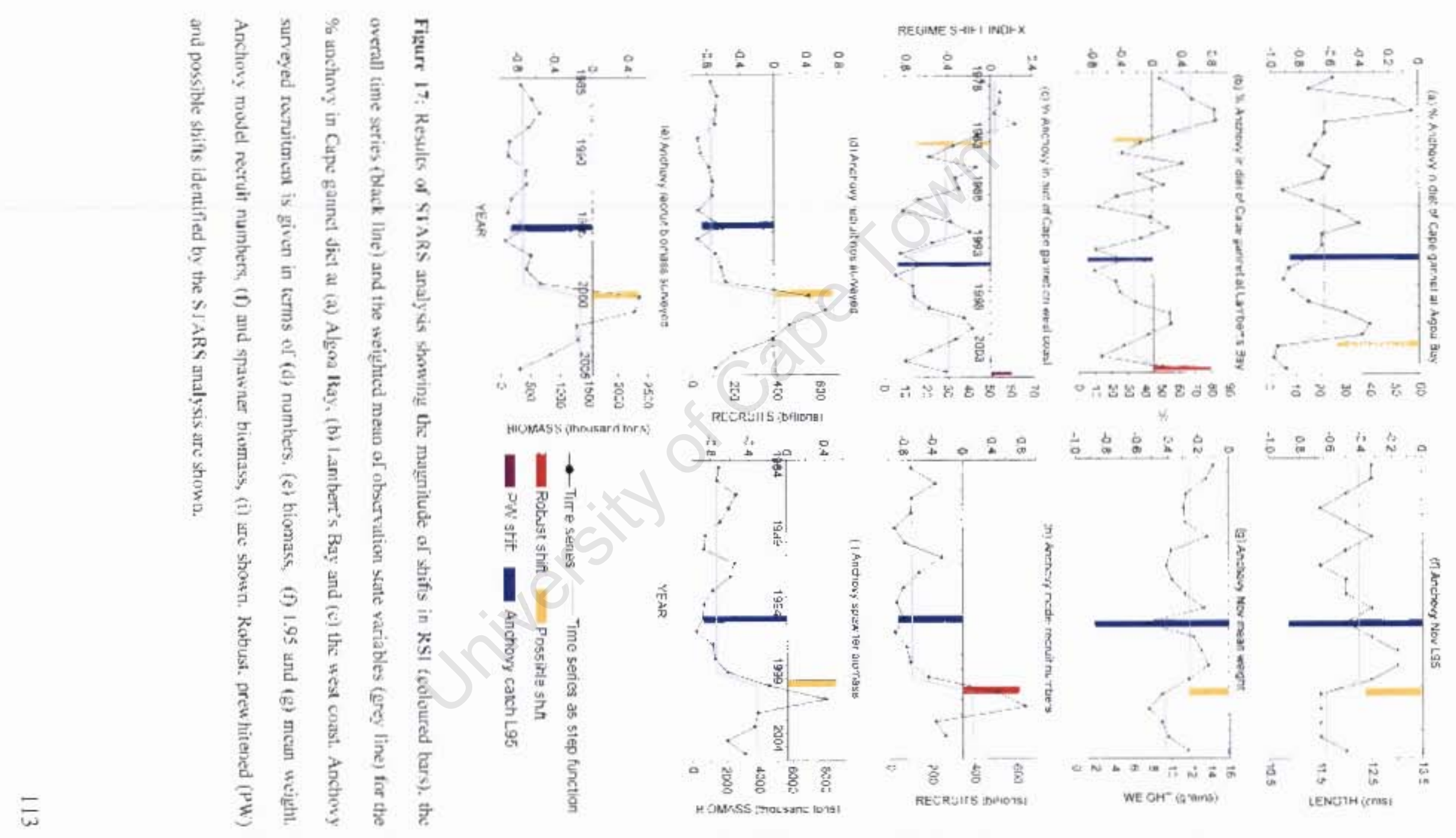

